\title{
Adolescent girls' voices on enhancing their own productivity in Pakistan
}

\author{
Iram Kamran \\ Population Council \\ Tahira Parveen \\ Population Council \\ Maqsood Sadiq \\ Rehan M. Niazi \\ Population Council
}

Follow this and additional works at: https://knowledgecommons.popcouncil.org/departments_sbsr-pgy

Part of the Demography, Population, and Ecology Commons, Family, Life Course, and Society Commons, Gender Equity in Education Commons, and the Inequality and Stratification Commons How does access to this work benefit you? Let us know!

\section{Recommended Citation}

Kamran, Iram, Tahira Parveen, Maqsood Sadiq, and Rehan M. Niazi. 2018. "Adolescent girls' voices on enhancing their own productivity in Pakistan." Islamabad: Population Council. 


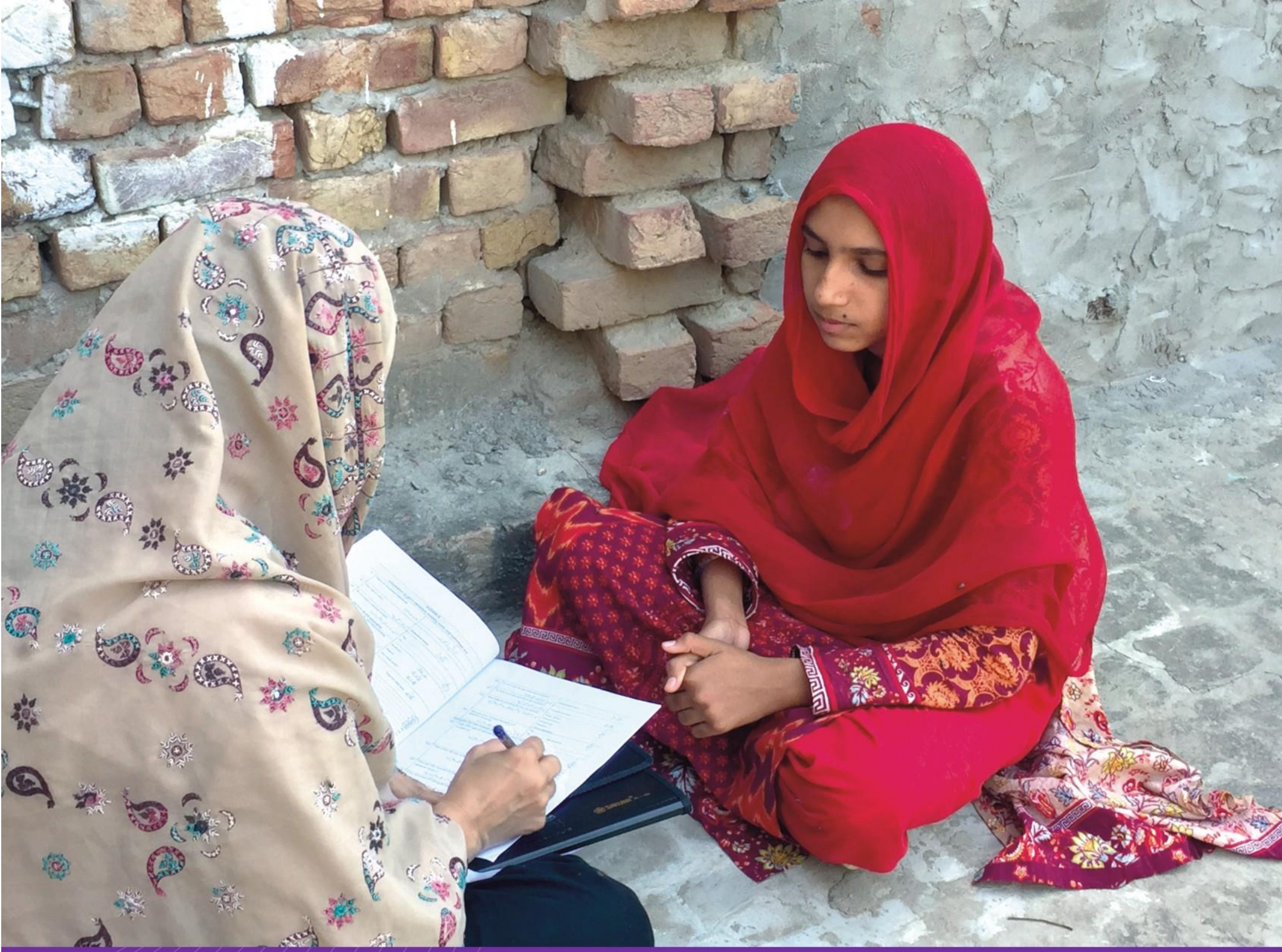

\section{Adolescent Girls' Voices on Enhancing their Own Productivity in Pakistan}

December 2018

Authors:

Iram Kamran

Tahira Parveen

Magsood Sadiq

Rehan Niazi 



\section{Adolescent Girls' Voices on Enhancing their Own Productivity in Pakistan}

December 2018

Authors:

Iram Kamran

Tahira Parveen

Maqsood Sadiq

Rehan Niazi

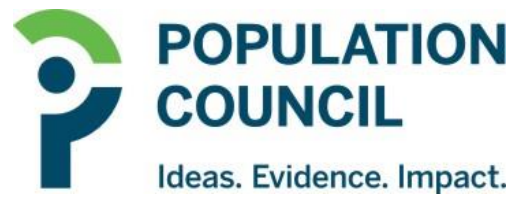




\section{popuntow COUNCIL \\ Ideas. Evidence. Impact.}

The Population Council confronts critical health and development issues-from stopping the spread of HIV to improving reproductive health and ensuring that young people lead full and productive lives. Through biomedical, social science, and public health research in 50 countries, we work with our partners to deliver solutions that lead to more effective policies, programs, and technologies that improve lives around the world. Established in 1952 and headquartered in New York, the Council is a nongovernmental, nonprofit organization governed by an international board of trustees.

Population Council

3rd Floor, NTC Building (North), Sector F-5/1

Islamabad, Pakistan

Tel: +92519205566

Fax: +9251282 1401

Email: info.pakistan@popcouncil.org

http://www.popcouncil.org 


\section{Table of Contents}

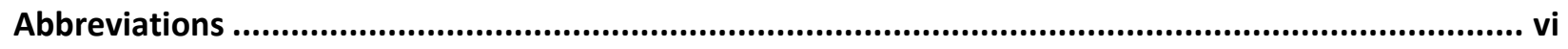

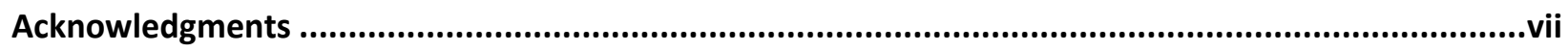

Executive Summary ....................................................................................................................................

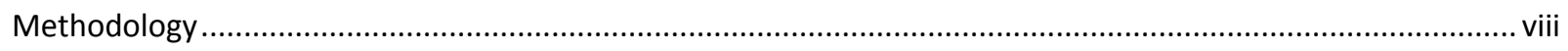

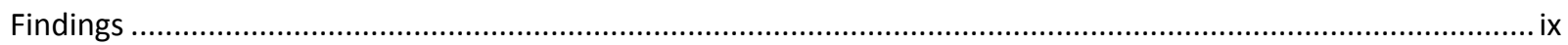

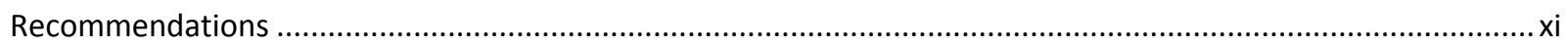

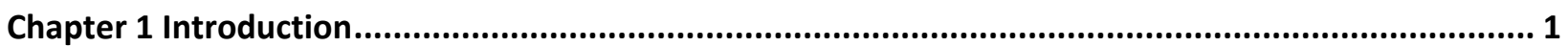

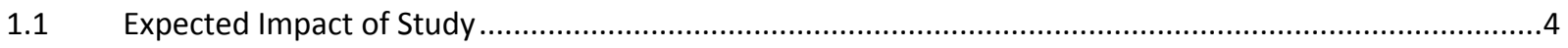

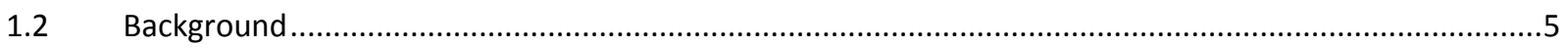

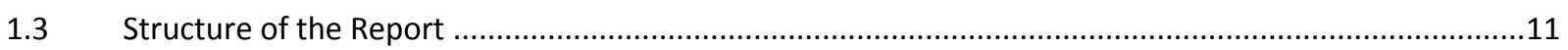

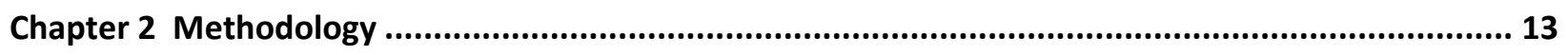

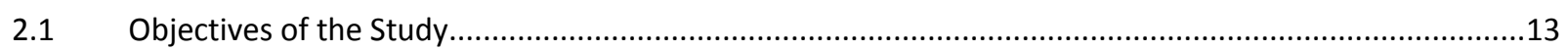

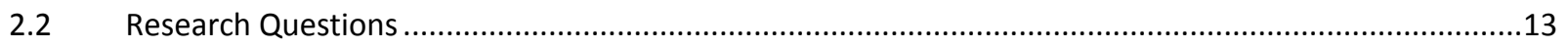

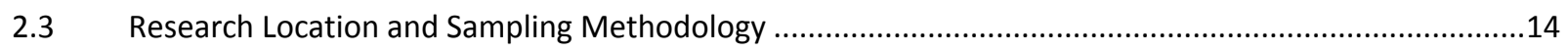

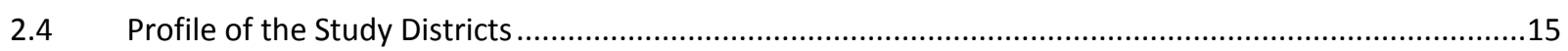

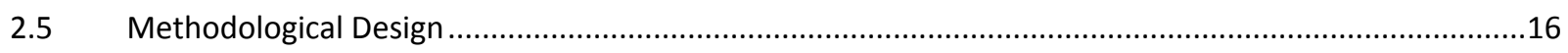

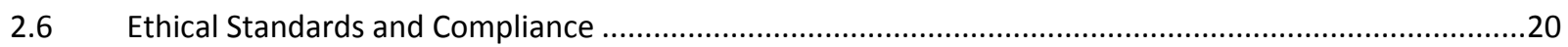

Chapter 3 Adolescent Girls in the Study Districts: Transition Status and Time Use ............................ 21

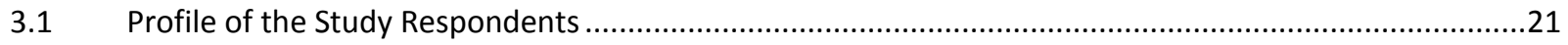

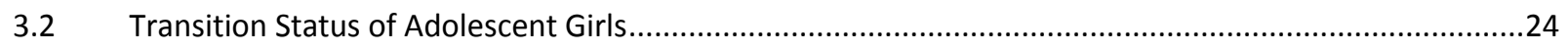

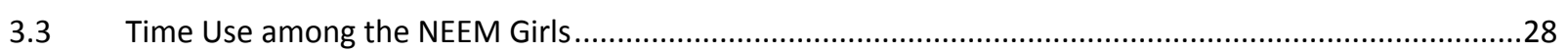

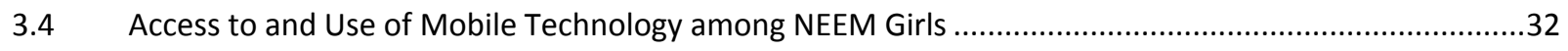

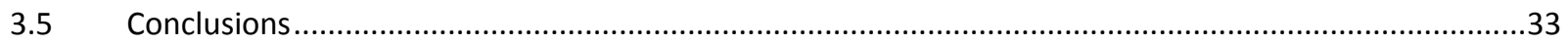

Chapter 4 Why the Girls Are Not in School: Perspectives and Potential for Change......................... 35

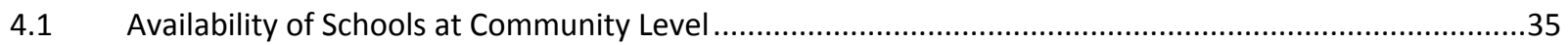

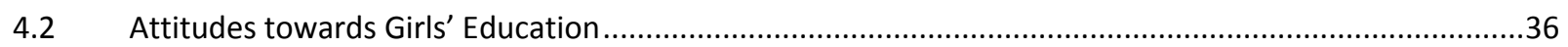

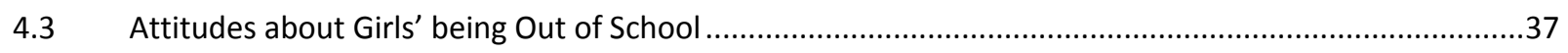

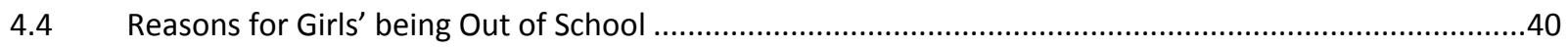

4.5 Gender Differences - Reasons for Boys' Dropping Out of School ..........................................................58

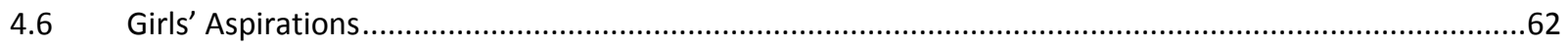

4.7 Respondents' Suggestions for Getting Girls Back to School ..........................................................64

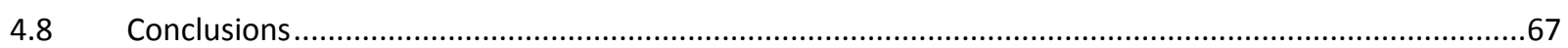

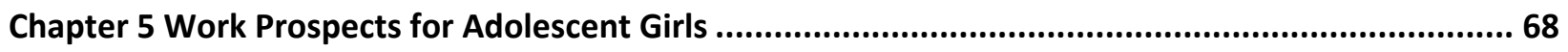

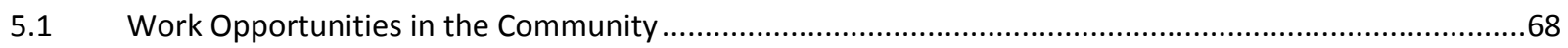

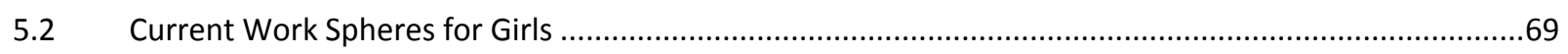

5.3 Girls' Perspectives on the Effects of Working for Pay .......................................................................

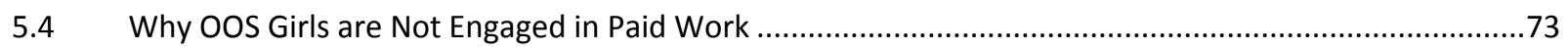

5.5 Boys' Participation in Economic Activities in the Study Communities ....................................................78

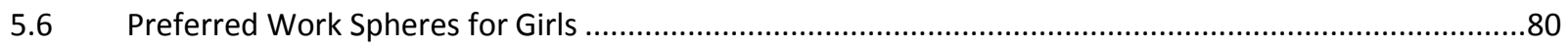




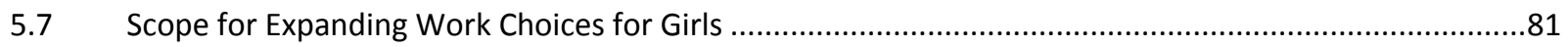

5.8 Respondents' Suggestions for Persuading Parents to Permit their Daughters to Work .........................84

5.9 Perspectives of Employers on Girls' Employability ..........................................................................8

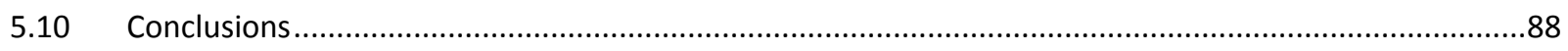

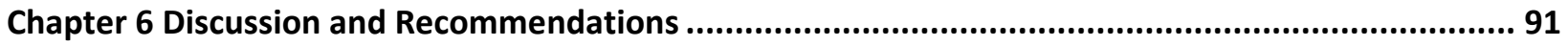

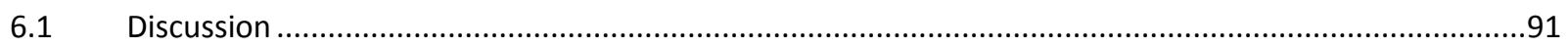

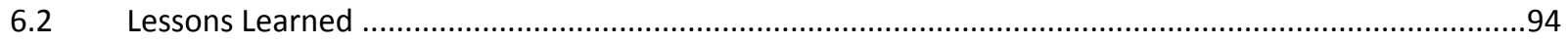

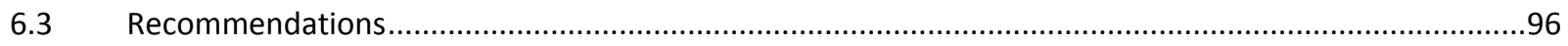

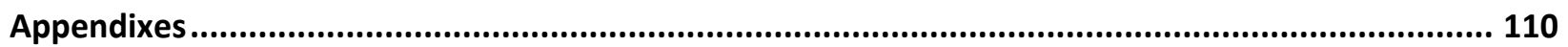

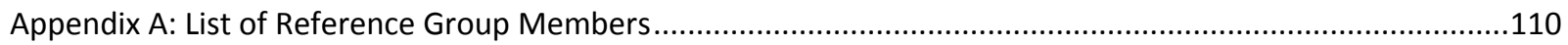

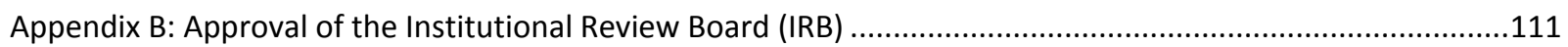

Appendix C: Socio-demographic Characteristics of the Study Respondents ...................................................112

Appendix D: Access to and Use of Mobile Technology among Girl Respondents .............................................115

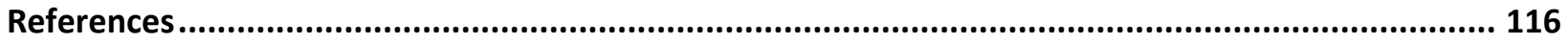




\section{List of Tables}

Table 1.1: Key population and development indicators for adolescent girls in Pakistan ........................... 2

Table 1.2: Net enrollment rates at primary and secondary level, Pakistan 2001-02 and 2014-15........... 6

Table 1.3: Net enrollment rates among girls at primary and secondary level, by socioeconomic status,

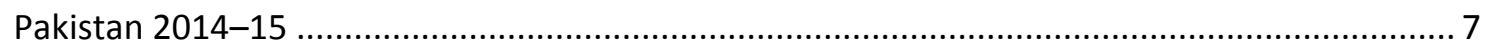

Table 2.1: Profile of overall population and specifically of girls aged 15-19 years in the study districts ... 16

Table 2.2: Number of in-depth interviews and focus group discussions conducted in study districts, by

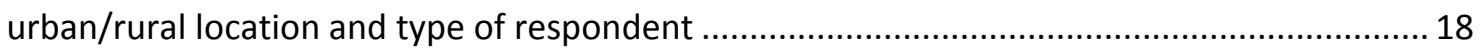

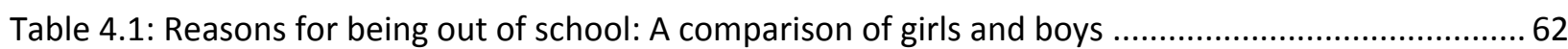

\section{List of Figures}

Figure 1.1: Unemployment rates by educational attainment among older youth (ages 15-24),

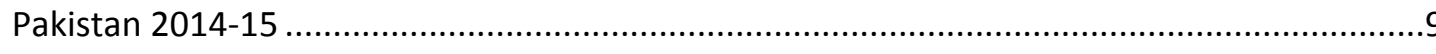

Figure 2.1: Map of Punjab showing three different regions and location of study districts .................. 14

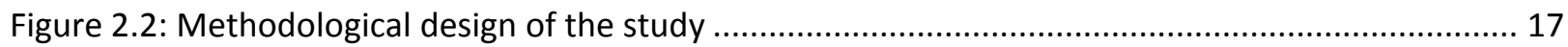

Figure 3.1: Transition status of older adolescents (15-19 years) in Faisalabad, Kasur, and Rajanpur

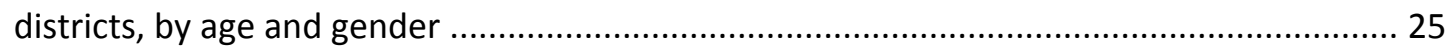

Figure 3.2: Transition status of richest vs. poorest girls (15-19 years), by district .............................. 27

Figure 3.3: Transition status of girls (15-19 years), by urban/rural location and district ...................... 27

Figure 3.4: Mean hours spent on various activities by girl respondents, by district $(\mathrm{N}=107)$................ 29

Figure 3.5: Mean hours spent by girl respondents on various activities, by schooling status and district ( $\mathrm{N}=24$ girls with no schooling, $\mathrm{N}=83$ girls who dropped out) .................................. 30

Figure 3.6: Mean hours spent by girl respondents on personal activities and domestic chores, by age and district $(\mathrm{N}=107)$

Figure 3.7: Mean hours spent by girl respondents on unpaid work and leisure activities, by age and district $(\mathrm{N}=107)$.

Figure 3.8: Percentage distribution of time ( 24 hours) across various activities among girl

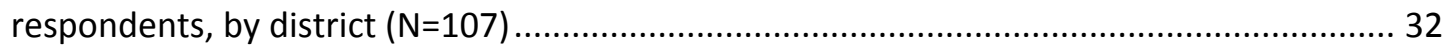

Figure 4.1: Reasons why girls are out of school, from the perspective of girls, mothers, and fathers .... 40

Figure 4.3: Summary of factors that contribute in girls' dropping out ................................................. 58

Figure 5.1: Girls' view of the effects employment would have on their lives ....................................... 72

Figure 5.2: Reasons given by girls for not being able to engage in paid work.................................... 74 


\section{Abbreviations}

\begin{tabular}{|c|c|}
\hline AYSP & Adolescent and Youth Survey of Pakistan \\
\hline ASPRs & Age-specific Participation Rates \\
\hline CSR & Corporate Social Responsibility \\
\hline FGDs & Focus Group Discussions \\
\hline IDIs & In-depth Interviews \\
\hline ILO & International Labor Organization \\
\hline IRB & Institutional Review Board \\
\hline LFS & Labour Force Survey \\
\hline LHWs & Lady Health Workers \\
\hline MICS & Multiple Indicator Cluster Survey \\
\hline MPI & Multidimensional Poverty Index \\
\hline NEEM & Not in Education, Employment, or Marriage \\
\hline NER & Net Enrollment Rate \\
\hline NGOs & Non-governmental Organizations \\
\hline NEF & Non-formal Education \\
\hline oos & Out-of-school \\
\hline PDHS & Pakistan Demographic and Health Survey \\
\hline PEF & Punjab Education Foundation \\
\hline PIHS & Pakistan Integrated Household Survey \\
\hline PSLM & Pakistan Social and Living Standards Measurement Survey \\
\hline RRG & Research Reference Group \\
\hline SDGs & Sustainable Development Goals \\
\hline SES & Socio-economic Status \\
\hline SMAM & Singulate Mean Age at Marriage \\
\hline SPDC & Social Policy and Development Centre \\
\hline UNDP & United Nations Development Programme \\
\hline UNICEF & United Nations Children's Fund \\
\hline UNIDO & United Nations Industrial Development Organization \\
\hline USAID & United States Agency for International Development \\
\hline UN Women & United Nations Entity for Gender Equality and the Empowerment of Women \\
\hline VTI & Vocational Training Institution \\
\hline
\end{tabular}




\section{Acknowledgments}

We gratefully acknowledge the financial support of the United Nations Children's Fund (UNICEF) in conducting this important study of "Adolescent Girls' Voices on Enhancing Their Own Productivity in Pakistan," which sheds light on the circumstances, hopes, and possibilities for one of the least visible segments of the population in Punjab: adolescent girls aged 15-19 years who are neither in school nor at work, and who have yet to marry.

We are indebted to Dr. Zeba A. Sathar (T.I.), Country Director, Population Council, for her technical guidance, inspiration, and encouragement at every stage of the research and report writing, and also the trust she reposed in the research team. We are most fortunate to have benefited from the technical expertise of Dr. Sajida Amin, Senior Associate, Population Council, New York office, who guided us based on her vast experience on the Bangladeshi Association for Life Skills, Income, and Knowledge for Adolescents (BALIKA) project. We also express our gratitude to Dr. Thoai D. Ngo, Director, Poverty, Gender, and Youth Program (PGY), Population Council, New York office, for his technical review of the report. We also thank Dr. Gul Rashida, Technical Advisor, Population Council, for her selfless help in extracting the findings of our study.

We are deeply grateful to Ms. Rosemary Arnott, Gender and Development Specialist, UNICEF, for her bridging role between UNICEF and other stakeholders such as the Research Reference Group and the Population Council on this study, as well as her invaluable technical review of the report that led to its finalization. We thank the members of the Research Reference Group, who took out the time to provide important inputs into the finalization of the study's methodology and study tools.

Special thanks are due to members of our field team for their excellent contributions and dedication. We also appreciate the efforts of our data processing team, who transcribed, translated and coded data in NVIVO against a stringent timeline. We extend our sincere thanks to Mr. Usman Ghani who provided outstanding support during training of the field staff, and managed, organized, and processed the data set smoothly. We also highly appreciate the contribution of Ms. Zeba Tasneem, Senior Program Officer at Population Council, who supported us in the analysis of qualitative data.

We are extremely grateful to Ms. Kiren Khan, whose meticulous review of literature, inputs, and editing helped shape this report and greatly eased its finalization in a short span of time.

Our gratitude is also due to the Administration and Financial Management team at the Population Council Islamabad office, who worked hard to facilitate the implementation of field activities. We also thank Mr. Ali Ammad for formatting and laying out this report.

Finally, we owe a debt of gratitude to all our respondents-including men, women, and girls-who participated in our inquiry and remained enthusiastically involved during in-depth interviews and focus group discussions. It would not have been possible to generate the useful data and insights documented in this report without their open-hearted cooperation. We especially thank the influential community members in each of the study districts who helped us-voluntarily and painstakingly-in the identification and recruitment of respondents, obtaining permissions from parents, and arranging the interviews and discussions. 


\section{Executive Summary}

Of the 11 million adolescent girls aged 15-19 years in Pakistan, 6 million reside in Punjab. About 37 percent of these girls are neither at school, nor employed for pay or profit, and they have not yet made the transition to marriage. These girls are busy in household work, caring for younger siblings, and supporting their parents' economic work. But they are deprived of opportunities to interact in an institutional setting, such as a school or formal workplace, where they might earn an income of their own and build the knowledge, skills, and relationships that could enable them be more empowered and productive as adults.

This study, entitled "Adolescent Girls Voices on Enhancing their Own Productivity in Pakistan," was conducted in Punjab by the Population Council, with the support of the United Nations Children's Fund (UNICEF), to examine the lives, aspirations, and perspectives of the largely invisible and marginalized group of older adolescent girls (ages 15-19 years) who are "not in education, employment for pay or profit, nor in marriage" ("NEEM"). The study seeks to identify the reasons for the exclusion of the NEEM girls from education and participation in paid work; explore opportunities and avenues for changing these girls' existing opportunity structures; and probe the gender norms and behaviors underlying their marginalization to obtain insights into what it would take to change their situation.

\section{Methodology}

The study was conducted in three districts of Punjab. To select these districts, we divided the 36 districts of the province into three regions comprised of contiguous districts. From each region, we selected one district on the basis of the proportion of older adolescent girls who are NEEM. Kasur and Rajanpur represent areas with high proportions of NEEM girls (54 percent and 40 percent respectively) within their respective regions. On the other hand, Faisalabad was selected for having the lowest proportion of NEEM girls (34 percent) and also because it is a more developed district with greater economic opportunities. This selection was intended to capture differences in the perspectives and circumstances of girls from the most and least restrictive settings in the province. With respect to poverty, early marriage, female literacy, and proportion of girls currently in school, Faisalabad district is relatively more developed on almost all indicators while Rajanpur lags furthest behind. Within each of the three districts, we randomly selected one urban (town) and two rural communities for data collection.

The study is mainly qualitative, based on focus group discussions (FGDs) and in-depth interviews (IDIs). In addition, secondary data has been analyzed to build a picture of the life trajectories of older adolescents (ages 15-19 years) in each of the three districts, including segmentation by gender, urban-rural residence, and wealth index status. During primary data collection, 42 IDIs were conducted with NEEM girls to learn about their experiences, perspectives, and available opportunities for effecting transformative change in their lives. A structured questionnaire was also administered to the interviewed girls. In addition, we conducted a total of 40 FGDs, including 20 with adolescent girls (1519 years), 10 with mothers, and 10 with fathers of girls in the same age group. The FGDs with fathers also included several influential male community members. Finally, 9 informal interviews were conducted with potential employers in the study areas. About 232 adolescent girls, more than 180 
'gatekeepers,' i.e., mothers, fathers, and influential community members, and 9 employers participated in these exchanges.

\section{Findings}

1 NEEM girls are more likely to be poor and living in rural areas. Secondary data analysis shows that NEEM girls comprise substantially higher proportions of the poorest girls than of the richest girls in all districts. This difference is narrowest in Rajanpur (65 percent in the lowest and 48 percent in the highest wealth quintile). In all districts, there is a strong negative association between age and school enrollment: as age increases, the percentage of adolescents currently in school decreases, dropping more sharply for girls compared with boys.

2 NEEM girls spend a considerable portion of their time on domestic chores. Analysis of the girls' time use over the course of a 24-hour day shows that they allocate a significant number of hours to domestic work. In addition, they are providing unpaid support to their parents in their economic activities, mainly agricultural work, and especially in Rajanpur. On average, the NEEM girls are spending 5.7, 6.7, and 5.6 hours a day on domestic duties in Faisalabad, Kasur, and Rajanpur, respectively. In addition, as unpaid helpers to their parents, they contribute $0.5,0.5$, and 3.1 hours of work a day, respectively. The burden of domestic duties is additional to involvement in unpaid work, and girls in Rajanpur have a conspicuously higher workload that the other groups of girls.

3 There are important differences in time use among NEEM girls across segments. Time use varies among NEEM girls across districts, urban/rural location, as well as socio-demographic differences such as age, wealth, and schooling history. Among girls from the more urbanized Faisalabad, the time use pattern reflects greater exposure, with more time spent on personal and leisure activities and sleep; less time spent on domestic duties; and the least time spent on unpaid work. In Kasur, NEEM girls are spending more time on domestic duties and less time on sleep, personal and leisure activities than their peers in Faisalabad. On the other hand, girls' time use in Rajanpur reflects a pattern of poverty, with far fewer hours for personal activities, and about half of the day spent on domestic duties and unpaid work, mostly in the fields. The younger girls (15-16 years), in particular, are spending more time on unpaid work than their peers in Faisalabad and Kasur. These girls have less leisure time (3.1 hours) than girls from Faisalabad ( 4.3 hours) and Kasur (3.5 hours).

4 Access to mobile phones is generally low among NEEM girls, and varies across districts. Girls in Faisalabad generally have higher access and are more adept at utilizing mobile phones for various purposes. Access to and knowledge about mobile phones are lower in Kasur and lowest in Rajanpur. Free use of mobile phones by girls is perceived quite negatively by parents of adolescent girls, who fear that such access could lead to undesirable relationships and scandal.

5 Most of the NEEM girls and their parents are very keen-even desperate-for a resumption of the girls' education. Both girls and parents recognize education to be an important pathway for improving a girl's life by socially preparing her, improving her judgment, and enabling her to find better quality employment. Most girls express strong feelings of sadness and deprivation at not being able to go to school. They dream of being strong professionals but are also painfully 
resigned to the unattainability of these dreams without education. Most (197 of 232) are ready to resume their education, as they consider it pivotal for changing their life trajectory. Parents acknowledge that education would mean improved prospects for their daughters, including better marriages, and cite poverty-related constraints as the main reason for not sending them to school.

6 Girls confront a series of challenges-at home, on the way to school, and in school-which can compel them to drop out. The main reasons include non-availability of girls' schools within the community and problems in the household, particularly financial issues and girls' expected heavy contribution to domestic responsibilities, especially when their mothers are sick or have to work. Physically accessing schools is a major challenge due to insecure environments that exert a strong pressure on parents to restrict their daughters' mobility. Some school-related issues, such as co-education and absence of female teachers, are also unacceptable to parents. Other problems include physical and emotional punishment by teachers, and teachers' exploitation of girls for personal chores during school hours.

Notably, boys' reasons for dropping out differ greatly from those of girls. The foremost reason mentioned for boys is their own lack of interest. Otherwise, boys mainly drop out to supplement their household income, in part due to the expectation that education will not necessarily improve job prospects.

$7 \quad$ Among steps to persuade parents to send their girls to school, respondents emphasize more schools, safe transportation, and financial incentives. Respondents say that higher level public schools for girls must be set up within each community, or reliable and safe transportation arranged for girls to attend more distant schools. Moreover, financial assistance should be provided to girls' families, to ensure that their attendance does not cause any spending from their strained budgets, and to compensate for the loss of income from unpaid work.

8 There is a huge difference in the values attached to educational attainment and employment among girls. It is considered respectable for girls to attain an education, but their employment is generally not appreciated, largely because of gender norms that strongly discourage the free interaction of males and females, especially for unmarried females, and the resulting risk of gossip and scandal.

9 Girls see that involvement in economic activity could improve their lives. Most respondents, especially the NEEM girls, perceive that work opportunities are limited for girls who lack education. Although they are less enthusiastic about work than education, they realize that engaging in paid economic work would improve the girls' lives by providing them with a better standard of living, earning them respect in the household and a say in decision-making, and strengthening their capacity to cope with challenges, including after marriage. The girls claim they would also feel great personal satisfaction in contributing to their families' financial uplift.

10 Strong social pressure prevails against girls' participation in independent economic activities. Parents are very reluctant to let their girls work alongside males; they fear this would inevitably lead to undesirable relationships and activities that could dishonor the family. Even where parents are personally willing, they fear gossip and pressure from the community. Security risks in going outside the community, such as sexual harassment or worse, are also an important 
consideration. Parents would thus like girls to work from home or at least within the community, although they acknowledge the lack of local work and training opportunities.

11 Employers are positive about recruiting girls and consider them to be more efficient workers than boys. However, parents are not so receptive to girls' working at factories, primarily because they would be working alongside males. Both parties suggest this issue could be alleviated through provision of gender-segregated work spaces and transport arrangements by employers. In addition, employers suggest that the girls acquire specialized technical skills. Some also suggest provisions for parents to periodically visit the work environment.

12 Parents strongly prefer that girls be involved in home- or community-based work. They may not be willing to compromise on gender segregation and security, but are open to training and work opportunities that can enhance their girls' productivity without exposing them to social risks. However they stipulate that training be provided within the community and no interaction with males be involved. The main suggested spheres of work include stitching and embroidery, homebased packaging work for factories, dairy product processing, and online work. In addition, girls are keen to take up beauty care work. They are also interested in mobile repair work, but parents reject this idea as it would involve open access to mobile phones and interaction with male customers.

\section{Recommendations}

Effecting transformative change in the lives of the NEEM girls will require a combination of measures to increase their access to education and work opportunities. Interventions must be carefully calibrated to respond to the different ages, levels of educational attainment, and aspirations of the NEEM girls, as well as the often considerable differences in the opportunities and challenges prevailing across specific settings.

\section{To increase girls' access to education and skills:}

1.1 More secondary schools need to be set up for girls, especially in the public sector. Investments should also be made in introducing reliable school bus services for communities where schools are not available within walking distance.

1.2 The acceptability of co-educational schools should be increased by recruiting more female teachers, appointing female heads of school, introducing gender-segregated classes, and taking other suitable measures in consultation with communities.

1.3 Separate, accelerated classes could be introduced for older students who wish to reenter the regular school system after a prolonged absence or dropping out.

1.4 As the NEEM girls are mainly poor, financial incentives such as conditional cash transfers or food, and provision of free tuition, textbooks, uniforms, and stationery items will be necessary in some communities.

1.5 There is also a great need to foster a positive and supportive social environment at school where students' dignity is ensured, particularly by enforcing the ban on corporal punishment, and ensuring that teachers do not otherwise humiliate or discourage 
students or exploit them for labor. Moreover, struggling students should be provided with remedial support, and grade repetition minimized as this promotes dropping out. Functioning bathroom facilities should also be provided.

1.6 In communities with an entrenched pattern of seasonal absence among students-due to involvement in harvest or other agricultural activities--school timings should be made flexible and calendars adjusted around busy seasons, to avoid overburdening young people.

1.7 Distance learning opportunities must also be actively explored and developed to offer both formal courses, pertaining to the completion of secondary and higher secondary education, as well as non-formal courses.

1.8 Programs for non-formal education (NFE) should be offered to out-of-school girls, at schools or other safe spaces in the community. The Population Council's proven safe space model can be adapted to provide a platform for NEEM girls (Bruce 2015).

\section{To increase girls' access to paid work opportunities:}

2.1 Interventions should be preceded by and based on comprehensive assessments of livelihood opportunities, conducted by specialists, looking both at the market and stakeholders, as well as communities' receptivity and preferences regarding a range of options. Special attention should be paid to understanding girls' and women's current participation in agricultural work as unpaid workers, to identify means for leveraging this participation for better paid roles. The assessments should also be informed by the experience-especially evaluated activities-of other stakeholders working to induct women into livelihood activities, such as rural support programs, NGOs, and international organizations, especially the United Nations Entity for Gender Equality and the Empowerment of Women (UN Women) and the United Nations Industrial Development Organization (UNIDO).

2.2 Girls' vocational skills should be developed:

a. The specific skills imparted should ideally be identified in the assessment of livelihood opportunities. The current study indicates potential for both home-based and factory work, although the former is strongly preferred. Existing preferences could be the starting point of interventions, with more unconventional options introduced as the confidence of communities grows. Skills for external employment should reflect available opportunities, such as the types of factories in the vicinity. For home-based work, promising spheres include stitching, handmade leather goods, processing of dairy products, beauty care services, and computer-based work, such as transcribing and tasks related to search-engine advertising.

b. Training must be imparted by female trainers and mentors, with input from specialized vocational training institutions as well as employers/industry leaders.

2.3 To encourage girls to work at factories and other workplaces outside their communities, large firms in the vicinity of target communities should be encouraged to provide 
transport for female employees. This can be a game-changer, even in the face of discouraging norms. Alternatively, arrangements for chaperoning girls to their workplaces could be facilitated at the community level.

2.4 Employers should be encouraged to introduce girl-friendly measures like female-only work areas and strong policies against sexual harassment in the workplace.

2.5 To facilitate girls in engaging in economic work from home, they should be mentored and linked with the market and with credit opportunities. Continued support and mentoring for the girls should be provided, particularly during the early stages of starting a business and finding employment. Access to markets could be enhanced by contracting businesses to help sell products and encouraging women to start group businesses with partners who focus on marketing. Major corporations, through their corporate social responsibility activities, may be a good source of training opportunities for youth, marketing for products, and seed funding for women's small businesses.

\section{To leverage interventions for transformative social change:}

3.1 Interventions should be framed around girls' practical needs, such as identification of accessible work opportunities, training, and transport arrangements, that also reflect the priority concerns of the target communities. However, to the extent possible, these practical measures should be leveraged to achieve change at a more strategic level, by influencing the norms that restrict the capacity of girls and women to increase their selfreliance and agency. Compared with education-related interventions, those that seek to economically empower girls might meet with resistance and should therefore be introduced with extra sensitivity.

3.2 Ensuring community leadership of interventions will be crucial, not only for the sustainability of interventions, but also as a possible basis for mobilizing community members, especially in the form of women's organizations, which could be trained to play a confident and active role in interventions and other community matters. Community engagement also offers an opportunity to involve local religious leaders in advocating the cause of girls' education, and their right to inherit and to earn. Such efforts can capitalize on the Population Council's recent work to induct religious leaders in promoting birth spacing and girls' education, which has shown success in Punjab. As fear of violence is a central barrier in girls' access to education and employment, interventions for adolescent girls should address gender-based violence in community advocacy and mobilization efforts, and facilitate community-level responses to minimize risks. Communities' awareness should be built of girls' rights as enshrined laws for child protection and against child marriage, sexual harassment at the workplace, and domestic violence, etc.

3.3 Specific interventions should be framed within an implementation science framework, for example as randomized control trials, to build evidence of what does-and doesn'twork. This will ensure that ultimately only the most effective measures are advocated and up-scaled. 



\section{Chapter 1}

\section{Introduction}

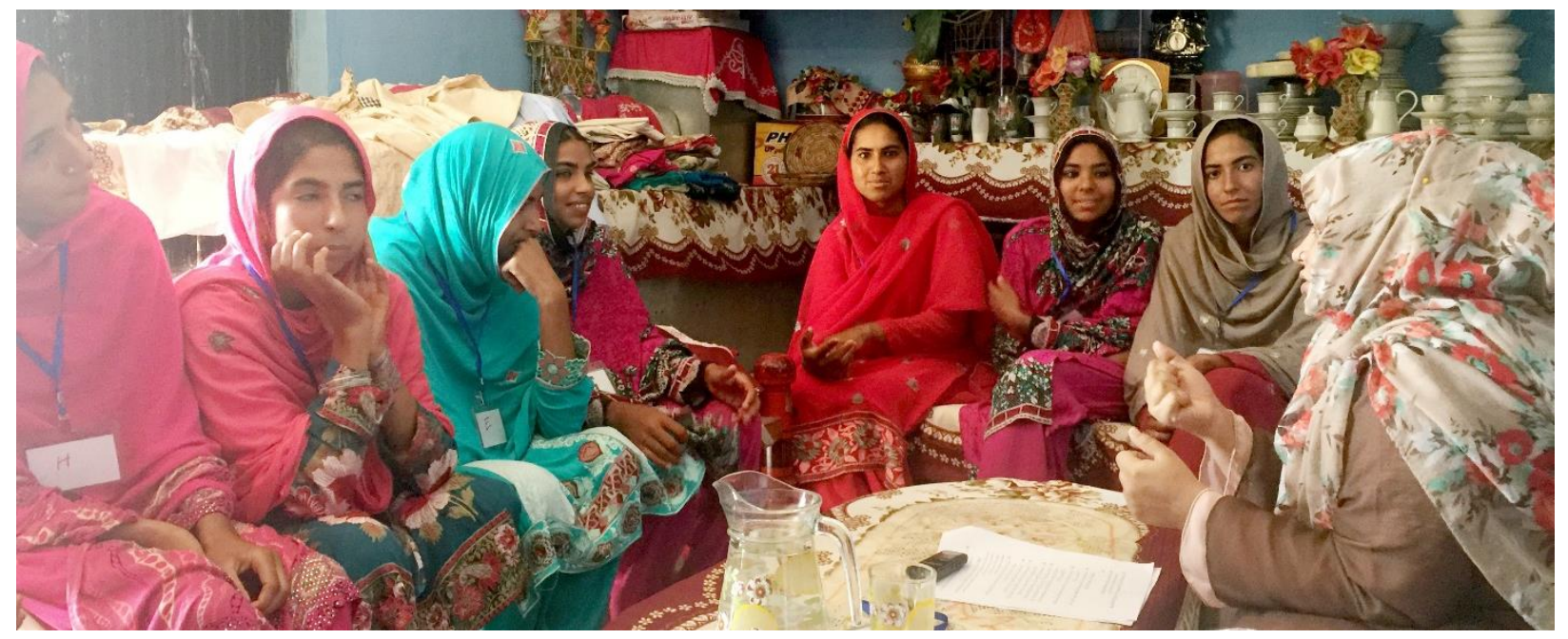

The Population Council's Adolescent and Youth Survey of Pakistan (AYSP) 2001-02 revealed many facets of gender disparity in the lives of young people in the country (Sathar et al. 2003a). ${ }^{1}$ Compared with males, higher proportions of females had never attended school or dropped out. At all levels of schooling, girls had access to fewer schools than boys. Females experienced greater mobility restrictions and were more likely to be engaged in domestic unpaid work. Girls had less say than males in education and work decisions. Although age at marriage was rising among girls, the data did not indicate a corresponding increase in their participation in education or skills development. And while most young men eventually entered the paid labor force, less than 40 percent of all young women had made this work transition by the age of 24 , and employment domains were strongly segregated by gender. The survey also furnished important information about the attitudes of young people in Pakistan. Importantly, 80 percent of all females said they would do paid work if opportunities were available; they saw paid work as a way to enhance their income as well as independence.

According to recent estimates, there are currently 23 million adolescent girls (10-19 years) in Pakistan, including 12 million aged 10-14 years and 11 million aged 15-19 years (Table 1.1). In the latter cohort, only 36 percent are in school while 12 percent are married. Approximately 42 percent have either never attended school or dropped out prematurely, and have not yet made either of the other major transitions involved in growing up in Pakistan, i.e., initiation of paid work or, later, marriage. While these girls may be busy with multiple responsibilities, such as household work, caring for younger siblings, and assisting their parents in agricultural work, they are largely deprived of opportunities to interact in an institutional setting, such as a school or workplace, where they might build the

${ }^{1}$ The AYSP was a nationally representative survey of young people aged 15-24 carried out by the Population Council. It covered key aspects of adolescents' lives, including the timing of several transitions to adulthood and a detailed accounting of time use over the previous 24 hours. 
knowledge, skills, or relationships that could enable them to be more empowered and productive as adults.

Table 1.1: Key population and development indicators for adolescent girls in Pakistan

\begin{tabular}{|c|c|c|c|c|c|}
\hline Indicators & Pakistan & Punjab & Sindh & $\begin{array}{c}\text { Khyber } \\
\text { Pakhtunkhwa }\end{array}$ & Balochistan \\
\hline Population (million)a & 207.8 & 110.0 & 47.9 & 30.5 & 12.3 \\
\hline Sex ratio & 105.1 & 103.5 & 108.6 & 102.7 & 110.6 \\
\hline $\begin{array}{l}\text { Population average annual growth } \\
\text { rate }(\%)(1998-2017)\end{array}$ & 2.40 & 2.13 & 2.41 & 2.89 & 3.37 \\
\hline Urban population (\%) & 36.38 & 36.71 & 52.02 & 18.77 & 27.55 \\
\hline Poverty headcount (\%) & 38.8 & 31.4 & 43.1 & 57.8 & 71.2 \\
\hline 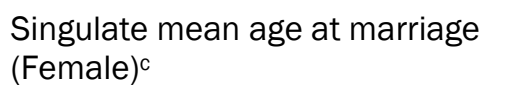 & 22.90 & 23.12 & 23.20 & 21.85 & 21.62 \\
\hline \multicolumn{6}{|l|}{ Indicators for Girls (15-19 years) } \\
\hline Population (million) ${ }^{d}$ & 11.13 & 5.99 & 2.47 & 1.72 & 0.58 \\
\hline Percent marriedc & 11.6 & 10.3 & 11.4 & 17.5 & 13.3 \\
\hline Literacy ratec & 68.0 & 74.2 & 63.4 & 55.8 & 42.1 \\
\hline Labor force participation rate & 18.0 & 23.7 & 9.7 & 7.9 & 23.7 \\
\hline Unemployment rate & 10.4 & 9.0 & 11.6 & 24.1 & 10.2 \\
\hline Percent currently in schoolc & 36.4 & 40.2 & 33.8 & 29.2 & 17.5 \\
\hline $\begin{array}{l}\text { Percent not in school, not working } \\
\text { for pay or profit, and not marriedc }\end{array}$ & 41.6 & 36.6 & 47.2 & 49.9 & 56.8 \\
\hline \multicolumn{6}{|c|}{$\begin{array}{l}\text { Sources: } \\
\text { a Pakistan Population and Housing Census } 2017 \\
\text { b Multidimensional Poverty Index (MPI) 2014-15 } \\
\text { c Pakistan Social and Living Standards Measurement Survey (PSLM) 2014-15 } \\
\text { d Pakistan Population and Housing Census } 2017 \text { (Estimate based on PSLM 2014-15 proportions) } \\
\text { e Labour Force Survey 2014-15 }\end{array}$} \\
\hline
\end{tabular}

Pakistan's youth policies currently make no reference to gender, wealth quintile, or age (Sathar et al. 2016). This is one reason why girls who are not in school, not in work for pay or profit and not married are not only less visible in their communities, but are also easily missed by the radar of official statistics and in development interventions. A recent report in Pakistan again highlighted the powerful influence of gender inequalities on the trajectories of young lives, finding that adolescent girls aged 15-19 years included the largest proportion of individuals who were neither at school, nor working, though not yet married. The report argued for a more segmented approach to programming for youth, in which the special needs of homebound, older adolescent girls are especially addressed (Sathar et al. 2016). In subsequent discussions, the Population Council and the United Nations Children's Fund (UNICEF) agreed that this group of vulnerable girls-those who are 15-19 years old and "not in education, employment for pay or profit, or marriage" ("NEEM"-an acronym coined for this study), requires further investigation to be brought to the attention of policymakers and other change agents in Pakistan. While earlier studies had explored adolescent girls' access to education and related-bottlenecks, and how 
adolescence often serves to limit girls' mobility, the voices of the girls themselves regarding their NEEM status, and the voices of family and community members who make decisions which influence their lives, were missing.

As the NEEM girls are not yet married, there may be time to address the gaps in their opportunity structures through targeted interventions. However, such interventions must be based on both a clear understanding of the girls' context and evidence of what works. In particular, the views of the girls themselves must be heard. How does the Pakistani adolescent girl who is not in school, not employed, and not yet married view the opportunities that are available to her, both real and perceived? How did she get here and how does she spend her days? Is she content or does she dream of something more? Would her family and community support her in making other choices, if they were available?

The current qualitative study is inspired by these and related questions to deepen our understanding of the girls' perspectives and shared realities, to better understand what support can be provided to them, so they can achieve their desired full potential. It also aims to identify the locally acceptable ways in which girls' current and future lives may be positively transformed, especially through access to safe and fair work opportunities, and whether they have the time to utilize opportunities for productive development and personal growth.

The study has been conducted by the Population Council with the support of UNICEF, and is broadly aligned with the targeted priorities for adolescent girls articulated in UNICEF's Gender Action Plan 2018-2021 (UNICEF 2018). The work of the Council and of UNICEF on gender equality and the empowerment of adolescent girls is grounded in the Convention on the Rights of the Child, the Convention on the Elimination of All Forms of Discrimination against Women, and the Convention on the Rights of Persons with Disabilities. It is further anchored in the landmark Beijing Declaration and Platform for Action.

UNICEF's Gender Action Plan reinforces the point that "advancing gender equality and the rights of women and girls is essential to realizing the rights of all children." UNICEF aims to support "the achievement of gender equality goals in conjunction with partners and national stakeholders, as outlined in the 2030 Agenda for Sustainable Development and the Sustainable Development Goals" (UNICEF 2018). Adolescent girls' wellbeing and empowerment is a key priority of the plan, with two particularly relevant underlying strands: advancing adolescent girls' secondary education, learning and skills; and preventing and responding to child marriage and early unions. The plan points out that, in many places, a girl reaching puberty is a signal for constraining her movements, schooling, friendships, sexuality, and life exposure, while the opposite is often true for boys. "Simultaneously, adolescent girls also experience the burden of domestic work, the expectation to be married or sexually active, and the likelihood of pregnancy, along with the experience of sexual and other types of violence. Because of these obstacles, millions of adolescent girls across the world are denied their potential.... UNICEF places a special focus on this group of children-disadvantaged adolescent girls-for whom investment in multiple interlinked areas has the potential to bring about transformative change, with continuing multiplier effects for their families, communities, and especially the next generation."

The study was conducted in three districts of Punjab, Pakistan's most populous province. It is based on interviews and discussions with adolescent girls, parents of adolescent girls, other community 
'gatekeepers,' and potential local employers of adolescent girls. While the study is not representative of all of Punjab, it is reflective of the social status of adolescent girls in the province, and of some of the barriers that prevent them from actualizing their aspirations. Qualitative findings are complemented by an analysis of secondary data and existing literature.

\subsection{Expected Impact of Study}

The most important aspect of any study is the potential impact that the study expects to achieve. UNICEF commissions research in order to generate evidence that can "inform and guide policy, programming and advocacy on behalf of children" (UNICEF Policy on Research, April 2016). Indeed, research is one of three key pillars of the organization's work in evidence generation. UNICEF believes that research plays a critical role in bringing new ideas and perspectives into play; and that research should address well-defined questions of relevance to advancing the rights and well-being of children, their families and communities.

The Population Council has studied adolescent girls and fueled projects and programs to improve their lives for more than two decades, resulting in data on nearly 200,000 adolescents in 16 countries. A major focus of this work has been on identifying what aspects of girls' education support healthy transitions to adulthood. Rigorous research is at the heart of the Council's Girl Innovation, Research and Learning (GIRL) Center-it ensures that the programs and policies that affect adolescent girls are evidence-based and more likely to succeed.

The results of this study of NEEM girls will inform future policy in relation to the approximately 5 million girls who share their situation across the country. We trust that it will generate an informed dialogue in Pakistan, and encourage policy-makers, government officials, civil society organizations and others to bring this group of girls into much clearer policy focus. Its findings will be especially useful for key organizations and institutions striving to foster gender equality in Pakistan, such as UNICEFparticularly its education section; other UN agencies, such as UN Women, the United Nations Educational, Scientific, and Cultural Organization (UNESCO), the United Nations Population Fund (UNFPA), the United Nations Industrial Development Organization (UNIDO), and the International Labour Organization (ILO); donor agencies such as the Department for International Development, UK (DFID); civil society organizations; and state authorities at federal and provincial levels. The study has the potential to impact on public programs and initiatives so that the latter start to focus on this previously invisible group of girls.

We hope that this study will contribute to ongoing plans to bring many more out-of-school girls back to school, and to create comfortable environments for girls to stay there. We also trust that it will give rise to stronger communications for encouraging families and communities to enable their adolescent girls to travel to school or to take advantage of non-formal education opportunities closer to their homes. In addition, we expect the study will encourage donors and NGOs working in the country to design interventions to enhance the girls' productivity and help draw official attention to their concerns in this area, utilizing the findings about the values and obstacles that hold back change as well as what is appropriate in the girls' own context to change their current restricted situation into an enabling environment that allows them opportunities for greater education, skills building, self-development, and economic activity. 


\subsection{Background}

\subsubsection{Adolescents and Their Transition to Adulthood in Pakistan}

Analysis of the AYSP data by Lloyd and Grant (2004) is helpful in sketching the larger picture of transition from adolescence to adulthood in Pakistan, and how these transitions can be different based on gender and other socioeconomic variables. The early phase of the transition (10-14 years) is marked by puberty (Sathar et al. 2003) and completion of primary education among those enrolled. During the middle phase of the transition (15-19 years) and in the first few years after assuming the legal age of majority (18 years), young people begin to take up adult roles, including paid work, marriage, and departure from home. The last phase of the transition (20-24 years) entails further movement into the workplace and out of the natal home, which is usually linked to marriage for young women and often with work for young men. A key gender difference is that while the first measured transition among most young males is to paid work, for most young females, it appears to be to marriage and leaving home, although many young girls have already assumed the domestic work burden before marriage as well (Lloyd and Grant 2004).

Some transitions are premature, particularly to paid work among out-of-school youth (especially boys) and to marriage among girls. Schooling has a huge influence, with those attending school allowed to complete childhood without taking up the burden of work or marriage; thus, "subsequent transitions are already scripted at the time parents decide about school enrollment at the age of five or six-well before the adolescent years" (Lloyd and Grant 2004). At the same time, there are large lags between some transitions that can blur the line between childhood and adulthood: young males take up paid work many years before they marry, and young females who attend school marry many years after leaving school. The data also indicates some shifts in the transitions among females: adolescent girls are more likely to enter paid work during the middle phase of the transition (15-19 years) and also to delay marriage compared to their older counterparts (20-24 years) during the same phase of the transition, whether or not they have ever attended school.

Gender and age combine with other factors, especially location and socioeconomic status (SES), to influence opportunities for young people. A recent analysis by the Population Council (2016) finds that school enrollment is higher among younger adolescents (10-14 years) than older adolescents (1519 years), and among urban than rural young people, with a significant reduction of gender differences in urban areas. The study notes, however, that gender differences in workforce participation persist across the rural/urban divide. Likewise, Faizunisa and Ikram (2004) find stark differences in educational attainment, employment, recreation, and health seeking behavior among young people across provinces and urban/rural residence, and most acutely by gender, with girls significantly less likely than boys to get an education or be part of the paid labor force, especially in rural areas.

Among the provinces, girls' enrollment is highest in Punjab, but the gender gap among the poorest rural adolescents is also highest there, exceeding 50 percentage points. Availability of sufficient resources in richer households does reduce discrimination, and the gender gap in enrollment narrows steadily from the lowest to the highest economic group. Among older adolescents who ever attended school, the gap between boys and girls in the richest group is small relative to that in the poorest group 
in both urban and rural areas; thus, poor girls living in rural areas suffer a triple disadvantage with poverty and rural location compounding the gender disadvantage (Lloyd, Mete, and Grant, 2007 in Sathar et al. 2016).

\subsubsection{School Enrollment in Pakistan}

Huge proportions of children and adolescents in Pakistan are currently out of school. The net enrollment rate (NER) is 57 percent at the primary level and 34 percent at the secondary level (PSLM 2014-15). Although gender differences in enrollment have narrowed over time, they remain high, especially at secondary levels, in rural areas, and among poorer households (Sathar et al. 2016). Table 1.2 indicates clearly that the gender gap in enrolment remains largely a rural phenomenon; in urban areas, female enrolment is nearly at par with male enrolment at the primary level, and has actually exceeded male enrolment at the secondary level.

Table 1.2: Net enrollment rates at primary and secondary level, Pakistan 2001-02 and 201415

\begin{tabular}{|c|c|c|c|c|c|c|}
\hline & \multicolumn{3}{|c|}{ 2001-02 } & \multicolumn{3}{|c|}{ 2014-15 } \\
\hline & Male & Female & Overall & Male & Female & Overall \\
\hline \multicolumn{7}{|c|}{ NER at Primary Level (ages 5-9, classes 1-5) } \\
\hline Pakistan & 46.4 & 38.3 & 42.4 & 60.1 & 53.0 & 56.7 \\
\hline Urban & 56.9 & 54.2 & 55.6 & 66.7 & 65.7 & 66.2 \\
\hline Rural & 42.9 & 33.0 & 38.1 & 57.4 & 47.7 & 52.8 \\
\hline \multicolumn{7}{|c|}{ NER at Secondary Level (ages 10-14, classes 6-10) } \\
\hline Pakistan & 27.6 & 20.7 & 24.3 & 36.4 & 31.8 & 34.2 \\
\hline Urban & 35.7 & 39.8 & 37.8 & 43.2 & 47.0 & 45.1 \\
\hline Rural & 24.5 & 12.4 & 18.8 & 33.3 & 23.9 & 28.9 \\
\hline
\end{tabular}

Source: Pakistan Social and Living Standards Measurement Survey (PSLM), 2001-02 and 2014-15.

Notably, Lloyd, Mete and Grant found considerably more urban parents (93 percent) than rural parents (80 percent) expressing the aspiration that their daughters obtain secondary or higher education (2007, in Sathar, Wazir and Sadiq 2013).

Apart from residence, household wealth also exerts a powerful influence on the enrollment of girls. Table 1.3 compares the NER across SES levels among primary- and secondary-age girls in urban and rural areas. Clearly, poor girls in rural areas are at a severe disadvantage. 
Table 1.3: Net enrollment rates among girls at primary and secondary level, by socioeconomic status, Pakistan 2014-15

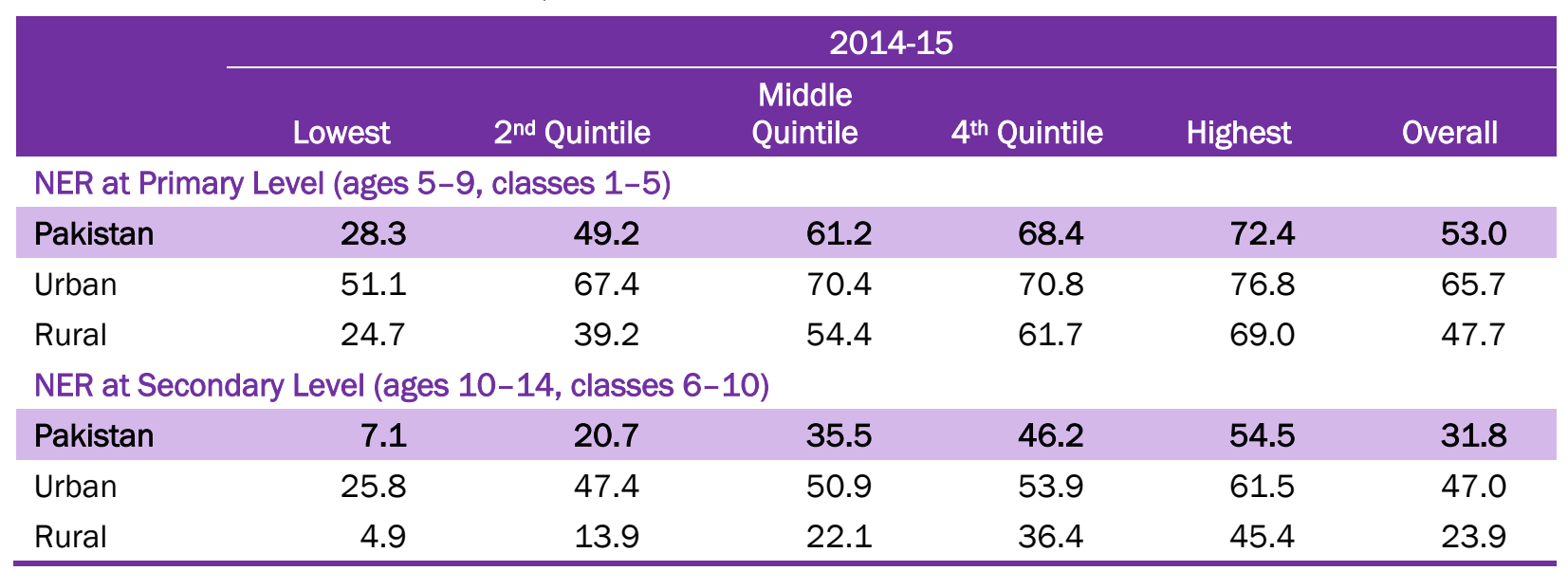

Source: Pakistan Social and Living Standards Measurement Survey (PSLM), 2014-15.

In recent years, private schooling has grown rapidly in Pakistan, catering not just to high- and middleincome families but also to poorer households (Majid 2012 in Sathar, Wazir and Sadiq 2013). Private schools are often perceived to offer better quality services and there is evidence that they lead to greater achievement in mathematics and language compared to public schools (Alderman et al. 2001 in Sathar, Wazir and Sadiq 2013). Communities in both urban and rural areas are moving towards higher girl's enrollment in private primary schools as they are becoming more available in their vicinity. A similar but less dramatic pattern is observed in secondary enrolment (Sathar, Wazir and Sadiq 2013).

\subsubsection{Impact of Education on Girls' Lives}

One of the immediate benefits of female education is that it brings about greater gender equity between boys and girls in time use and work burdens while they remain enrolled (Arends-Kuenning and Amin 2004, Lloyd and Grant 2005, Lloyd 2005a in Lloyd 2011). In Pakistan, the level of a girl's education is one of the strongest predictors of the age at which she will marry and how much autonomy she will have in her home (Zaidi et al. 2012): the timing of marriage is affected even by primary education, while a positive influence on autonomy is linked with at least mid-level schooling.

Education is known to reduce the risk of premarital sex, particularly among girls (Lloyd 2005b), and to effect a decline in rates of early marriage, particularly in sub-Saharan Africa (Mensch, Singh, and Casterline 2005 in Lloyd 2011). Likewise in Pakistan, being educated means later childbearing, largely through deferment of marriage. Moreover, educated girls and women are more likely to be involved in childbearing decisions, use contraceptives, have smaller families, and access pregnancy care. Improved seeking of pregnancy care is associated with eight or more years of education but contraceptive use and involvement in childbearing decisions are affected even by primary education. Aside from access to education, better quality of the schooling environment is also positively associated with desire to use- and actual use of- contraceptives (Zaidi et al. 2012). 
The importance of girls' education for socioeconomic development is affirmed by many studies (for example, Lloyd and Hewett 2003; Lloyd, Mete and Grant 2007; Hewett and Lloyd 2005; Gonsch 2010; and Huisman and Smits 2009 in Sathar, Wazir and Sadiq 2013). An educated girl will grow up to confront lower risks of maternal and child mortality, poor nutrition and associated problems among their children, and spousal violence compared to peers with little or no education (Pakistan Demographic and Health Survey 2012-13). Mothers' education is also a strong explanatory factor for children's schooling levels (Sathar et al. 1988, Sathar 1987, and Mahmood and Ringheim 1993, in Sathar and Kazi 2000). Research also shows that investment in secondary education, together with primary education, provides a clear boost to economic development (Lutz et al. 2008, in Sathar, Wazir and Sadiq 2013).

With regard to female work force participation, there is a positive correlation between years of education and being engaged in non-agricultural work at high levels of education (Zaidi et al. 2012). Moreover, education narrows the gender-related pay gap: Pakistani women with a primary education earn 51 percent of what men earn, while those with a secondary education earn 70 percent of what men earn (UNESCO 2013).

Lloyd (2011) cautions, however, that in societies where local cultures value strongly differentiated gender roles, as in Bangladesh and Egypt, greater schooling for girls may confer temporary benefits during adolescence that disappear as young women take up traditional adult roles. This could explain the finding by Sathar and Kazi (2000) of a weakening of the effects of education in rural areas of Pakistan; contrary to the situation in urban areas, the authors observe that education among rural women is only very weakly associated with mobility, perceived economic autonomy, and a say in household or external decisions.

\subsubsection{Adolescents and Young People at Work}

Economic work under the age of 15 is defined as child labor by various international labor conventions as well as by the Convention on the Rights of the Child, and many countries, including Pakistan, have agreed to take steps to eliminate it. Thus, economic work during this phase of life is discouraged and seen as jeopardizing schooling (Lloyd 2004). The Constitution of Pakistan calls for the state to ensure compulsory education of all children up to the age of 16 , which ought to limit the extent to which adolescents can participate in economic work. Moreover, the Constitution and various laws specify sectors where children may not work, as well as minimum ages of work-mainly 14 years, with some variation across provinces and work sectors (Wagelndicator 2017).

Children and adolescents in Pakistan are working in both the formal and informal sectors, and in both paid and unpaid capacities. According to the Labour Force Survey (LFS) 2014-15, 20 percent of adolescents (10-19 years) are in the labor force, with 2 percent unemployed, 10 percent in agriculture, 7 percent working in the informal sector, and only 1 percent engaged in the formal sector. Notably, 9 percent are working as family workers.

The labor force participation rate among youth (ages 10-24) is 41.3 percent among males and 16.4 percent among females (LFS 2014-15). Age-specific participation rates (ASPRs) in the early teens showed a declining trend between 2005 and 2015, which is encouraging: among young adolescents 
(10-14 years), the rate dropped from around 21 percent to 11 percent among boys; and from 9 to less than 8 percent among girls. Another positive sign was the increase in ASPR for young women (ages 20-24) from 21 to 26 percent, although the rate for male peers dropped from 88 to 82 percent (Sathar et al. 2016). Labor force participation rates among young females show a curvilinear, Ushaped relationship with education, with higher employment rates among those who are least educated and those with a degree, and negligible participation at other levels of education (Ibid.).

Among older adolescents (15-19 years), a tenth of both males and females are unemployed. At ages 20-24, 9 percent of men and a much higher 16 percent of women are unemployed. Unemployment is associated with living in urban areas and, as shown in Figure 1.1, with higher educational attainment, most starkly in the case of females (Sathar et al. 2016).

Figure 1.1: Unemployment rates by educational attainment among older youth (ages 15-24), Pakistan 2014-15

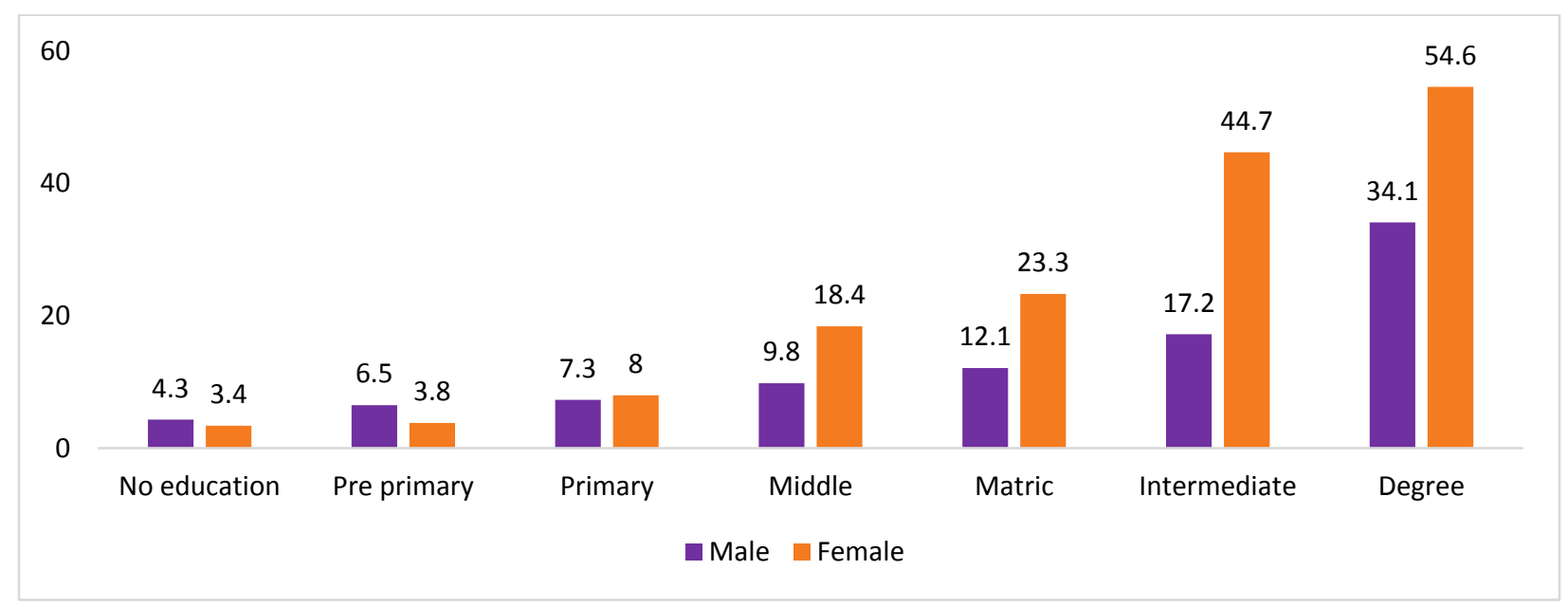

Source: Sathar et al. 2016 based on Labour Force Survey 2014-15 data.

In addition to the issue of higher unemployment among females in Pakistan, a number of studies have documented the gender gap in the quality of work as well, with female participation generally concentrated in the informal sector and in less paid positions. According to the Social Policy and Development Centre (2010), women's labor force participation increased remarkably between 1973 and 2008, but the majority are unpaid family helpers and their share among total employed women has registered an alarming increase. Agriculture remains a major employer of both men and women, but the concentration of women in this sector has increased while that of men has declined. Females are largely employed in agriculture, manufacturing, and community and social services; in agriculture and manufacturing, more than 90 percent of women are in low-pay jobs. Among unpaid family helpers, 94 percent are associated with agriculture. The majority of working females who are illiterate, or educated up to primary education, are employed in this sector.

In the manufacturing sector, females are mainly involved in export-oriented industries, chiefly textile, apparel, and leather manufacturing. They are usually educated up to Matric or less and work in lowpay jobs (SPDC 2010). 
The study also finds that illiteracy is much higher among female than male workers, and only 4 percent of employed females are graduates, compared to 7 percent of males. Women who graduate are working in community, social or personal services, but otherwise the link between education and employment is very weak and women's entry into higher educational institutions does not appear to ensure their subsequent entry into the labor force (SPDC 2010).

Females tend to work in the informal labor market where most are not eligible for fringe benefits and tend to work more days and longer hours than male workers (Haque 2006). They seldom join trade unions, which are heavily male-dominated (Saigol 2011). Moreover, a large number of women are home-based workers who have no direct access to the market and are often exploited by middlemen (Saigol 2011).

Notably, despite their huge presence and role in the agriculture sector, women in Pakistan do not generally own land, and when they do, they seldom exercise effective control over it in terms of decision-making. Socio-cultural, traditional, emotional and legal constraints prevent them from demanding their land rights. Moreover, they often have difficulties in accessing credit or extension services, as agricultural policies are dominated by a patriarchal bias, and are usually not represented on water boards and irrigation bodies (Saigol 2011).

\subsubsection{Impact of Work on Women's Lives}

Studies suggest mixed effects of economic work on the lives of women in Pakistan. Certainly, women engaged in paid work do report higher self-esteem and economic security (Siddiqui et al. 2006, Shaheed and Mumtaz 1981, National Commission on the Status of Women 2005). But while paid work is generally reported to enhance women's say in household decisions (Shaheed and Mumtaz 1981, Sathar and Kazi 2000, Khattak 2001), Siddiqui et al. (2006) note that this power may be restricted to household provision and children's education, and women seem to agree with men that it should remain limited.

Many studies report a doubling of women's work burdens as they continue to be responsible for domestic work while assuming the added responsibilities of paid work (for example, Mahbub ul Haq Human Development Center 2000, Shaheed and Mumtaz 1981, and Khattak 2001). Khattak (2001) found that large proportions of women in the urban manufacturing sector no longer identified household chores as their primary responsibility, but they remained responsible for these chores and usually delegated them to female relatives in the household. Unfortunately, it is older daughters who most commonly take their working mothers' place in the home (Sathar and Kazi 1988, Fuller and Liang in Shahidul and Karim 2015), and are often withdrawn from school to fulfill this need. In urban settings, however, a mother's working outside her home is associated with less gender discrimination in sending children to school compared to mothers who do not work (Kazi 1999, Khattak 2001).

In her study of working women in Karachi, Kazi (1999) found child deaths to be significantly higher for informal sector workers employed outside the home even after controlling for income and education; women working outside the home were at a greater disadvantage in terms of child survival than homebased workers also from poor households. There is also evidence that women engaged in paid work are more likely to suffer spousal violence (Siddiqui et al. 2006, PDHS 2012-13) and to fear their 
husbands for this reason (Sathar and Kazi 2000). Participation of women in the work force is linked with higher use of contraceptives, but the nature of work is an important factor. Most working women are employed in the informal sector, which they typically join to meet financial needs after having several children; while women working in the formal sector, especially those in jobs valued by society and with hope of upward mobility, have lower fertility (Sathar and Kazi 1990).

Khattak (2001) concludes that work can be simultaneously empowering and disempowering, often due to its informal nature and the overriding influence of poverty. Siddiqui et al. (2006) similarly note that working women may have more autonomy in some respects but that this is limited not only by gender, but also by their age and the hierarchy within their households. From their analysis of survey findings from rural communities in agro-climatically and ethnically diverse areas of Punjab, Sathar and Kazi (2000) conclude that the community has a strong role in conditioning the impact of women's work. For example, women in barani (rain-fed) areas may enjoy making certain household decisions but do not enjoy economic autonomy due to their limited work opportunities. Mobility is much higher in central Punjab, a factor which emerges as important in accessing markets and as well as sources of health care and family planning.

\subsection{Structure of the Report}

The objectives and methodology of this study are outlined in Chapter 2. In Chapter 3, we share profiles of the study respondents, followed by findings from a quantitative analysis about the status of schooling, marriage, and employment among older adolescent boys and girls (15 to 19 years) in the three districts where the study was conducted. Time use among the girls is also analyzed. Chapter 4 looks at why NEEM girls are not in school, probing the reasons, the girls' aspirations, and views regarding prospects for girls resuming their' education. In Chapter 5, we take an in-depth look at why the girls are not engaged in any paid work, and their interest and preferences in this regard, as well as the views of parents, community members, and local employers. Measures that could be taken to increase employment among NEEM girls are explored in detail. Finally, Chapter 6 discusses the findings of the study and suggests actions that can be taken to provide opportunities to NEEM girls to learn and earn. 



\section{Chapter 2 Methodology}

This chapter outlines the specific objectives and research questions guiding this study, and explains the methodology used to collect and analyze data.

The methodology was designed and executed by the Population Council research team, with inputs from a

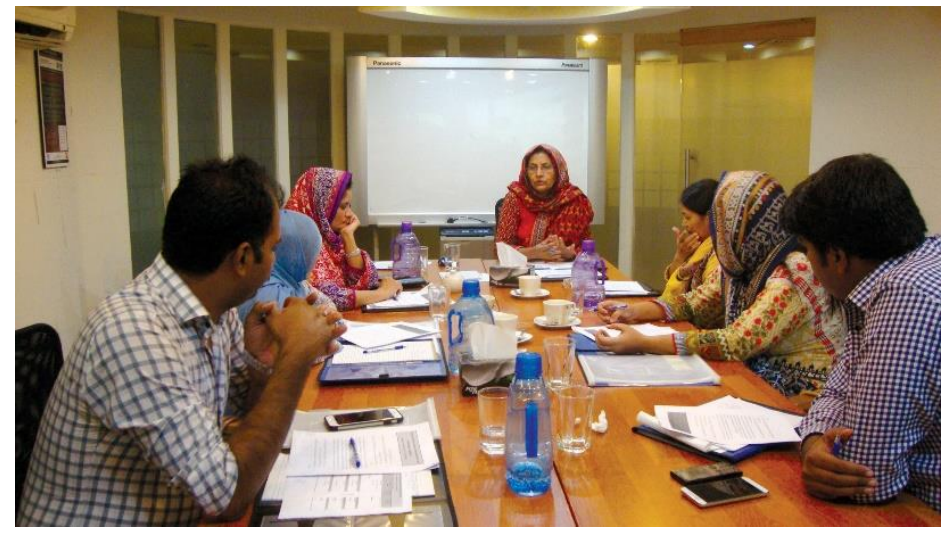
Research Reference Group (RRG), established and led by UNICEF, throughout key phases, including methodology design, district selection, finalization of study tools and feedback on pre-tests, and review of draft reports. A list of the RRG members is provided in Appendix A.

\subsection{Objectives of the Study}

The study had the following objectives:

- To identify the reasons for the exclusion of adolescent girls (aged 15-19 years) who are not in education, employment, or marriage-henceforth referred to as "NEEM girls"-from opportunities to acquire an education and participate in paid work;

- To explore avenues for improving the NEEM girls' existing opportunity structures;

- To obtain insights into what it would take to improve the education and job opportunities of marginalized adolescent girls while also identifying the presumed underlying gender norms and behaviors that may act as barriers for girls in achieving their aspirations and goals.

\subsection{Research Questions}

In pursuit of the above objectives, the study was framed around four research questions:

1 How do the girls and their parents view their current status in society in regard to rights and entitlements? Do the girls and parents want a change in the status quo?

2 What are the main factors preventing girls from obtaining an education or continuing their education? What were girls' own choices and preferences when the decision to not go to school was made by their parents or guardians?

3 What are the main factors preventing these girls from being involved in any paid economic activity? What are girls' own choices and preferences in this regard?

4 What can motivate the girls and their parents to make transformative changes that enhance the productivity of their lives? What kind of supportive environment, circumstances, and 
opportunities could cause a turnaround for these girls in terms of educational attainment and economic activity?

\subsection{Research Location and Sampling Methodology}

The study was conducted in three districts of Punjab, namely Faisalabad, Kasur, and Rajanpur.

For district selection, the province's 36 districts were divided into three regions, each comprising adjacent districts, as shown in Figure 2.1. The intent in dividing the province into these three regions was to capture intra-provincial variations by selecting one district from each.

Next, we used a secondary analysis based on the Punjab Multiple Indicator Cluster Survey (MICS) 2014 to rank districts within each of the three regions by the size of the population of NEEM girls. From each of Regions 1 and 2, we selected one district with a high proportion of NEEM girls, specifically Rajanpur from Region 1 and Kasur from Region 2. As the third district in the sample, however, we looked for a district with the lowest proportion of NEEM girls and with a higher availability of economic opportunities. This was intended to capture differences in the perspectives and circumstances of girls from the most and least restrictive settings in the province. The third district thus included in the sample is Faisalabad from Region 3 (Figure 2.1).

\section{Figure 2.1: Map of Punjab showing three different regions and location of study districts}

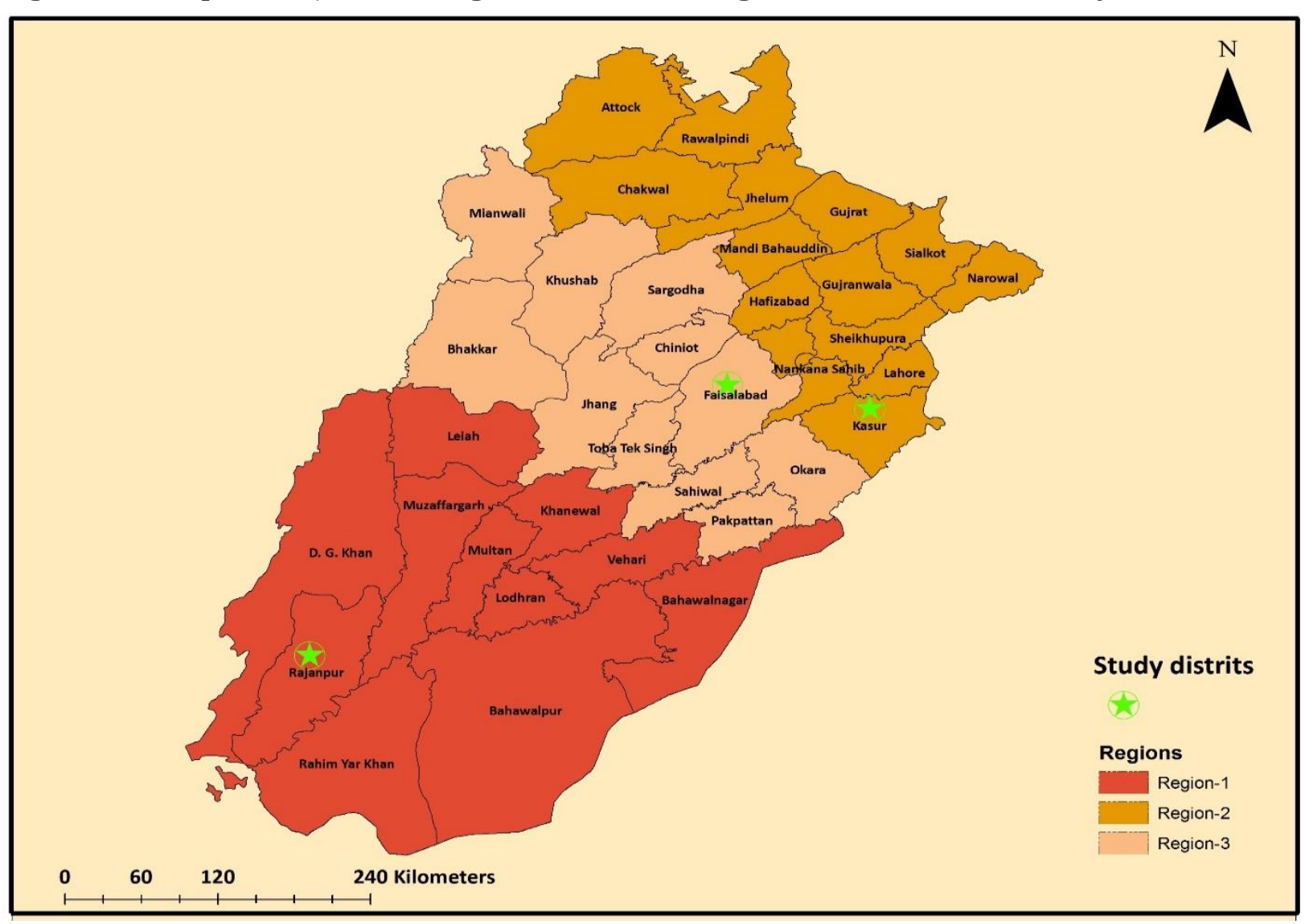


Within each of the three selected districts, we randomly selected two rural communities and one urban community (i.e., a town) to capture both settings. These communities were randomly selected from administratively defined rural and urban union councils. A total of nine study sites were thus selected, six rural and three urban, in three districts across Punjab.

Within each community, influential community members and female school teachers were identified as facilitators to support the research team in building connections with parents and community leaders. Prior to collecting data, we engaged in a dialogue with the community leaders and parents of girls to explain to them the purpose of the research. Since it was difficult to do a full count of adolescent girls, respondents for the study were identified with the help of girls and their parents, using the snowball technique to locate eligible respondents.

\subsection{Profile of the Study Districts}

Although Faisalabad and Kasur are geographically close-only 230 kilometers apart via the LahoreIslamabad motorway-they are starkly different in terms of urbanization, population density, and extent of industrialization. According to the latest Population and Housing Census (2017), Faisalabad is far more urbanized (48 percent) than Kasur (27 percent), with a population density of 1,344 people per square kilometer compared to 864 persons in Kasur. The Census also declares Faisalabad to be the third largest city in Pakistan, after Karachi and Lahore, while Kasur remains a mainly rural district. Moreover, the textile industry is historically extensively established in Faisalabad, while in Kasur there is only one tehsil, Chunian, where an industrial estate has been deliberately set up to encourage industrial activity.

As Table 2.1 shows, of the three study districts, Faisalabad has the highest and most urbanized population and the lowest level of poverty. The singulate mean age at marriage (SMAM) for females is also highest in this district. On the other hand, Rajanpur is less populous and has the least urbanized population, the highest level of poverty, and the lowest SMAM for females, although it is not far behind Faisalabad in this respect.

Older adolescent girls (15-19 years) comprise 12 percent of the total female population of Faisalabad, 13 percent in Kasur, and 9 percent of the female population in Rajanpur, according to the Pakistan Living Standards Measurement Survey (PSLM) 2014-15. Their numbers are highest in Faisalabad and lowest in Rajanpur, reflecting the overall population sizes as provisionally estimated in the Census 2017.

Among these girls, quite a high proportion (18 percent) are married in Rajanpur compared to the other two districts. The literacy rate in this group is also lowest in Rajanpur, with less than half the girls literate, compared to over three quarters in Kasur and Faisalabad. Similarly, only about a quarter of girls in this group are currently in school in Rajanpur, compared to around two fifths in Faisalabad and in Kasur, which has the highest proportion in school at 42 percent.

Of the total population of girls aged 15-19 years in each study district, the percentage of NEEM girls also varies, with the highest proportion in Rajanpur (54.3 percent), followed by Kasur (39.7 percent) and Faisalabad (33.7 percent). 
Overall, the figures show that Faisalabad district is relatively more developed on almost all indicators; Kasur is somewhere in the middle; and Rajanpur depicts a more deprived situation in terms of poverty, early marriage, female literacy, proportion of girls currently in school, and the proportion of NEEM girls.

Table 2.1: Profile of overall population and specifically of girls aged 15-19 years in the study districts

\begin{tabular}{|c|c|c|c|}
\hline \multirow{2}{*}{ Indicators for overall population } & Faisalabad & Kasur & Rajanpur \\
\hline & & & \\
\hline Population (millions) ${ }^{\mathrm{a}}$ & 7.874 & 3.455 & 1.996 \\
\hline Sex ratio & 105.1 & 107.6 & 106.2 \\
\hline Urban population (\%) & 47.76 & 25.78 & 16.89 \\
\hline Poverty headcount $(\%)^{b}$ & 19.4 & 21.9 & 64.4 \\
\hline Singulate mean age at marriage $(\text { Female })^{c}$ & 27.68 & 26.30 & 24.63 \\
\hline \multicolumn{4}{|l|}{ Indicators for girls aged $15-19$ years } \\
\hline Population $^{d}$ & 474,000 & 212,000 & 90,000 \\
\hline Proportion of girls to total female population ${ }^{c}$ & 12.36 & 12.72 & 9.26 \\
\hline Percentage of girls who are marriedc & 5.7 & 9.7 & 17.9 \\
\hline Literacy ratec & 82.3 & 78.9 & 49.3 \\
\hline Percentage currently in schoolc & 41.0 & 42.2 & 26.3 \\
\hline $\begin{array}{l}\text { Percentage of girls not in school, not working for } \\
\text { pay or profit, not marriede }\end{array}$ & 33.7 & 39.7 & 54.3 \\
\hline $\begin{array}{cl}\text { Sources: } & \\
\text { a- } & \text { Population and Housing Census 2017, } \\
\text { b- } & \text { Multidimensional Poverty Index (MPI) 2014-15, } \\
\text { c- } & \text { Pakistan Living Standards Measurement Survey (PS } \\
\text { d- } & \text { Population and Housing Census 2017; estimate bas } \\
\text { e- } & \text { Multiple Indicator Cluster Survey (MICS) - Punjab, } 201\end{array}$ & $\begin{array}{l}\text { 4-15, } \\
\text { SLM 2014-15p }\end{array}$ & & \\
\hline
\end{tabular}

The study incudes both secondary data analysis and primary data collection components. We conducted district-level secondary analysis of the latest data available through the Punjab MICS 2014 and PSLM data series to analyze the life trajectories of older adolescent girls (15-19 years) in each of the study districts, following segmentation by urban-rural residence and wealth index status. The segmentation depicts a breakdown of this group by status and size in terms of educational attainment, livelihood activities, and marriage and fertility patterns.

The overall methodological design for primary data collection is shown in Figure 2.2, which identifies the themes probed and methods used in data collection from various types of respondents. 
Figure 2.2: Methodological design of the study

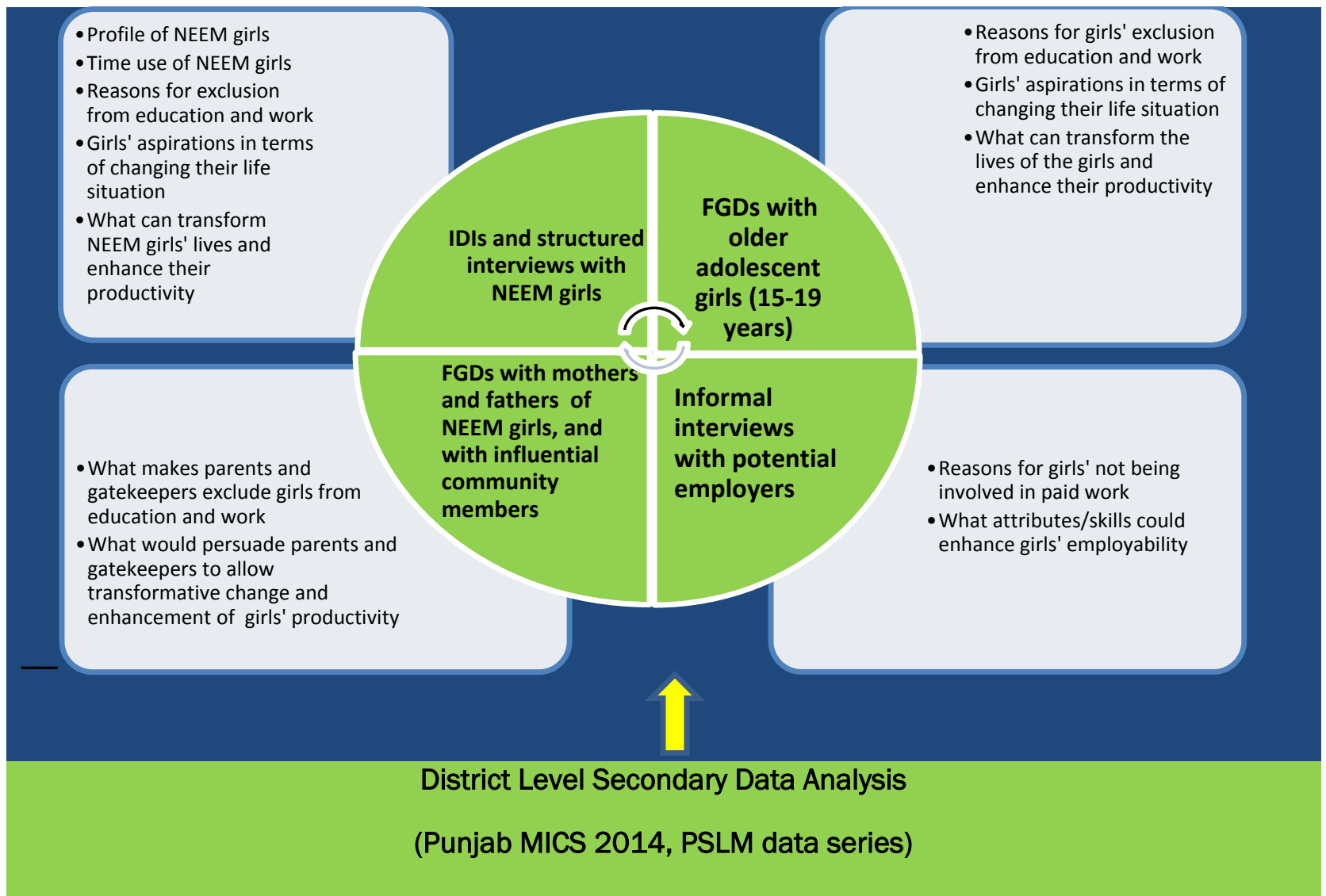

NEEM girls=Older adolescent girls (15-19 years) who are not in education, employment, or marriage.

As shown above, primary data collection was carried out using a mainly qualitative approach, based on focus group discussions (FGDs) and in-depth interviews (IDIs), to probe more deeply for insights from girls, mothers and fathers, community gatekeepers, and potential employers. In addition, a small quantitative tool-a structured questionnaire-was used to collect background information and time use data about the adolescent girls with whom IDIs were conducted.

A total of 42 IDIs were conducted with NEEM girls to learn about their opportunities and the possibilities of transforming their lives to be more productive. The structured questionnaire was administered prior to these interviews to help in compiling a picture of how the girls spend their time, the spaces they use, and some attitudinal questions predicting future behaviors.

We conducted a total of 40 FGDs, including 20 with adolescent girls (15-19 years), 10 with mothers, and 10 with fathers. The distribution of IDIs and FGDs across the three districts is presented in Table 2.2. The FGDs with fathers also included a few influential male community members, ${ }^{2}$ and an additional 9 informal interviews were conducted with potential employers in the study areas.

\footnotetext{
2 The men who participated in the FGDs were fathers of adolescent girls aged 15-19, but not fathers of any of the girls who were interviewed in this study.
} 
The FGDs and IDIs were conducted across the nine study locations. About 232 adolescent girls and more than 180 gatekeepers (mothers, fathers, and influential community members) participated in these exchanges.

Table 2.2: Number of in-depth interviews and focus group discussions conducted in study districts, by urban/rural location and type of respondent

\begin{tabular}{|c|c|c|c|c|c|c|c|c|c|c|}
\hline \multirow[b]{2}{*}{ District } & \multicolumn{2}{|c|}{$\begin{array}{l}\text { Structured } \\
\text { interviews and } \\
\text { IDls with girls* }\end{array}$} & \multicolumn{2}{|c|}{$\begin{array}{l}\text { FGDs with } \\
\text { girls }\end{array}$} & \multicolumn{2}{|c|}{$\begin{array}{l}\text { FGDs with } \\
\text { mothers }\end{array}$} & \multicolumn{2}{|c|}{$\begin{array}{c}\text { FGDs with } \\
\text { fathers and } \\
\text { community } \\
\text { representatives }\end{array}$} & \multicolumn{2}{|c|}{$\begin{array}{l}\text { Informal } \\
\text { interviews with } \\
\text { employers }\end{array}$} \\
\hline & Rural & Urban & Rural & Urban & Rural & Urban & Rural & Urban & Rural & Urban \\
\hline Faisalabad & 10 & 4 & 4 & 2 & 2 & 1 & 2 & 1 & 2 & 1 \\
\hline Rajanpur & 10 & 4 & 5 & 2 & 3 & 1 & 3 & 1 & 2 & 1 \\
\hline Kasur & 10 & 4 & 5 & 2 & 2 & 1 & 2 & 1 & 2 & 1 \\
\hline Total & 30 & 12 & 14 & 6 & 7 & 3 & 7 & 3 & 6 & 3 \\
\hline $\begin{array}{l}\text { Overall } \\
\text { Total }\end{array}$ & \multicolumn{2}{|c|}{42} & \multicolumn{2}{|c|}{$\begin{array}{c}20 \\
\text { (190 girls) }\end{array}$} & \multicolumn{2}{|c|}{$\begin{array}{c}10 \\
\text { (86 mothers) }\end{array}$} & \multicolumn{2}{|c|}{$\begin{array}{c}10 \\
\text { (69 fathers }+20 \\
\text { influential } \\
\text { community } \\
\text { representatives) }\end{array}$} & \multicolumn{2}{|c|}{9} \\
\hline
\end{tabular}

*Structured interviews and IDIs were conducted with the same girls.

A profile of the respondents is presented in Chapter 3.

The instruments used to conduct the IDIs and FGDs included:

- Guidelines for in-depth interview and structured questionnaire with NEEM girls

- Guidelines for FGDs with unmarried girls ages 15 to 19 years (not restricted to girls who are out of school and not working)

- Guidelines for FGDs with mothers of girls ages 15 to 19 years (not restricted to mothers of interviewed girls)

- Guidelines for FGDs with fathers of girls ages 15 to 19 years (not fathers of interviewed girls) and influential community representatives ${ }^{3}$

- Guidelines for informal interviews with local and potential employers.

The research tools were finalized in three phases. First, draft guidelines developed by the team at the Population Council and shared with the RRG. (A list of the RRG members is provided in Appendix A.) After incorporating the RRG's comments, the guidelines were pre-tested by the Population Council's research staff in Rawalpindi district and the tools further refined in the light of the experience. Finally, another pre-test was conducted in Attock district by the study team engaged for actual data collection,

3 A total of 20 male influential community representatives participated in the FGDs with fathers, including 7 each from Faisalabad and Rajanpur and 6 from Kasur. They included teachers, the mosque Imam, farmers, government employees, and personnel from local NGOs. At least 2 of these community representatives were identified by the community members in each FGD. 
after it had been trained. The tools were finalized after incorporating feedback from this second pretest.

\subsubsection{Study Team and Training}

Prior to commencement of data collection, a team of 6 ( 4 female and 2 male) members was provided 5 days' in-depth training in conducting the IDIs and FGDs and administering the relevant questionnaires by senior Population Council staff. The training methodology was participatory, using short lectures followed by discussions and extensive role play, with one day for hands-on practice using the different instruments in actual field visits to communities. This was followed by thorough debriefing and reinforcement of concepts.

\subsubsection{Field Work and Quality Control Processes}

Actual data collection commenced directly after the completion of training and the duration of field work was about one month, from September to October 2017. A number of quality assurance measures were undertaken for this activity. Roles and responsibilities of each team member were clearly defined along with work plans and timelines. During field work, team supervisors daily discussed the activities and checked transcribed data to identify potential gaps in the information collected. They also frequently observed the FGDs and IDIs being conducted to ensure that comprehensive and accurate information was being collected. Senior staff of the Population Council stayed on site to observe the process and provide hands-on guidance where needed.

Through careful instrument development, close quality monitoring, and strict observance of ethical standards (outlined below), we have minimized the risk of imbalance or bias in the data collected for the study. A minor issue that may be mentioned is that during some FGDs, the discussion took longer than the duration that had been specified to participants at the outset, due to which some respondents, especially adolescent girls, had to leave the discussion before it ended. We would also like to point out that interviews with adolescent boys were not included in the study design, and therefore the our findings about gender differences in reasons for being out of school and about boys' participation in economic activities are based on the perspectives of girls and parents.

\subsubsection{Data Processing and Analysis}

FGD transcriptions were completed in the field, immediately after each discussion, to preserve the essence of the discussion and note relevant observations, while transcriptions of IDIs were carried out at the Council office to expedite data processing. Translation of all FGDs and IDIs from Urdu to English and data coding in NVIVO software (version 10) were carried out simultaneously at the Council office. The data was sorted based on themes and sub-themes across the categories of respondents. Node reports of different thematic areas were keenly analyzed to identify factors associated with girls' exclusion from education and economic activity, as well as willingness to change their lives and ways

suggested for enhancing their productivity. Frequencies of different responses under each of the themes were also calculated to assess the intensity of individual points across districts and respondent types. 
For the structured questionnaire administered to the interviewed girls, a data file was initially prepared and tested with all necessary skips and checks to address response inconsistencies. Data from the questionnaires was entered into the latest version of CSPro and analyzed using SPSS version 21 . The data manager conducted quality checks to ensure completeness and identify mistakes in data files, and made corrections after verifying with study coordinators. Univariate analysis and bivariate analysis was carried out, which was then triangulated with qualitative findings.

\subsection{Ethical Standards and Compliance}

Throughout the research, the study team adhered to ethical guidelines both of the Population Council and of UNICEF. The Population Council requires all studies involving human subjects to be reviewed by its Institutional Review Board (IRB) before the activity is initiated. The purpose of the IRB review is to ensure that appropriate steps are taken to protect the rights and welfare of women, men, girls and boys participating as subjects in a research study. Ethical approval from the IRB was obtained for this research on July 3, 2017 and is attached in Appendix B.

Informed consent from the respondents was obtained after briefing them in depth about the study, its objectives, procedures, and uses. The approximate time required for interviews and group discussion and the possible risks, if any, respondents might face were also explained. Written consent was obtained using a separate form for each of the respondents. Assurance was provided to respondents about the anonymity and confidentiality of their responses. The focus group discussions and in-depth interviews were conducted at times convenient to respondents and also in private, maintaining auditory privacy.

All data collected for the study has been kept confidential through secure storage, without identifiers of individuals. Participation was voluntary and respondents were not compensated in any way. The participants were informed that they could refuse to answer any question that made them uncomfortable, could terminate the interview at any time, and that no action would be taken against those who refused to participate.

The Council's research team is well versed with the local culture, customs and beliefs in the study areas. Additional field staff hired for data collection worked under the direct supervision of the Council's own research team. The comprehensive 5-day training organized for data collection teams also covered the ethical standards to be followed during field work. The relevant training sessions ensured that research team members were aware of differences in culture, local customs, religious beliefs and practices, norms of personal interaction as well as gender roles, age, and ethnicity, and were mindful of the potential implications of these differences while carrying out all research activities. 


\section{Chapter 3}

\section{Adolescent Girls in the Study Districts: Transition Status and Time Use}

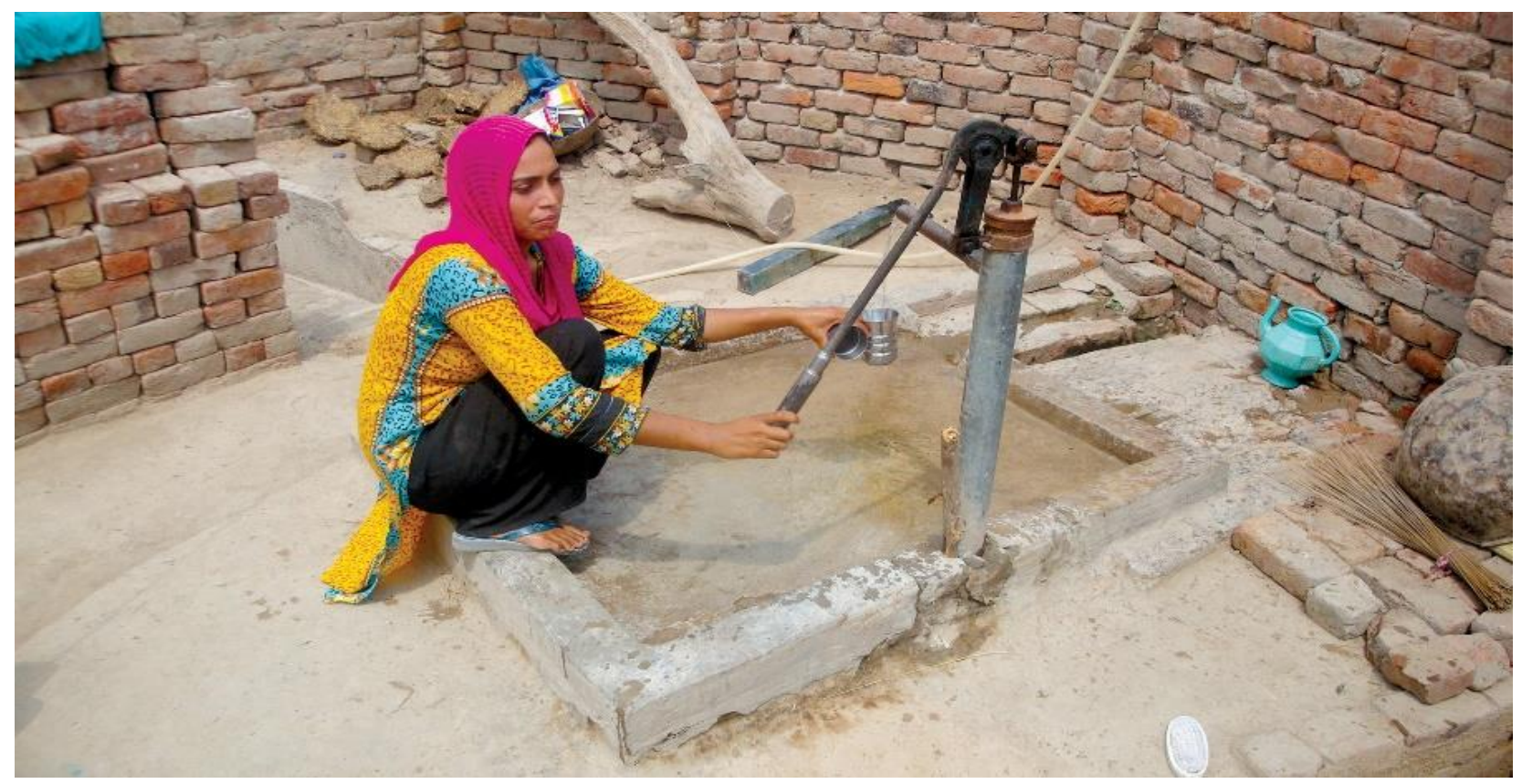

This chapter begins with a brief profile of the respondents in this study. We then present an overview of adolescents in the study districts with respect to their schooling, work, and marriage status. The analysis, based on secondary data, is segmented by gender, wealth status, and urban/rural location to show how these factors can potentially influence the trajectories of young lives. Subsequent parts of the chapter focus on the cohort of girls of primary interest to this study-the older adolescent girls (15-19 years) who are not in school, not working, and not married (i.e., NEEM girls). We take a detailed look at the reported daily activities of these girls, specifically how much time they spend on each set of activities, and how this varies by district and age. A brief review is also presented of the girls' access to and utilization of mobile phones, which were explored to assess the potential for interventions based on mobile technology.

\subsection{Profile of the Study Respondents}

\subsubsection{Interviewed Girls}

A total of 42 girls participated in the in-depth and structured interviews. Of these, 29 were from rural areas and 13 from urban or town areas. Most of the girls were between 15 and 18 years of age, while eight girls, from Faisalabad and Kasur, were 19 years old. 
While all of the girls were out of school at the time of the interviews (as per selection criteria), the majority-36 girls-had attended school in the past. Eight girls had never attended school, while 16 had dropped out before completing primary education, and 18 had left school between fifth and eighth grades.

Most of the girls were at middle birth order. Fathers of 15 girls and mothers of only 4 had attained some education, ranging from primary to secondary level, while all other parents had no schooling. More details about these respondents are available in Table C1 in Appendix C.

\subsubsection{Girls Who Participated in FGDs}

A total of 190 girls participated in FGDs across the districts, including 58 from Faisalabad, 67 from Kasur, and 65 from Rajanpur. Of these girls, 120 were 15-17 years of age and 70 were 18-19 years old. About a quarter of the girls had never been enrolled in school, while 98 had dropped out-79 before completing primary education, and 19 during middle grades. However, about 20 percent of the girls were in school at the time of the discussion, studying at secondary or higher level. With regard to educational attainment among the respondents' parents, we found the same pattern as for the IDI respondents: both parents of the majority of girls did not have any education. Table C2 in Appendix C provides further details of the profile of these respondents.

\subsubsection{Mothers Who Participated in FGDs}

A total of 86 mothers with at least one daughter aged 15-19 participated in the FGDs, including some whose daughters were also interviewed as part of this study. Over half of the mothers were 30 to 40 years of age, while about 40 percent were of ages 41 to 50 . Most of the mothers (91 percent) had not attained any education, particularly in Rajanpur. However, about 40 percent-mainly from Faisalabad and Kasur-reported that their spouses were educated to at least some level. Half of the mothers were housewives, while a third were working as unskilled laborers: the majority of these working mothers were from Rajanpur, where they were primarily engaged in cotton picking. On the other hand, most of the spouses of the women were involved in some economic activity, mainly agriculture related work, and unskilled and skilled labor. More details about these respondents are provided in Table C3 in Appendix C.

Nearly a quarter of mothers from the central Punjab districts, i.e., Faisalabad and Kasur, reported that their older adolescent daughters (ages 15-19) had no schooling, while the majority said their daughters had at least some years of schooling. On the other hand, the majority of mothers (71 percent) from the southern district, Rajanpur, reported that their daughters had never gone to school, while 23 percent reported that their daughter had dropped out from primary level.

Interestingly, involvement of daughters in paid or unpaid economic activity also presented quite a different picture across the southern and central districts. A substantial number of mothers reported no involvement of their daughters in any economic activity in both Faisalabad (92 percent) and Kasur (96 percent). Only a few mothers from Faisalabad mentioned that their daughters were currently studying or involved in farming activities, while some mothers from Kasur mentioned that their daughters were doing tailoring work. On the other hand, more than half of the mothers from Rajanpur- 
the southern district-reported that their daughters were working as paid or unpaid laborers, mainly in cotton fields, while the rest said their daughters were not engaged in any economic activity (Data not shown).

\subsubsection{Fathers and Influential Community Members Who Participated in FGDs}

A total of 70 fathers with at least one daughter aged 15-19 and 20 influential community members participated in the FGDs with men. Among the community members, 7 each were from Faisalabad and Rajanpur and 6 from Kasur, including teachers, mosque imams, farmers, government employees, and personnel of local NGOs. The respondents were equally distributed across the age groups 30-40, 4150 , and 51 and above. About half had no schooling: fewer of these respondents were from Faisalabad, compared to Kasur and especially Rajanpur. Almost all the respondents were working-mainly in agriculture-related activities or as unskilled daily-wage laborers-while a few were employed in government or private sector jobs, especially as teachers. Contrary to what mothers reported, the majority of respondents said their wives had no schooling, especially in Rajanpur, and almost all reported their spouses to be housewives. Further details about these respondents are provided in Table C4 in Appendix C.

With regard to the educational attainment of their adolescent daughters (15-19 years), a few of the fathers from Faisalabad, a third from Kasur, and more than two-thirds from Rajanpur reported that their daughters had never attended school. Further, half of the fathers from Kasur and about a quarter from Rajanpur also reported that their daughters had dropped out while in primary school. Overall, the status of daughters' schooling was far better in Faisalabad than in Kasur and especially Rajanpur.

In contrast to what was reported by mothers regarding the work status of their daughters, the majority of the fathers across the districts said that their daughter just took care of household chores and was not involved in any economic activity, while a few reported that their daughters were currently studying in school (Data not shown).

\subsubsection{Potential Employers Interviewed at Factories}

A total of nine potential employers were informally interviewed in the study, three from each of the districts, to obtain an idea of the current status and possible opportunities for girls' employment. The only criterion assigned for the selection of workplaces for these interviews was that they be situated in the vicinity of the study communities.

In Faisalabad, interviews were conducted at two large cotton factories and one cardboard factory. Two of these had female employees, while one did not employ females. In Kasur, interviews were conducted at two garment factories and one cotton factory; female employees were working at only one of the garment factories. In Rajanpur, interviews were conducted at two large cotton concerns and one cotton ginning factory; none of these had any female employees. 


\subsection{Transition Status of Adolescent Girls}

Ages 15 to 19 mark the middle phase of young people's transition to adulthood. As mentioned earlier, this is the time when adolescent boys and girls in Pakistan begin to take up adult roles, such as entry into the labor force, leaving home, and marriage. Data from the AYSP 2001-02 indicate gender differences in these transitions, with more girls assuming household responsibilities at an early age and getting married, and more boys starting paid work. Adolescents who are not in school are more likely to make these transitions prematurely.

\subsubsection{Differences across Gender and Districts}

Analysis of the Punjab MICS 2014 data presents a clear picture of the status of adolescents in terms of schooling; work for pay or profit; and marriage in each of the study districts, including differences across gender, districts, and ages. Figure 3.1 shows separately the proportion of older adolescents in each district who are:

1 Currently in school

2 Not in school, working, and not married

3 Not in school, working, and married

4 Not in school, not working, and married

5 Not in school, not working, and not married

The first striking observation from these graphs is that, as age increases, the percentage of adolescents currently in school decreases. The percentage of girls currently in school is already low in the study districts, especially in Rajanpur, and drops more sharply with increasing age compared to boys. The proportion of boys and girls currently in school is highest in Faisalabad and conspicuously low in Rajanpur. 
Figure 3.1: Transition status of older adolescents (15-19 years) in Faisalabad, Kasur, and Rajanpur districts, by age and gender

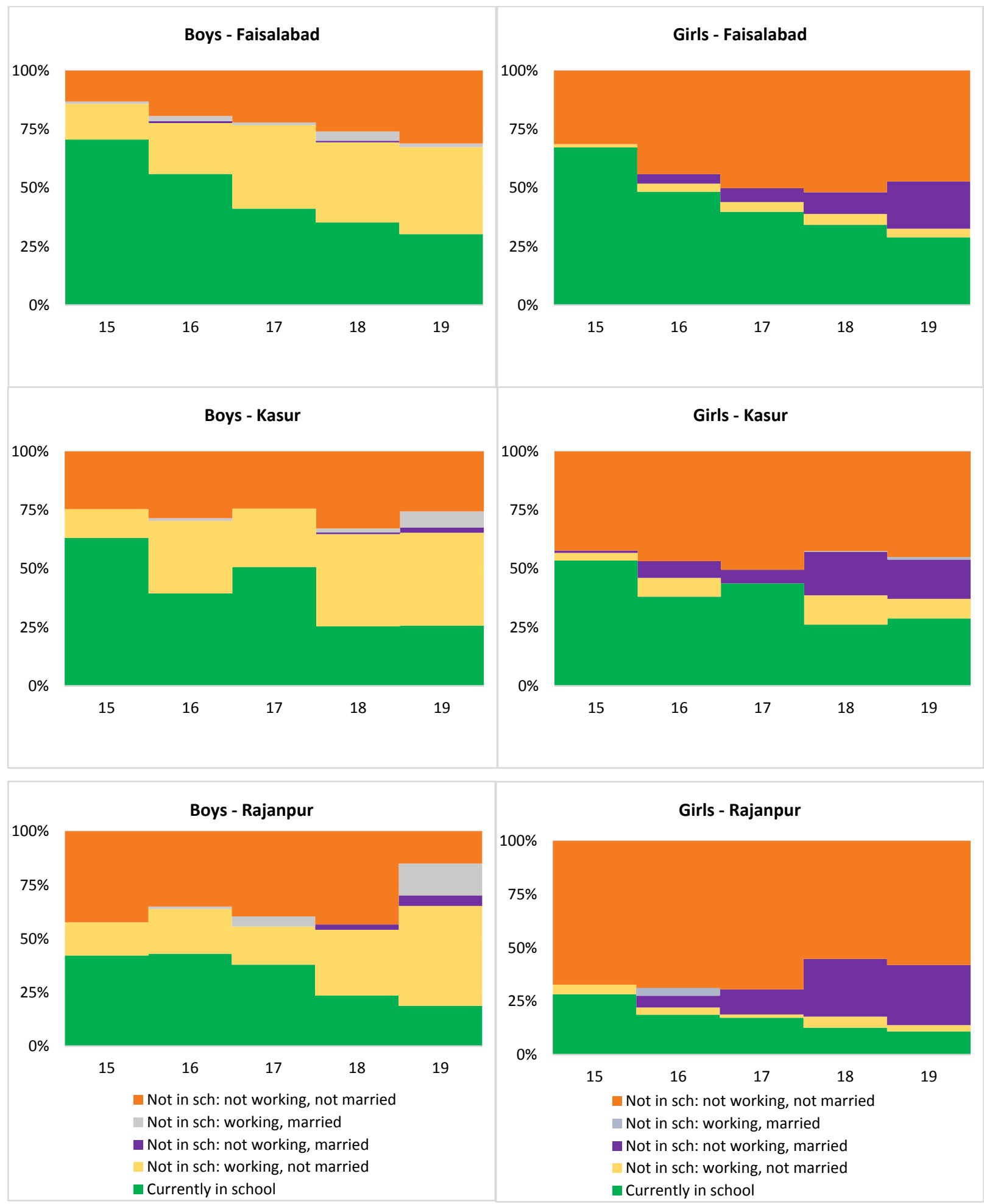

Source: MICS Punjab 2014. 
The yellow segments of the graphs in Figure 3.1 represent out-of-school (OOS) adolescents who are not married, but working for pay or profit. Although children aged 5-16 are legally required to attend school, among boys of ages 15-16, a third in Kasur and a fifth in Rajanpur and Faisalabad are engaged in some paid economic activity, and the proportions at work rise further with age. However, participation in work is much lower among OoS girls (15-19 years): on average 10 to 13 percent are working for pay or profit, compared to a third of boys in the same category. As mentioned in Chapter 1, labor force participation among females is generally very low in Pakistan. According to the Labour Force Survey 2014-15, only 18 percent of girls aged 15-19 participate in the labor force, and this proportion has fallen by one percentage point since the $2009-10$ survey.

This corroborates the findings of Lloyd and Grant (2004) that while, among young Pakistani males, part of becoming an adult involves a shift from unpaid economic work for family to outside paid work, there appears to be no such transition for young females. The overwhelming majority of girls commence non-economic household work as children, and remain in that status as adults.

The purple segments in Figure 3.1 indicate OOS adolescents who are not working (unpaid work is included in this category) but are 'ever married.' Overall in Punjab, about 10 percent of girls aged 1519 years are ever married according to the Punjab MICS 2014. In our study districts, girls in this category comprise the same proportion (10 percent) in Kasur, a relatively higher proportion (13 percent) in Rajanpur, and a slightly lower proportion (8 percent) in Faisalabad. In contrast, 'ever marriage' in this age group is negligible among boys in all three districts.

The small gray segment in the graphs represents OOS adolescents who are both married and working for pay. About 15 percent of boys aged 19 are seen at this life stage in Rajanpur, but otherwise, the proportions of boys and girls in this category are negligible across the districts.

Finally, perhaps the most striking and noticeable segments of adolescents-those not in school, not working (unpaid work is included in this category) and not married-are depicted in orange in Figure 3.1. Overall in the three districts, about a quarter of boys are in this 'indefinable' state in their transitions. This ratio is almost double for females, with about half of the girls in the study district being out of school, not working for pay or profit, and not married. More than half of the girls in Rajanpur are seen in this category, with lower proportions in Kasur and generally the lowest in Faisalabad. Apart from these high proportions, it is alarming to note that in Rajanpur, the proportion of girls in this category is higher at lower ages, i.e. 15, 16, and 17, suggesting that life trajectories may be worsening for girls in this district. The large proportions of young people, especially girls, in this category underscores the need for urgent interventions to develop their potential for more productive activity.

\subsubsection{Impact of Wealth and Urban/Rural Location}

Figure 3.2 shows the status of adolescent girls (15-19 years) in the lowest and highest wealth quintiles in each district. Stark differences can be seen, both by wealth status and also across the districts. Among the poorest girls, only one out of five is in school in Faisalabad and Kasur, while in Rajanpur the proportion of such girls in school is negligible. On the other hand, among girls belonging to the highest wealth quintile, almost seven out of ten are in school in Faisalabad and Kasur, whilst only half are in school in Rajanpur. 
NEEM girls comprise substantially higher proportions of the poorest girls than the richest in all districts, although this difference is narrowest in Rajanpur. Among girls in both quintiles, Rajanpur has the highest proportion of NEEM girls.

Figure 3.2: Transition status of richest vs. poorest girls (15-19 years), by district

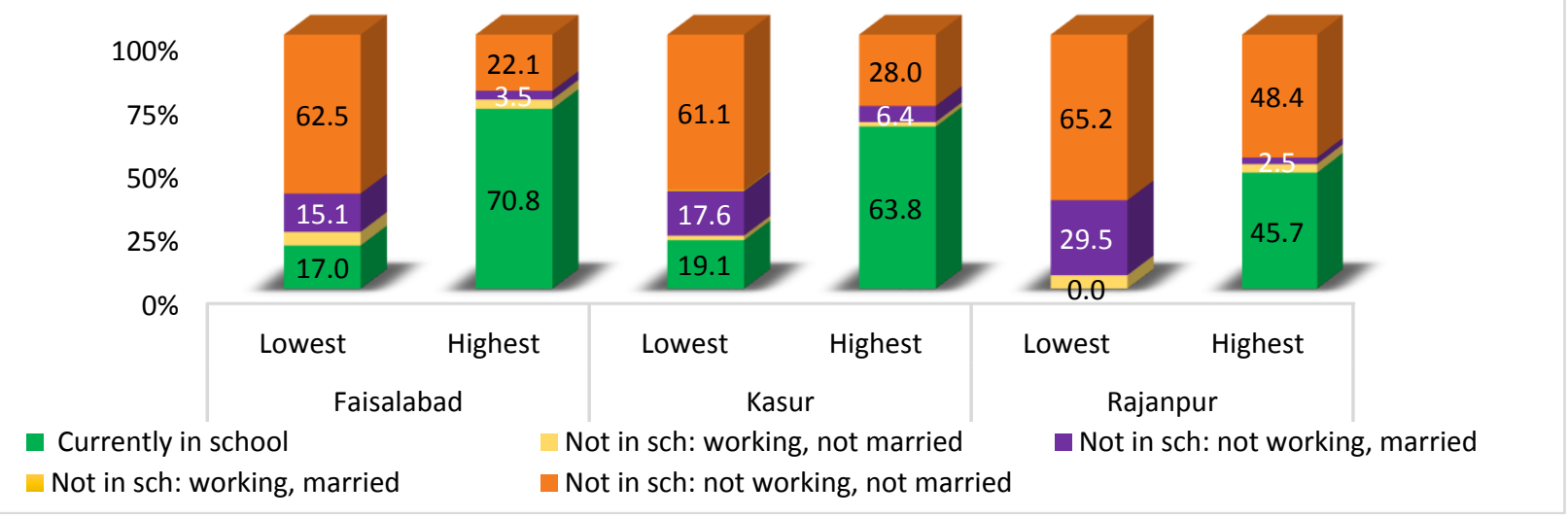

Source: MICS Punjab 2014

As Figure 3.3 below shows, urban/rural disparities also play an important role in the life trajectories of adolescent girls. In rural areas of Kasur and Faisalabad, only about one third of girls are in school; while in the urban areas of these districts, about half of all girls are attending school. The rural area of Rajanpur is most deprived, with only 14 percent of older adolescent girls currently in school.

The proportion of unmarried girls working for pay or profit ranges from 2 to 7 percent across rural and urban areas in the three districts: in each district, the proportion working is slightly higher in urban compared to rural areas. The proportion of OOS girls who are married and not working is almost double in rural areas, compared to urban areas.

In each district, the proportion of NEEM girls is conspicuously higher in rural than in urban areas. About half of the girls fall in this category in the rural areas of Faisalabad and Kasur: in Rajanpur, this is the case in urban areas, while the proportion of NEEM girls in rural areas is much higher at 67 percent.

Figure 3.3: Transition status of girls (15-19 years), by urban/rural location and district

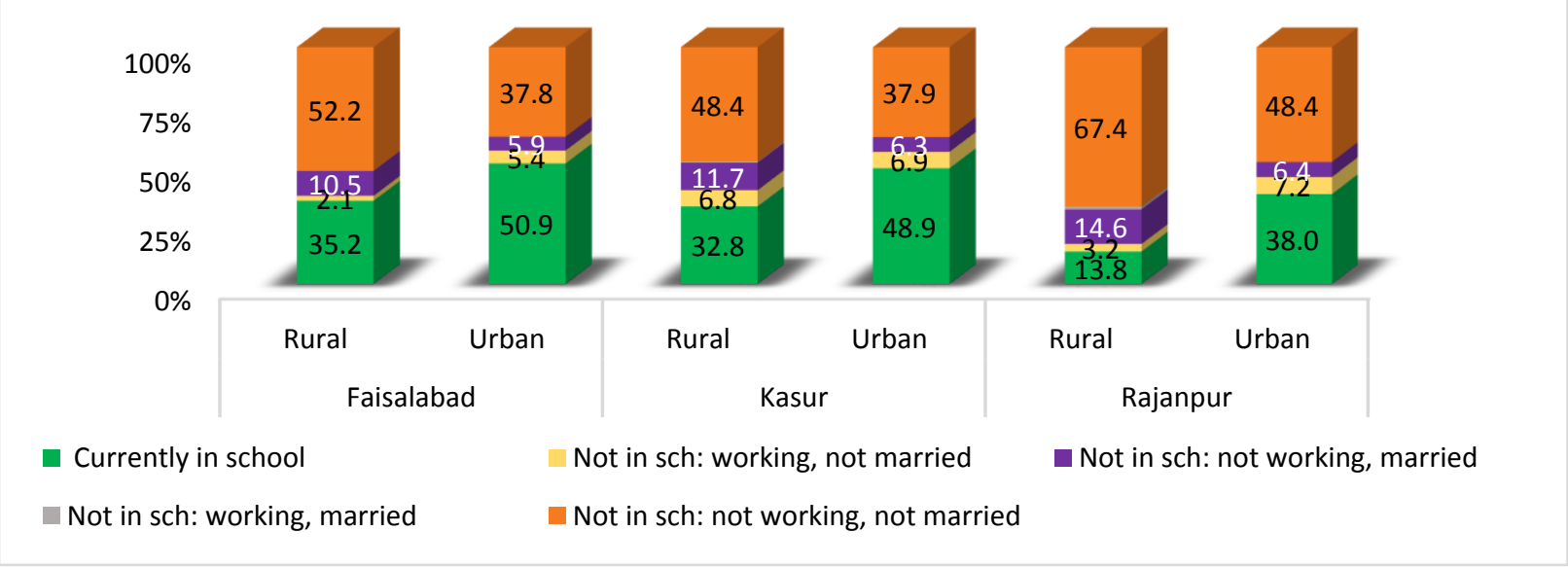

Source: MICS Punjab 2014 


\subsection{Time Use among the NEEM Girls}

In order to identify opportunities for effecting positive transformative change in the lives of NEEM girls, it is imperative to learn how they are currently living their lives. For example, what they do from morning to night; how much time they spend on different activities; whether they are actually engaged in activities that contribute to their household income but for which they do not receive any pay; and what time they have available to participate in any interventions that might be introduced for them. Since girls in this category are not in any formal environment, like a school or workplace, they are less visible and special efforts are needed to form an accurate picture of their time use.

Data about time use was collected from all the 42 NEEM girls who were interviewed for this study, using a short quantitative questionnaire. Time use data was also collected from 65 of the 005 girls who participated in the FGDs, ${ }^{4}$ and thus the analysis of time use presented in this section is based on the responses of a total of 107 adolescent girls. Of these girls, 23 had never attended school while the remaining 84 were dropouts.

The 107 girls were asked about their entire daily routine, from waking up to going to bed, accounting for all 24 hours. They were prompted regarding a total of 17 specific activities, and for subsequent structuring and analysis of the data, the activities were grouped into the following five categories:

\begin{tabular}{|l|l|l|l}
\hline Personal activities & Sleeping, bathing, dressing, eating, and other personal care \\
\hline Domestic chores & Household chores, care of household members, e.g., children and elderly \\
\hline Unpaid work & Assisting family members in paid work, learning a skill \\
\hline Leisure activities & Viting friends, watching TV, games/sports, using mobile phone, relaxing \\
\hline Religious activities & Offering prayers and reading the Quran \\
\hline
\end{tabular}

Figure 3.4 shows details of time spent by the NEEM girls on various types of activities in each district. With regard to personal activities, NEEM girls across the three districts show a similar pattern. Importantly, they are mainly involved in performing domestic duties-on which they spend about 7 hours a day-with no notable variation across districts. Clearly, taking care of the household is a major activity for these girls.

With regard to unpaid work, there is a stark difference between the central and southern districts. NEEM girls in Faisalabad and Kasur spend a mean 0.5 hour from their entire day on unpaid work, whereas girls from Rajanpur spend 3.1 mean hours a day on unpaid activities, mostly outside the house. But while they spend substantially more time on unpaid activity than their peers in Faisalabad and Kasur, they carry the same load of domestic chores, indicating that they are more heavily burdened.

\footnotetext{
${ }^{4}$ This data was collected where possible, when the participants were willing and had time.
} 
Overall, NEEM girls spend rather limited time on leisure activities, although regional variations are again observed: girls from the central districts, especially Faisalabad, spend more time on each of the leisure activities compared to girls in Rajanpur.

Figure 3.4: Mean hours spent on various activities by girl respondents, by district $(\mathrm{N}=107)$

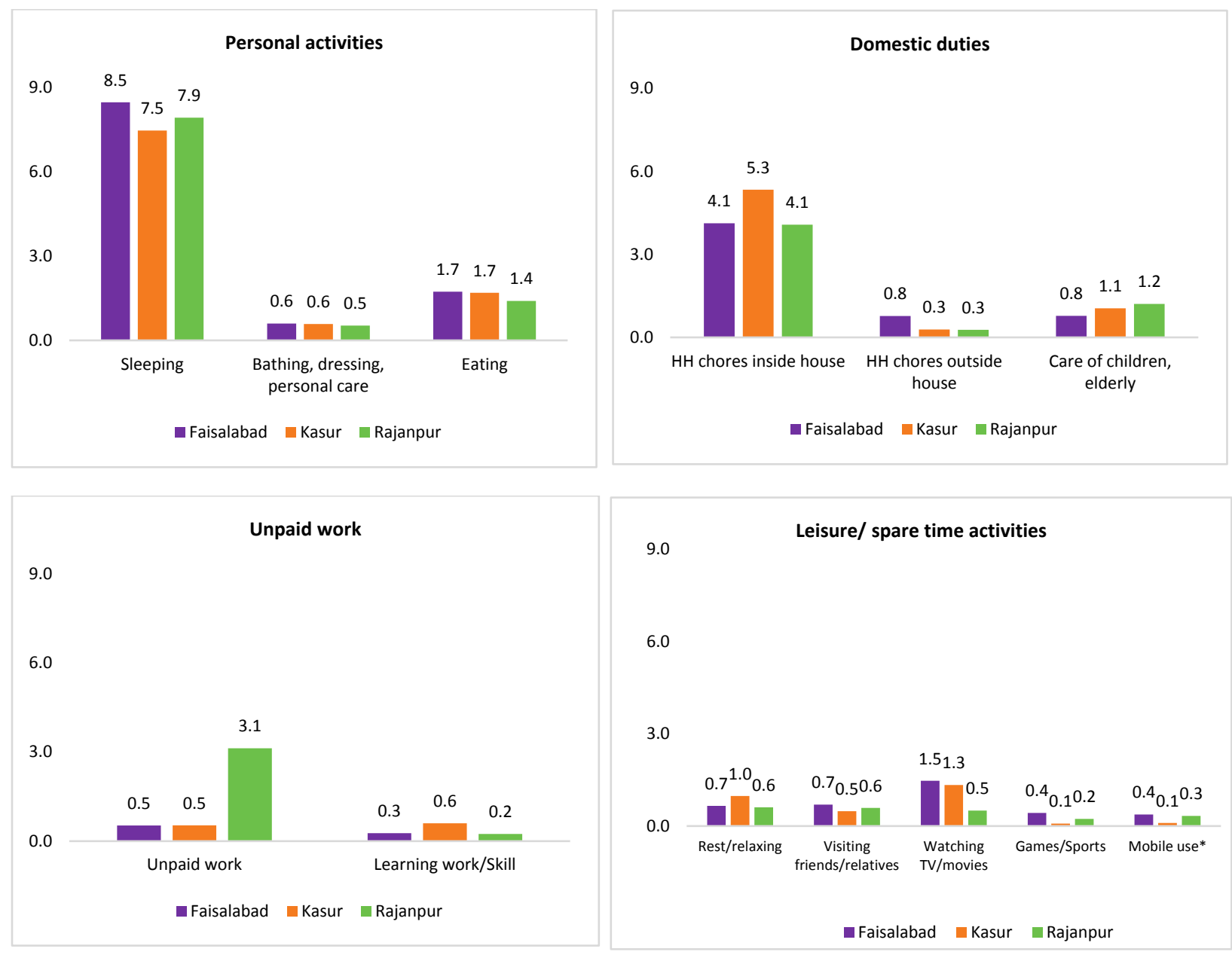

$\mathrm{HH}=$ Household

*Mobile use mainly included phone calls, listening to music, and taking photographs. 
Figure 3.5 compares time use among NEEM girls with no schooling with those who dropped out from school. Some differences in time use patterns can be observed.

In Faisalabad, girls who dropped out sleep more, are more occupied with personal activities, and spend less time on domestic duties than girls with no schooling.

In Kasur, no major difference is seen in time spent by the two categories of girls on personal activities and unpaid work. However, girls with some schooling are spending slightly more time on domestic duties, while girls with no schooling have more leisure time.

In Rajanpur, girls who have never been to school are spending more time on domestic duties and also spending almost double the time on unpaid work as girls who have some schooling, indicating that these girls are bearing more of the household and economic burden of the family. Girls with some education are spending more than twice as many mean hours on leisure activities as those who have never attended school.
Figure 3.5: Mean hours spent by girl respondents on various activities, by schooling status and district $(\mathrm{N}=24$ girls with no schooling, $\mathrm{N}=83$ girls who dropped out)

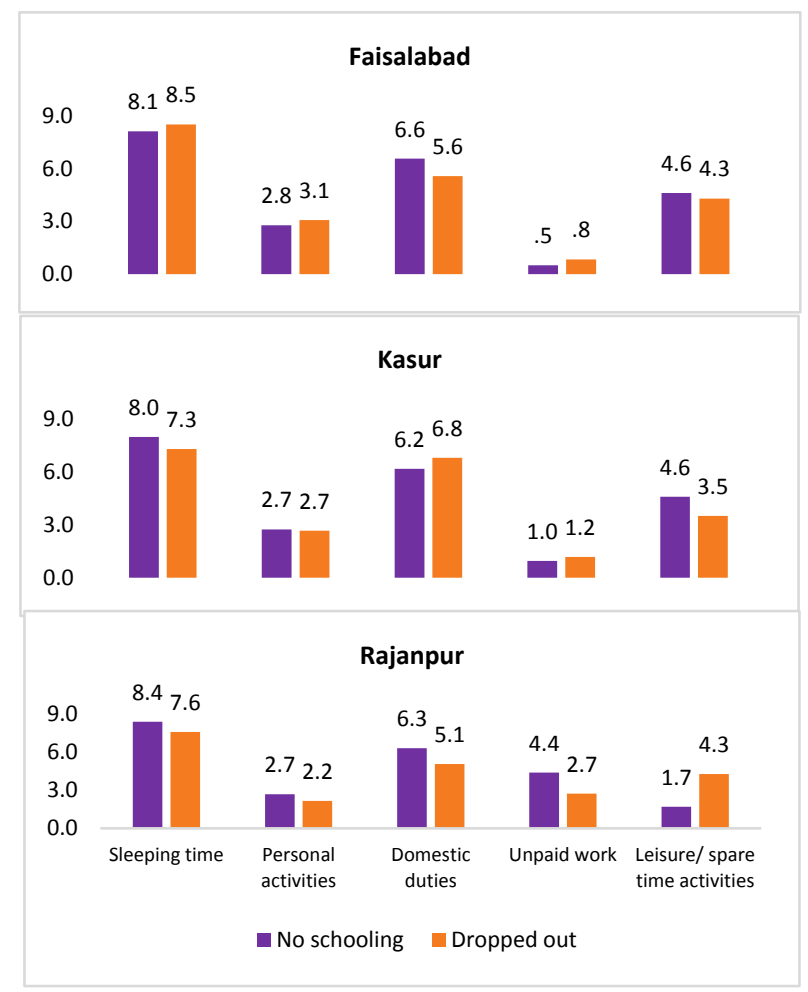

Figure 3.6 shows mean hours spent by NEEM girls in different age groups on personal activities and domestic duties. Older girls in Faisalabad are spending more time on personal activities than girls in other age groups, and even girls their age in other districts: this may be an effect of living in a more developed district. In Kasur and Rajanpur, no noticeable variation is observed in the mean hours being spent on personal activities across the age groups. There is variation in the time spent on domestic duties across the age groups in all districts, particularly Kasur and Rajanpur, although the patterns in these two districts are quite opposite. In Kasur, younger girls are spending more time on domestic duties compared to the two older groups; while in Rajanpur time spent on household chores increases with age. 
Figure 3.6: Mean hours spent by girl respondents on personal activities and domestic chores, by age and district $(\mathrm{N}=107)$

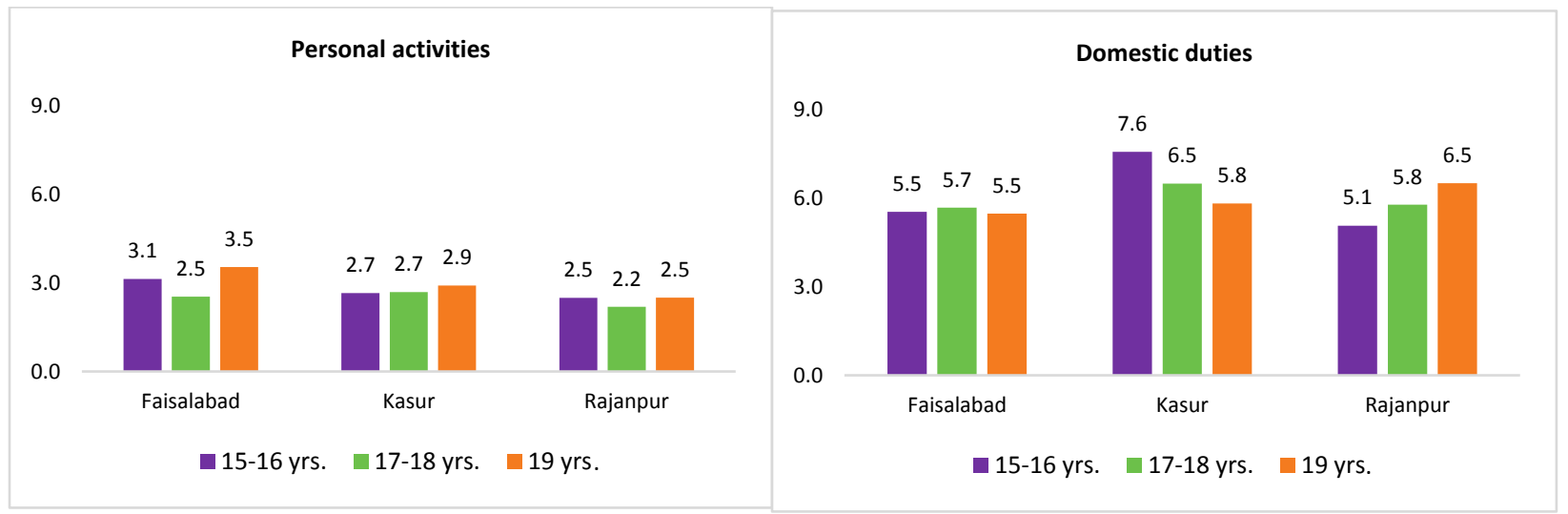

The time spent by girls in different age groups on unpaid work and leisure activities is shown in Figure 3.7. When NEEM girls from Faisalabad and Kasur are divided into age groups, it is apparent that older girls from both districts are spending slightly more time on unpaid work than younger girls of 15 and 16 years. However, data from Rajanpur indicates a different pattern and relationship between age and time division: younger girls spend relatively less time on household chores and more time on unpaid work, with the reverse the case for older girls. This could be because girls in Rajanpur are often involved in cotton picking and wheat harvesting-tasks which require them to travel outside the home with their mothers. Older girls stay at home to take care of household responsibilities; this may also be due to restricted mobility after puberty.

Girls in the two younger age groups (15-16 years and 17-18 years) in Faisalabad spend more time on leisure activities than girls of the same ages in Kasur and Rajanpur. Looking at the pattern within the districts, girls of both age groups again spend less time on leisure activities than older girls (19 years). This may be because-compared to older girls-the younger girls spend more time on domestic duties (in Kasur) and on unpaid work (in Rajanpur).

Figure 3.7: Mean hours spent by girl respondents on unpaid work and leisure activities, by age and district $(\mathrm{N}=107)$

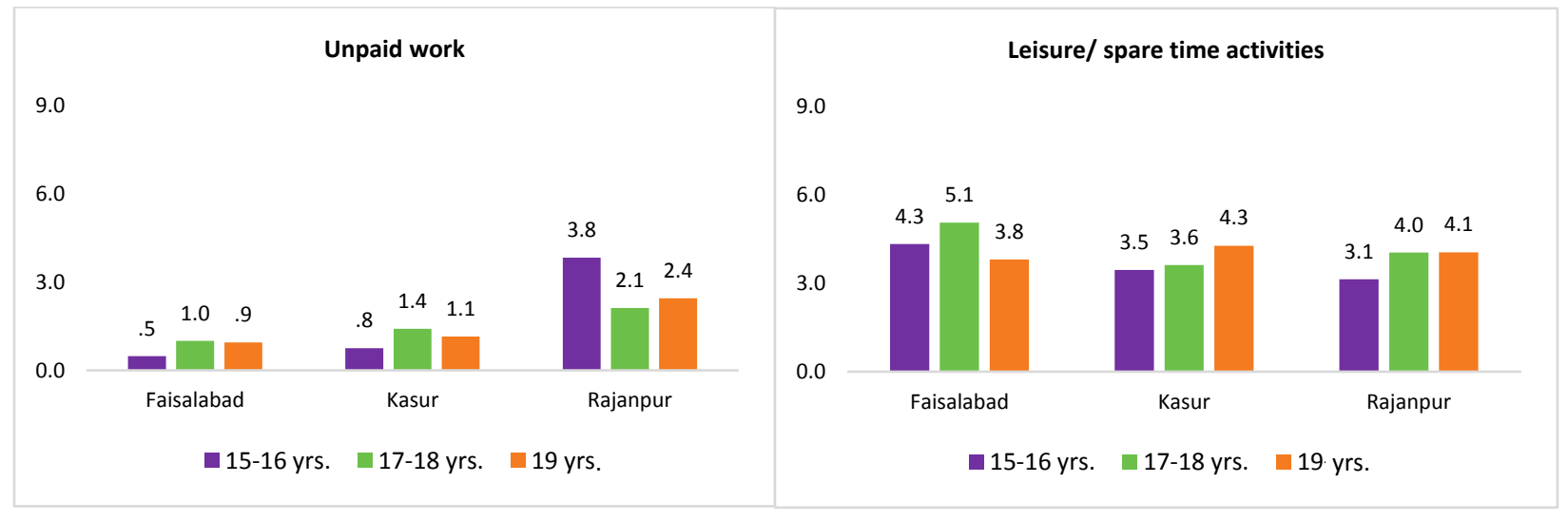

Figure 3.8 presents an overall picture of how much time of their day NEEM girls from the study communities are giving to different activities. The graphs clearly indicate that girls from communities 
in the southern district of Rajanpur are busier and have far less free time than girls living in the central districts. They are more involved in unpaid work and at times spend entire days out engaged in it, without any formal recognition of their contribution. In addition, before going to work or after coming home, they have to perform all the household chores that girls from Faisalabad and Kasur perform over the course of the whole day. It can be concluded from this time distribution that NEEM girls from the central districts have more relaxed schedules than girls in Rajanpur. This is probably due to the fact that they do not share the economic burden of their families, which may be a requirement for girls in Rajanpur, who live in more agricultural communities.

\section{Figure 3.8: Percentage distribution of time ( 24 hours) across various activities among girl respondents, by district $(\mathrm{N}=107)$}

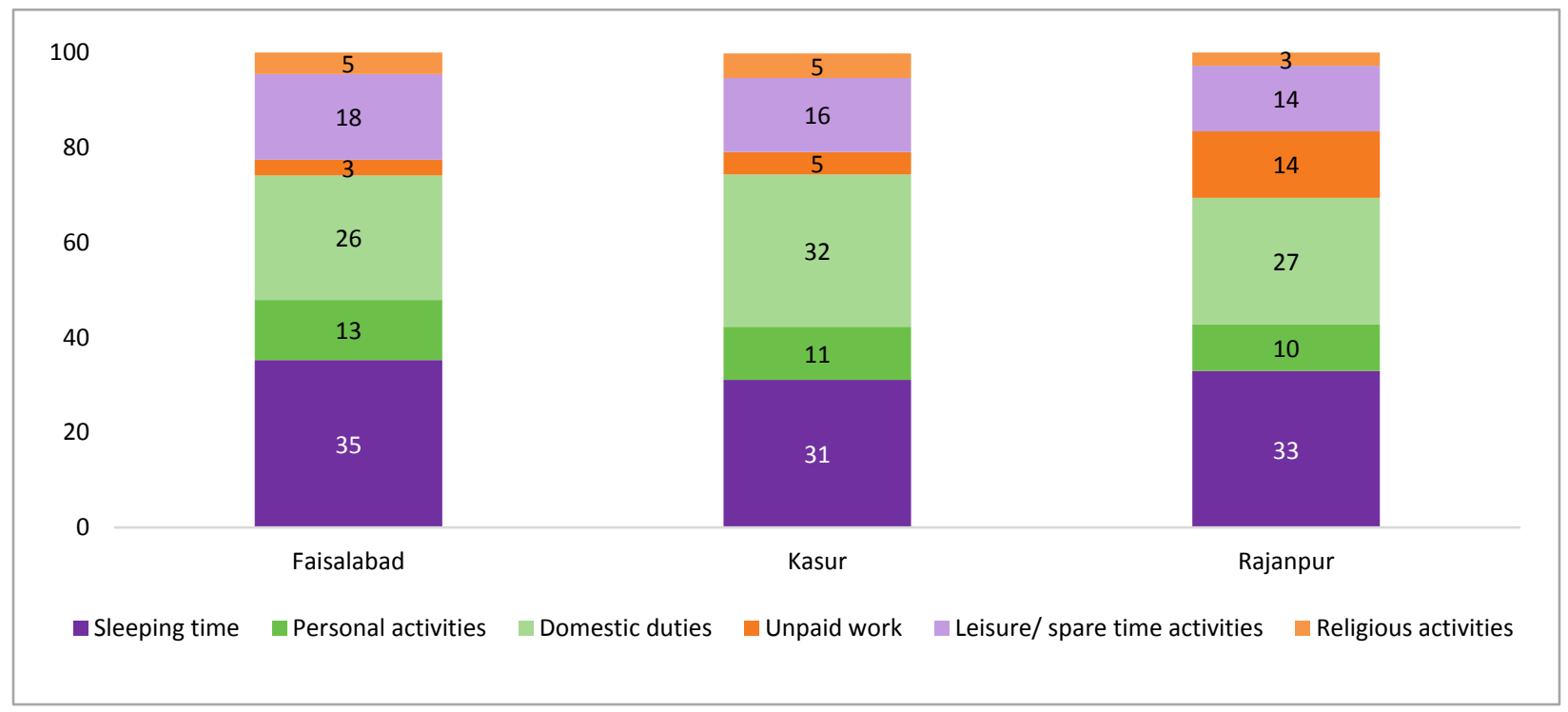

\subsection{Access to and Use of Mobile Technology among NEEM Girls}

Bearing in mind the increasing use of mobile technology and its potentially positive utilization, especially among youth, the 42 girls interviewed were asked whether they had access to mobile phones, knew how to use them for different tasks, and how much they actually used them. Of the 14 girls from each district, 13 had access to mobile phones in Faisalabad, 11 in Kasur, and only 8 in Rajanpur. In Faisalabad, most of the girls with access to phones knew how to make a phone call and to take pictures, but relatively few could send an SMS and use for browsing the Internet, social media, and for financial transactions was negligible. Knowledge and use of these functions was even lower among those girls who had access to mobile phones in Kasur and Rajanpur. More details about access to and use of mobile technology among NEEM/older adolescent girls are provided in Appendix D. 


\subsection{Conclusions}

The above analysis of transition status and time use among adolescent girls suggests that they are working hard, through their heavy contribution to domestic work, and also as unpaid family helpers, especially in agricultural work in Rajanpur.

The burden of domestic duties does not appear to be abated by involvement in unpaid work. Notably, the same persistence of domestic workloads is associated with schooling. Grant and Lloyd (2004) found that the distribution of work by type (i.e., noneconomic household work or economic work) does not change by age for females, whether or not they remain in school. Looking at data for 1,900 young adolescents (10-14 years) in the 1991 Pakistan Integrated Household Survey, Hazarika and Bedi (2003) also found that reducing school costs had no effect on the amount of work children had to do within the household (in Hunt 2008). Many studies have documented the role of entrenched gender norms in keeping girls and women tied to household duties: for example, a recent qualitative study of marginalized adolescent girls in Sindh found that girls were expected to complete their chores without wasting groceries, avoid arguing with family members, and were further discouraged from talking on the phone or going out (Plan Pakistan 2015). The large majority of these girls believed that men had more right to productive work than women, and their own perceived productive roles were seen to be aligned with their roles as daughters, wives, and mothers.

The analysis of transition status, time use, and mobile phone utilization also indicates clearly that there are important differences in the circumstances of NEEM girls, both geographically, i.e., across districts and urban/rural locations, and based on socio-demographic differences such as age, wealth, and schooling history. Girls from Faisalabad, due to urbanization, enjoy greater access to and utilization of mobiles than girls from other districts. They also spend more time on personal and leisure activities and sleep, less time on domestic duties, and the least time on unpaid work. Girls from Kasur reflect a pattern of a less developed district than Faisalabad, where girls spend more time on domestic duties, and less time on sleep, personal and leisure activities; and where younger girls spend more time on unpaid work than their peers in Faisalabad. On the other hand, girls' time use in Rajanpur suggests a pattern of poverty, with far fewer hours for relaxation and leisure activities, and girls spending about half of their day on domestic duties and unpaid work in the fields, mostly outside the home. Even young girls (15-16 years) are not getting much free time as they are the main contributors to unpaid work. They have far less leisure time than girls from Faisalabad and Kasur. 



\section{Chapter 4}

\section{Why the Girls Are Not in School: Perspectives and Potential for Change}

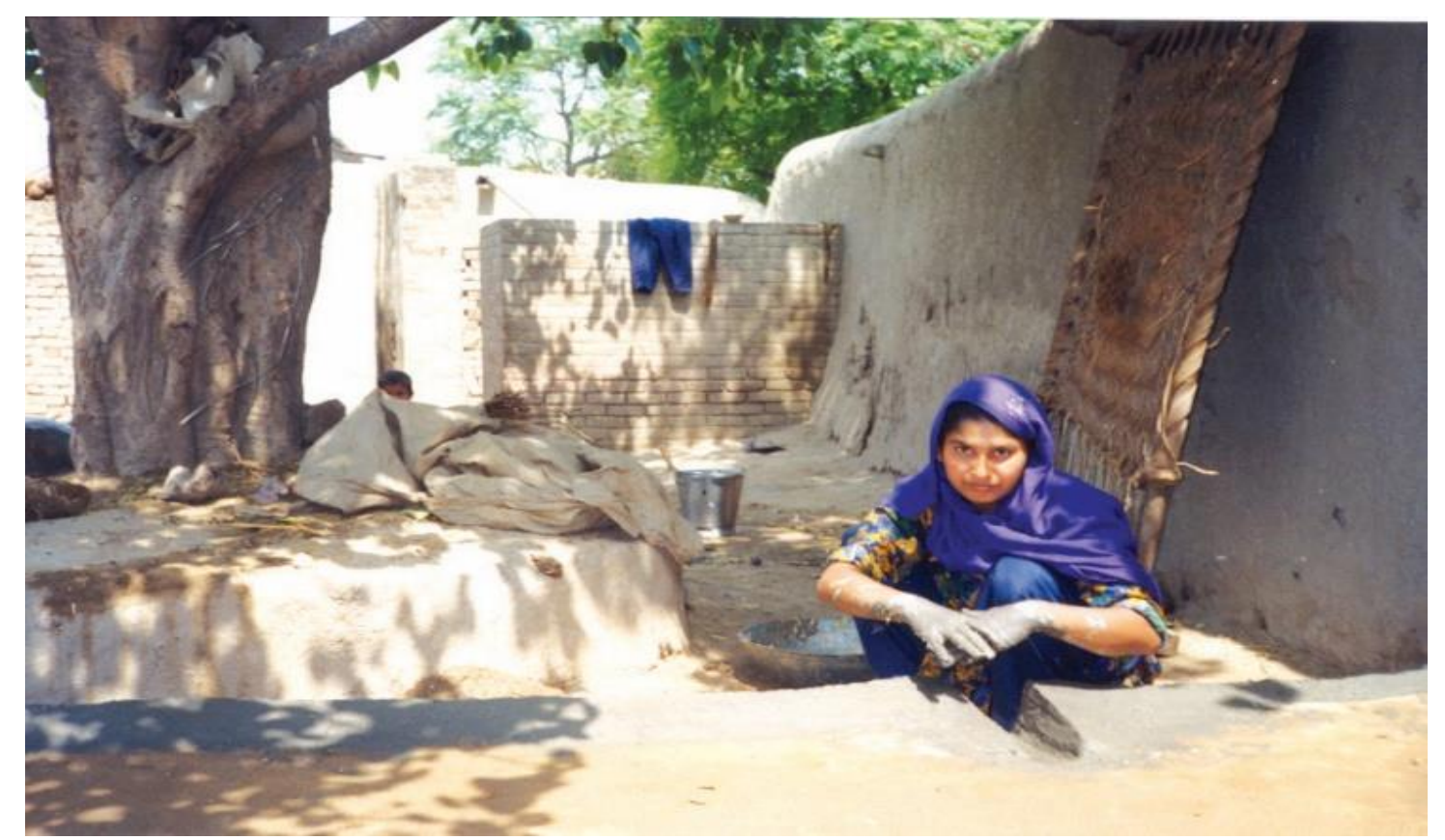

This chapter focuses on one of the major questions underlying the study: why adolescent girls (15-19 years) are out of school. We look at the availability of girls' schools in the study communities and explore the attitudes of girls, mothers, fathers, and influential community members to female education and the girls' being out of school. We then review reasons identified by these respondents for girls' not attending, or dropping out, from school. To understand the influence of gender, reasons for boys' exclusion from education are also reviewed, based on the perspectives of girls, mothers, and fathers. This is followed by a description of the girls' aspirations about resuming their education, and their perspectives, along with those of mothers and fathers, about the steps that could be taken to enable them to do so.

\subsection{Availability of Schools at Community Level}

In all three study districts, the availability of schools is higher in urban areas than in the rural areas, with multiple options for both public and private schooling systems available, especially in Faisalabad and Kasur. However, the situation in rural areas varies across districts. In Faisalabad and Kasur, almost all communities have at least primary public schools, usually combined for both girls and boys. A few communities also have small private schools. At least a middle school is also available, either 
within the community or in adjacent ones, as well as a number of private schooling opportunities for girls. Some such schools are being run by local educated community members. However, these schools are not financially accessible to girls of lower socio-economic status. For higher grades, public school options in rural areas are limited and children must either go to nearby towns or cities, or to distant rural communities that have high schools. Again, private schools or academies are available within the communities, but their fees are usually not affordable for all girls.

In Rajanpur district, due to the more scattered population, a single primary public school typically caters to the needs of two to three hamlets in the vicinity. Some of these schools offer co-education, with all male and no female teachers. For middle and secondary schooling, girls and boys usually have to go beyond their communities. In one of the study areas, a local educated woman was running a school for girls as a Punjab Education Foundation (PEF) initiative. For higher grades, there are no private facilities available and the only option for girls is to go to cities, which is not a common practice.

\subsection{Attitudes towards Girls' Education}

During both IDIs and FGDs, girls were asked for their point of view on education. The discussions strongly suggest that all girls-whether they have never been to school or have dropped out prematurely-have strongly positive attitudes towards education. As mentioned earlier, the majority of the OOS girls who participated in this study had attended school at some point but had dropped out for various reasons, none of which included not being in favor of education. The few girls who mentioned that they left their studies due to lack of interest also realize now that education is of great importance to them.

The majority of the girls think that education confers respectability upon girls within the community because it teaches them social etiquette, enabling them to behave properly with the elderly and with guests. It enables them to articulate and communicate their point of view with confidence, and teaches them how to behave and deal with others. Moreover, it prepares them to face any challenges that may arise in life. The girls expressed a sense of inadequacy, leading to shyness, at being uneducated and therefore unable to communicate in a 'refined' way, especially not being able to speak the national language, Urdu, or English. They speak only their native languages, Punjabi or Siraiki, and are impressed by people who can speak other languages, or at least use a few words of English.

Girls' education is really important. If a girl is educated, she will never be cheated if she faces some crisis in life. Now we are uneducated, we hesitate in answering you. If we were educated, we would know what we want and what we don't. As it is, we are uneducated, so it is an issue. Now when some guests come here and talk in Urdu or English, we cannot respond to them. IDI-Girl-Rural-Faisalabad

A girl becomes well behaved after getting educated. She becomes sensible. She learns how to talk in a proper way and how to behave, etc. Those who do not get an education do not know such things. The girl (who studies) learns to read Urdu. If she is educated, she can speak in Urdu. Sometimes there are people with whom you have to speak in Urdu. So this is why education is important, as it teaches you how to talk. IDI-Girl-Rural-Rajanpur 
The girls perceive education as key to achievement in life. They believe an educated girl can learn any skill, get a job, and support her parents financially. She can meet the needs of her family and also inspire others to educate their daughters. They also feel that mobility is more restricted for uneducated girls, while those who are educated can go out further; parents trust they will be able to find their way because they are literate.

There is a lot of difference between an educated and an uneducated person. One educated person can bring a change in the whole family. An educated person can get employed; an uneducated one cannot. FGD-Girl-Rural-Rajanpur

The educated ones (girls) can go out comfortably, but the uneducated ones are prohibited from going out. They cannot go anywhere alone. IDI-Girl-Urban-Kasur

It is also important to mention that girls not only link the importance of education with the betterment of their current situation, but also relate it to future opportunities. They explained that education plays an important role in a girl's future (marital) life, as she can support her family financially and also educate her children. Educated mothers do not need support from others to help their children in their studies. Education makes them more capable of surviving crises, and empowers and makes them change agents in their families. The girls also associate education with greater awareness about health, hygiene, and cleanliness.

Even if the girl gets divorced by any chance, she is still independent, and she can get a better education for her children. Then people will appreciate her and quote her example that she raised her children well. They (educated girls) become authority figures, acquire a lot of money, and become rich. IDI-Girl-urban-Rajanpur

Talking about gender disparities and their own deprivation with regard to education, several girls complained that boys' education is considered important and parents put all their efforts into educating their sons, while this is not the case for daughters.

For people here, girls are just there to do housework. They are here just to cook, clean, and do the laundry and that is it. But they think that boys can do jobs and can earn money, so that is why boys have more authority. I don't know why-this has something to do with parents' thinking. Maybe because girls stay at home and boys go out to work and earn. IDI-Girl- Urban-Kasur

\subsection{Attitudes about Girls' being Out of School}

During IDIs and FGDs, girls were asked how they feel about not being in school to assess their satisfaction (or lack thereof) with their current status. The majority of girls had attended school and almost all of them shared that they feel very discouraged about having left. Seeing other girls go to school triggers memories; they miss their friends and pine for school.

I feel bad. I miss talking to my classmates. I feel my best friends were from my school days. I just miss my friends. IDI-Girl-Urban-Faisalabad 
I just think that if I could have studied, I would have achieved a different level in life today. Nobody values an uneducated person. I wish to go to school too. Many of my friends are still studying and there are many who have left. School days are very beautiful days of one's life. It is so much fun. Of course, I feel disappointed and wish that I were educated too. I especially wish it when I see others (going to school). IDI-Girl-Rural-Kasur

These girls also feel that, being out of school, they will be unable to achieve the dreams they had cherished of being teachers, doctors, or officers, changing their lives, serving their country, and supporting their parents. This realization evidently breaks their hearts: during an FGD in Faisalabad, all of the OOS girls literally burst into tears as they shared how they felt about being out of school.

When we look at little girls going to school, we recall the time when we used to go to school too. I just wished to be educated and to do something for my parents. But I could not do anything for them. My father got ill and our family circumstances were miserable. I wished to be a teacher but now I think that even if I remain unable to study, I will definitely get my children educated. FGD-Girls-RuralKasur

I wish I could attend classes in school. I want to fulfil my father's dream. My father says that when he hears people talking about their children's education, he wishes his children would reach that status too. I think about it, and wish I could go to school. I recall those days when I used to go there with my friends. I enjoyed those days so much. What can I do now? FGD-Girls-Rural-Faisalabad

The girls see education as the only path to an improved life, and fear that their own failure to complete their schooling might have left them without any prospect of change. They feel a huge gap in their lives at being uneducated, and while they want to resume their education, they express a deep hopelessness in this matter, especially in Rajanpur, which is rooted in the perception that the gap cannot be surmounted because of the issues they face and because the time has passed. They expect they will not be able to do anything in their lives except household chores.

I feel very bad about it. When I look at people engaged in good jobs after getting educated, I wish I could also work like them. I want to be equal to them. I feel inferior when I think about how I am not educated. If I were educated, I could improve my own self. IDI-Girl-Rural-Rajanpur

In rural communities in Rajanpur, most of the OOS girls have to work long hours in the fields to assist their parents in earning enough to meet household expenses. In their opinion, if they were educated, they would have had a proper job like other educated people. All the girls from the rural areas of the district said it was their dream to get an education. Sixteen girls who had dropped out in different grades, and three who had never been to school, said they wanted to do something to get an education. Some of them also expressed hopelessness, saying they were of no use beyond domestic duties.

We really wish there was some facility for our education so that we could complete our education. We would study, and along with that, we would work as well. IDI-Girl-Rural-Rajanpur 
Mothers and fathers of the OOS girls were also asked how they viewed their daughters' situation. Across the districts, mothers expressed sadness and deep concern about their daughters being out of school. The discussions suggest that parents are worried and realize that education is important for their girls, even as they explain their limitations and helplessness in this regard. However, it is important to note that mothers articulated this feeling more explicitly than fathers.

When our daughters see that other girls are going to school and they can't, they cry and complain to us that why didn't you send us to school? FGD-Mothers-Rural- Rajanpur

Fathers of OOS girls also expressed their desire to educate their daughters. However, rather than sharing their feelings about not educating their daughters, they tended to be more focused on the implications of their predicament as well as the factors responsible.

Every parent has this desire that their child, girl or boy, should get educated. There are a lot of issues emerging regarding marriages. Who wants to marry uneducated girls nowadays? Every person wants his daughter to get educated; it is just the poverty that is the hindrance. FGD-Fathers-RuralFaisalabad

Interestingly, while almost all mothers, regardless of their own educational attainment, consider girls' education to be very important for improving their lives in every aspect, some fathers are a little skeptical about its benefits. Although they generally recognize the importance of education, a few fathers in Faisalabad and Rajanpur said they saw education as being less important than taking care of the household, firstly, because education would not benefit girls within the prevailing context of high unemployment, and secondly because girls can be more useful in the household.

There are the same problems everywhere, within and outside of Dijkot city. Even if a girl gets educated, what will she do after that? There must be 60 percent of girls like that, who have completed their education but are unemployed. They have reached the age of marriage-what should they do now? Their education is wasted. If there was any work available, then they could do it wholeheartedly and could help their future generations too. FGD-Fathers-Urban-Faisalabad

A few of the fathers from Rajanpur said that their priority was not education but meeting their households' income needs. They felt education had a high opportunity cost in terms of missed earnings from boys and girls. They pointed out that when girls pick cotton in the harvesting season, they earn significant amounts that help support their families.

For instance, the wage for picking cotton is 200 rupees for 40 kilograms of cotton. That means, if she picks 3,000 rupees worth of cotton in a month, she can earn about 6,000 rupees in two months. You and your team cannot give them anything, except talk to them about wisdom and getting education. Their parents also prefer the income from their children, so why would they send the kids to schools? If we give education to our children, they surely aren't going to earn this much money. FGD-FathersRural-Rajanpur

It is significant that this latter response comes from Rajanpur, the poorest of the three districts visited, and the one in which girls' involvement in unpaid agricultural work is conspicuously higher. The 
response confirms observations by Lloyd and colleagues (2007) that the indirect costs of schooling include foregone child labor inputs to the household's economic activities and domestic chores. As a child grows older, the opportunity cost of their time often increases, leading many to drop out of school (Hunt 2008). In West Bengal, India, Sengupta and Guha (2002) found girls' participation in income generating activities to have a strong negative influence on their schooling opportunities, increasing their chances of dropping out and reducing the odds that they would ever attend school.

\subsection{Reasons for Girls' being Out of School}

A main objective of this study was to understand the situation leading to girls' being out of school, and to acquire insights about the reasons from the girls themselves, as well as their mothers and fathers. Detailed discussions with the respondents revealed a range of reasons, with some reported more frequently than others. These are summarized in the word cloud in Figure 4.1, in which the size of the font reflects the frequency with which each issue was mentioned. Broadly, the barriers include nonavailability of schools; problems at the household level; issues in access to school; school-related problems; and social or community level obstacles. These issues can also be broadly divided into internal and external factors. Internal issues are mainly at the household level, while access, security, school-related, social or community problems are mainly external issues. By and large, it was observed that mothers mainly talked about household-related issues. Fathers talked less about these and more about access issues; whereas girls gave more account of security issues, school-related issues and household issues. These multiple perspectives highlight the respondents' differing concerns.

The following discussion, based mainly on IDIs and FGDs, also elaborates on how the intensity of these issues varies across categories of respondents and districts. Relevant findings from the literature review are also presented.

Figure 4.1: Reasons why girls are out of school, from the perspective of girls, mothers, and fathers

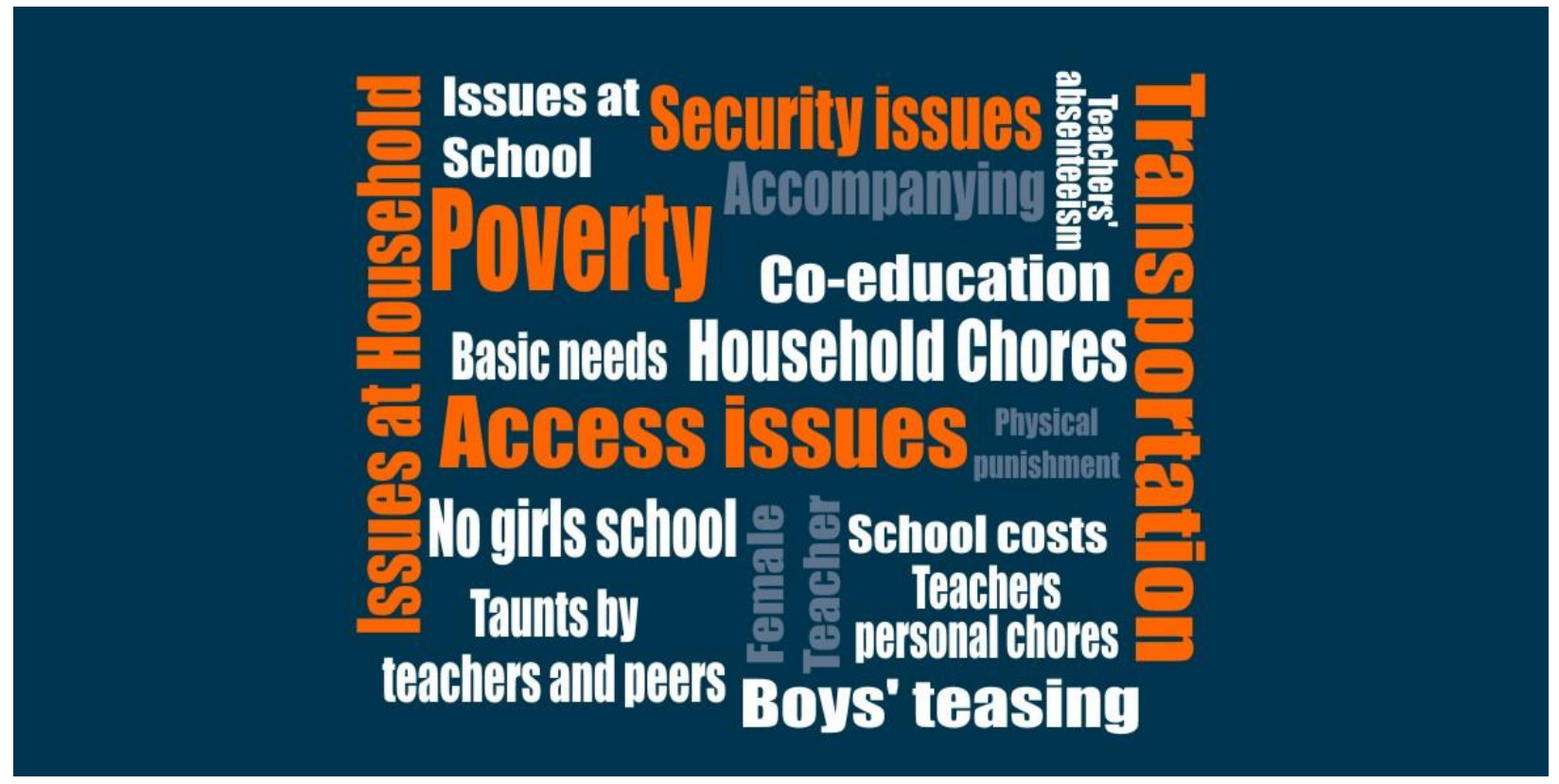




\subsubsection{Non-Availability of Schools for Girls}

In IDIs and FGDs, the most frequently mentioned reason for not going to school is absence of a public girls' school within the community. The study finds that the majority of OOS girls are living in communities where there are no girls' schools available, especially public sector schools. Where a school is available, many constraints are addressed and most girls do obtain an education to the level available.

Discussions with respondents indicate that in communities where primary schools are present, the majority of parents at least enroll their daughters, with the exception of those few who face some internal (household level) issues, which are discussed later. Most of those who enroll their daughters do want to educate them, but a few subsequently have them drop out, again, mainly due to internal issues. Even for those girls who complete their primary education, multiple factors will bar the way to further schooling unless there is a middle or high school for girls available in the community, especially in the public sector.

Everyone in this area is in favor of education. Parents, siblings, everyone wants a school in this area so that everyone could study. It's just that there is no school for girls here. That is why they remain uneducated. FGD-Girls-Rural-Rajanpur

If the school is near somewhere then we might get a chance to go there. If we are given a scholarship and the distance is not too far, then a lot of girls of this community might get an education. FGD-GirlsUrban-Kasur

Most of the study communities do have at least a primary school, but they do not have a public sector middle or higher level girls' school. This non-availability of schools for upper grades limits choices for girls. The majority of respondents mentioned this as a fundamental problem, linked with many factors that lead to girls' dropping out.

A number of other studies in Pakistan strongly support this finding. Girls' enrollment in rural communities is highly responsive to the presence of an all-girls school in the village (Lloyd et al. 2005), and has been observed to drop off sharply with each 500-meter increase in distance from the closest school admitting girls (UNESCO 2013). Using data at community and household level, Zaidi et al. (2012) have built the evidence that availability of schools in communities increases the probability of girls' enrollment at primary and lower secondary levels. Measuring the strong association between girl's enrollment and distance to school, Sathar, Wazir, and Sadiq (2013) found that, if a school is located within one kilometer, at the primary level, this raises the enrollment for girls aged 5-9 to 70 percent and at the middle or higher school level, it raises the enrollment of 10-14 years old girls to 65 percent. Likewise, if a primary school is located three kilometers away, the predicted probability for girl's attendance decreases to only one percent, and to 50 percent in the case of middle schools.

Within the province of Punjab specifically, school enrollment, particularly in secondary education, is largely constrained by the scarcity of schools. While primary education is supplied by both public and private schools, the secondary level is dominated by the public sector, and not every village has access to middle and high schools (Alam, Baez, and Carpio 2011). Because of the drop in the number of 
schools at the secondary level, travel time increases for both boys and girls (Rihani, 2006 in Sathar, Wazir, and Sadiq 2013).

\subsubsection{Household Level Issues}

Household level issues broadly include financial problems, girls' expected participation in domestic chores, and the concerns associated with girls reaching puberty. These matters are influenced, and may be intensified, by external issues, particularly if schools are not available within the community. Household level issues play a key role in determining whether girls attend school and whether and when they drop out. The situation evolves through a complex interplay of parental concerns, considerations, and decisions about which needs to prioritize, which to fulfill, and where to compromise. The major issues are described below.

\subsubsection{Financial Issues}

Financial issues were reported to be a major reason for girls being out of school. During in-depth interviews and FGDs with OOS girls, as well as FGDs with mothers and fathers, financial issues were mentioned by the majority of respondents in all districts, and more so in Rajanpur and Kasur. In fact, in Rajanpur all 14 girls interviewed, from both urban and rural areas, mentioned poverty as the major reason why they were out of school.

Many other studies in Pakistan also confirm the central role of poverty in keeping children in general and girls in particular out of school. Rihani (2006) identifies poverty as one of the most important factors for girls' dropping out from school (in Sathar, Wazir and Sadiq 2013). Most published studies analyzing the determinants of enrollment in Pakistan have found family income and girls' enrollment to be positively associated and statistically significant (e.g., World Bank 2002, Sathar and Lloyd 1994 in Sathar, Wazir and Sadiq 2013). Moreover, when results for boys and girls are compared, the effect of income is larger for girls than for boys. Zaidi and colleagues (2012) found the economic status of households to be an overriding factor in school enrollment in Pakistan. In consultations with education managers, teachers, parents, and in-school and OOS children in eight districts in Punjab, Hussain, Salfi and Khan (2011) found 91 percent of respondents affirming that low economic development and per capita income comprise a major reason for high dropout rates.

Hunt (2008) further elaborates that household income not only affects whether children drop out, but also their experiences while in school, for example, when they start school, how regularly they attend, and whether they have to temporarily withdraw (Croft 2002 in Hunt 2008). Poorer children not only have increased difficulties in accessing education on a sustained basis, the quality of education received can be weaker (Molteno et al. 2000 in Hunt 2008). Poverty also signifies higher vulnerability to shocks to income, and households often cope by withdrawing children from school, as has been observed in poor rural communities in Pakistan (Sawada and Lokshin 1999 in Hunt 2008).

As we probed the problem of financial constraints, it emerged that poor parents, despite their desire to educate girls, faced challenges at three levels: (a) meeting basic needs for food and shelter; (b) bearing school-related item costs; and (c) the cost of transport to school for girls. 
The first challenge, fulfilling the basic needs of the family, such as food and shelter, is more of a concern in the poorest households. These households are unable to meet expenses especially where there is only one bread earner and a large family to feed. Therefore, parents decide not to send girls to school, or to discontinue their education altogether. This factor, which was more frequently mentioned in Rajanpur and Kasur, was highlighted more by mothers and fathers than by the girls themselves, probably because it represents an area of concern for parents.

There are a lot of financial constraints. We do not have enough money to cook the meals at home, how are we supposed to bear the expenses of their books and notebooks? We do feel disappointed seeing them at home like this. FGD-Mothers-Urban-Kasur

I have three daughters. I always tell them that I cannot do anything for them because of our poverty. They are studying in third grade, and I always tell them that I will discontinue their schooling soon. My daughter does not want me to do that. She wants to study a lot. But what can I do, my medicine is too expensive. I am bound by my circumstances. FGDMothers-Urban- Rajanpur

Notably, girls also perceive that when it comes to decisions about reducing expenses on education, it is daughters' schooling, and not that of sons, that gets cut. This intersection of poverty and gender that has also been picked up in other studies. As Colclough, Rose and Tembon (2000: 1 in Hunt 2008) observe, while poverty is associated with underenrollment, "the gendered outcomes of such under-

Education is a right of girls, but we were compelled because we could not afford the educational expenses of our children. When they go to school, they need uniforms and pocket money too. When rich children spend money in the school, the poor children also want to do it. We discontinued their education after $4^{\text {th }}$ or $5^{\text {th }}$ grades because of all these reasons. We cannot bear the expenses. FGD-Fathers-Rural--Kasur enrollment are the product of cultural practice, rather than of poverty per se." Studies have found that the inability to pay school fees leads to more dropping out among girls than boys (e.g., Kadzamira and Rose 2003, Brown and Park 2002 in Hunt 2008). Conversely, when household income increases, there can be greater investment in girls' schooling, with no significant impact on that of boys (Glick and Sahn 2000 in Hunt 2008). In communities where patriarchal norms prevail, as in parts of Pakistan, sons are often viewed by parents as 'insurance,' while daughters are seen as 'liabilities' (Shahidul and Karim 2015, UNESCO 2013). The costs entailed in sending girls to school may be higher, while the benefits appear more tenuous (Shahidul and Karim 2015).

The second level of financial difficulty relates to the affordability of school-related items. In circumstances where there is one bread earner to feed 8-10 family members, poor parents are left with little to pay for school-related item costs after securing food. Even at public schools, items such as notebooks, stationery, bags, and uniforms have to be purchased. It was reported by all categories of respondents that failure to meet these needs can have a range of repercussions, including psychological pressure for mothers, fathers, and especially the girls themselves. The latter encounter extra difficulties at school for this reason, as discussed later in this section. 
The families that are financially stable are sending their daughters to cities for higher education. But the poor families cannot afford such expenses. That is a reason for girls not going to schools. The most important reason for not going to school is poverty. FGD-Mothers-Rural-Faisalabad

My father used to say that he is bearing household expenses with difficulty, how will he get us educated? There are fees, costs of stationery items; food and clothes are necessary provisions. How was he supposed to fulfill all those expenses? IDI-Girl-Rural-Rajanpur

The school charges too much fees, which we cannot afford. We live in poverty. Should we meet our own expenses or pay our children's fees? FGD-Fathers-Urban-Kasur

Lloyd and colleagues also found household poverty to be a factor preventing parents from sending their children to school as they were not able to cover expenses (2007, in Sathar, Wazir and Sadiq 2013). Allocation to the public education sector remains low in Pakistan, and despite fee waivers and provision of free textbooks, parents do need to pay for some expenses that are unaffordable for those who are poor (UNESCO 2013).

However, even if poor parents do succeed in meeting these expenses, their financial challenges may not be over. As mentioned above, in the majority of the study communities, options for middle and high schooling for girls are limited, especially in the public sector. To continue their education after primary level, they must either study in private schools if available-which are more expensive-or bear the high transport costs of reaching the closest public school for girls. Most parents cannot send their daughters by the usual means of transport because these are crowded with male passengers. They therefore need to arrange a separate pick and drop service, the cost of which may not be affordable. This problem was strongly reported as a major reason why girls drop out, by girls as well as mothers and fathers, particularly in rural areas of all three districts.

Every mother is concerned that her daughter has gone to the school only till fifth grade. We have no money actually, and it's impossible for us to bear the expenses of a pick and drop arrangement. FGDMothers-Rural-Kasur

The main issue is transport. People here go on private buses. It is a 7-mile trip and the fare ranges from 1,000 to 1,500 rupees per month. People cannot afford to educate their girls in these circumstances, nor can they afford their expenses. So they educate them only up to fifth grade. FGDFathers-Rural-Faisalabad 


\subsubsection{Household Duties of Girls}

During IDIs and FGDs, most of the girls also mentioned that a major issue in their households is the burden of domestic work, much of which they themselves must carry. This situation is aggravated when the mother is not able to perform household chores due to health issues, or if the mother works. The burden of household chores is then shifted to the eldest daughter of the household, who is withdrawn from school to assume her new role. In some cases, it was also reported that a girl may leave school if her elder sister gets married and moves to another house; the remaining sisters then start sharing household responsibilities with their mother. These situations apply to girls in all districts, especially Faisalabad and Kasur.

However, there is variation in reporting from mothers and fathers in this regard. Mothers from Faisalabad did not mention this as an issue for girls, although mothers from Kasur did mention that sometimes a girl has to discontinue her studies if any one of their parents, especially the mother, is sick. This means she has to perform all household chores. Girls also have to assist a mother

We have so many domestic problems due to which my daughter couldn't continue her studies. My wife is paralyzed so my daughter could only study to ninth grade and then had to stay at home to take care of our animals. She also does all the domestic work. She wanted to continue her studies but our domestic issues didn't allow it.

FGD-Fathers-Rural-Faisalabad working as a domestic servant outside the home.

I had a desire to study further. I wanted to be a doctor, to get the whole sixteen years of education. But I studied till only fifth grade. My mother is not well; that's why I left school. My mother's discs are damaged. She cannot do household chores. We are two sisters, and my sister is younger than me. FGD-Girls-Urban-Kasur

In addition, many studies indicate that household fertility levels are linked with girls' dropping out of school. It is likely that this is connected not only with the increased financial burden, but also the increased load of domestic duties associated with the birth of a child. In Pakistan, high fertility, particularly in rural areas, alongside the poor nutritional and health status of poor rural children of school age, have been found to affect schooling (Sathar, Wazir and Sadiq 2013). Lloyd, Mete and Grant (2006) found the birth of an unwanted child to be one of the most significant factors associated with dropout rates for girls in rural Khyber Pakhtunkhwa (formally known as NWFP) and Punjab. Empirical evidence from the Pakistan Social and Living Standards Measurement survey (PSLM) 201112 confirms that the probability of attending school is significantly higher for children with fewer siblings compared to those in families with 6 or more children under 15 (75\% vs. 66\%). These differences are even more pronounced for girls (Sathar, Wazir and Sadiq 2013).

In Rajanpur, mothers and fathers mentioned that girls do not go to school or discontinue education altogether because their mothers go out for work such as cotton picking and wheat cutting. In such situations, the older girls have to take care of younger siblings and perform household chores in place of their mothers. The majority of poor mothers also emphasized that they need their daughters to assist them in earning and working in the fields. Girls, along with their brothers, are considered earning hands from childhood and get informally involved in economic activities by assisting their mothers and 
fathers. Mothers explained that, due to poverty, they either do not enroll their daughters in school or stop sending them in the interest of more income for the household.

Due to domestic chores, my mother made me discontinue my education-for domestic chores, and also harvesting of wheat. FGD-Girls-Rural-Rajanpur

In some homes, mothers do not allow girls to go to school. They want them to take care of their younger siblings while the mothers are busy picking cotton. They also tell the girls to look after their livestock, and the girls go to earn some money from picking cotton. These are the kinds of problems with poor people. FGD-Fathers-Urban-Rajanpur

Several other studies in Pakistan have also found mothers' work participation to be associated with their daughters' 'suppressed' school attainment, as discussed in Chapter 1 in regard to the impact of work on women's lives.

In one FGD, mothers also explained that even those daughters who are attending school are not sent to school in the busy seasons, especially the cotton picking season, which extends over 2 to 3 months of the year. They are sent back to school when the season concludes. Such children work and attend school on a seasonal basis. This is described by Hunt (2008) as a type of child labor that does not necessarily impede educational access, but can create pressure on a child's time and lead to erratic school attendance, regular school absences, or increased instances of lateness, eventually leading to dropping out. Girls' participation in seasonal agricultural work, when it clashes with schooling timetables, can lead to temporary withdrawals from school, also potentially contributing to permanent withdrawal.

\subsubsection{Puberty and Related Issues}

It was mentioned by girls and their mothers that reaching the stage of puberty raises another barrier against girls going to school. Parents associate adolescence and puberty with added risks, and become more sensitive about their daughters' movements, mainly due to the existing cultural settings in which girls' mobility is restricted. It is not considered safe or appropriate to send out a young girl unaccompanied, even to school. In rural areas especially, people say that when a girl reaches the age of puberty or has grown up, she should not be allowed to leave the house.

\section{Going to school is important but everyone has their own household circumstances. Sometimes family members do not allow it; sometimes brothers prohibit their sisters, saying they are grown up now, so they should sit at home. FGD-Girls-Rural-Kasur}

Girls raised this issue from all three districts, especially during FGDs. They mentioned that they have to face a number of problems when they reach the age of puberty. Their roles and expectations undergo a change as their mobility becomes restricted. Explaining the risks attached to this sensitive age, girls in a FGD in a rural area of Faisalabad, said that parents start to fear that "Now there is a possibility that the girl might get pregnant, because they don't trust her environment; that is why they become conscious, because it is associated with honor (izzat)." They explained that even with this fear, some parents want to continue to educate their daughters, but there is pressure on them from family 
members (such as maternal and paternal uncles and aunts) to discontinue their daughters' studies. Some parents persist against these pressures while others succumb.

While this issue was mentioned by several mothers from Faisalabad and Kasur, it was a serious concern among mothers in Rajanpur, probably due to the more traditional and conservative setting there. Most of the mothers from both rural and urban areas strongly emphasized that they stop their daughters from going to school as soon as they reach the age of puberty. A few mothers even seemed to consider it a sin to send a girl out alone after puberty. They felt that, after this stage, guarding girls was essential and that a household member (preferably male) must accompany them at all times when they go outside.

The risks articulated by girls and their mothers are by no means unique to the study areas or indeed to Pakistan. Rihani (2006, in Sathar, Wazir and Sadiq) lists early marriage and/or pregnancy, and the threat of sexual harassment and violence in school and en route to school among the main barriers leading to low girls' enrollment at secondary level. Studies in other developing countries also show that when girls reach puberty, they face risks such as sexual coercion, unwanted pregnancy, early marriage, and HIV, which may interfere with their school progress or force them to drop out. In particular, premarital sex, including nonconsensual sex, can lead to school dropout and remains a risk that adolescents need to manage while attending school (Hallman 2007, Biddlecom et al. 2006 in Lloyd 2011).

In one of the rural communities from Rajanpur, mothers mentioned that while schools were present, they had a co-education system and only male teachers were available, which they considered too risky an environment for their daughters.

\subsubsection{Difficulties in Reaching School}

When schools are outside their communities, a number of physical access issues also arise for girls. Mothers and fathers discussed this problem in detail. If a girl of any age has to go outside her community for schooling, she has to be accompanied by someone, preferably a male member of the household. After reaching the age of puberty particularly, girls are never left unattended, and are not allowed to go alone to school due to a number of social and security risks, which will be outlined in the next subsections. In a series of logistic regression studies of enrollment and attrition (using secondary data from the National Adolescent and Youth Survey 2003), Callum, Sathar and Haque (2012, in Sathar, Wazir and Sadiq 2013) showed that even after taking school availability into account, girls in households allowing unrestricted mobility to school had 1.5 times higher odds of ever being enrolled than those who required an escort. Once in school, the need for an escort implied 1.6 times higher odds of dropping out.

According to respondents, since fathers and brothers of the girls are engaged in economic activities, they can neither spare the time to pick and drop the girls every day, nor afford to sacrifice a portion of their earnings due to this lost time. Therefore, the educational aspirations of the girls and their parents' desires for them in this regard have to be compromised. The girls also realize this to be an important issue. However, respondents also note that some brothers do play a supportive role in escorting their 
sisters to and from school. Girls who did not have elder brothers and have had to abandon their studies because nobody could escort them, fervently express the wish that their situation was otherwise.

The school was very far from here and my compulsion was that there was nobody to pick or drop me. One problem was the commute and the other was that there were men in the school that was near us. The whole school mainly consists of boys; there are very few girls there. IDI-Girl-Rural-Rajanpur School is far from here, about 4 to 5 miles, which is really too far for us to drop girls and bring them back. We do not want to send our girls to school alone. Circumstances are not favorable, so they cannot continue their studies. Where we face such types of problems, how can we send our daughters to school? FGD-Fathers-Rural-Faisalabad

My father could not afford the expenses and then there was the commuting issue as well. The school is far away and there was no one who could drop me to school. That is why everyone said studying till middle (eighth grade) is enough. IDI-Girls-Rural-Kasur

In situations where schools are too far away and cannot be reached on foot, the most important problem is transport arrangements, especially in rural areas, where the means are not frequently available. In remote areas, public transport is available at particular timings-usually in the mornings and evenings-and the timings do not suit girls going to school. Moreover, as mentioned earlier, parents do not consider it safe to let their daughters travel alone on public transport while private pick and drop services can be costly; in the absence of feasible alternatives, the issue is resolved by discontinuing daughters' schooling.

My parents did not send me to school. We were facing financial constraints too and the school is quite far away; there is no means of transportation. IDI-Girl-Rural-Rajanpur

\subsubsection{Security Issues - Parents' Top Concern}

In most of the discussions with girls, mothers, and fathers, across all study districts, one refrain was constant: "The [social] environment outside the house is not good for girls." This phrase mainly referred to personal security threats that girls have to face if they step outside the home. This problem emerged as a very important reason for the dropping out of girls, and was generally highlighted more by girls and mothers, than by fathers. Certain kinds of security issues were more strongly emphasized by girls; others by mothers and fathers. In rural communities, the limited local availability of schools above primary level exacerbates risks and parents' concerns about their daughters' security. While mothers from all three districts referred to these issues, particularly in Faisalabad and Rajanpur, they were more frequently reported from rural than from urban areas.

Mothers from rural Faisalabad and Kasur shared during FGDs that the routes to girls' schools are not safe. These mothers particularly mentioned that girls have to walk along paths leading through thick fields of sugarcane, which reduces their field of vision and makes them more insecure. They may be ambushed by robbers or suffer sexual violence. In one of the FGDs, mothers shared an incident where a local girl and her brother were robbed en route to school. The incident resulted in the girl being withdrawn from school. 
Yes, once some girls used to go to the school in Baaght. Their brothers were with them too. Some robbers came there and put pistols to their heads. Their brothers said to leave the girls alone as only they had the money with them. They did not let them harm the girls, but still the girls got very scared. They even fainted from the terror and later dropped out of school because of this fear. FGD-Mothers-Rural-Faisalabad

The other major issue, reported by mothers in all three districts, was the fear that the girls might be kidnapped, a fear based on incidents that had occurred nearby. Mothers from Faisalabad narrated two cases of attempted abduction, where the girls had been able to run away and save their lives. In one of the incidents, a girl mentioned that her young female cousin had been kidnapped, then raped. Due to that incident, she too had to discontinue her studies.

A girl here was about to get on a rickshaw when they tried to kidnap her. She ran away from there and when she came home, she fainted. We have to go to the neighboring village. We have to accompany them to the school, to pick and drop them by ourselves. Now either we can earn for them or take them to school. My younger children are in school; I myself have to go there to pick them. Mothers-Rural-Faisalabad

Such crimes spark great fear among parents and girls, and it is not only the girl affected but also other girls in her vicinity who discontinue their studies as a result.

In addition, mothers and fathers from Rajanpur were very concerned about co-education in schools. The presence of exclusively male teachers and staff further added to their worries. Hearing about other girls' relationships with boys or men can compel parents to stop sending their own daughters to school, not only due to their own concerns but also because of gossip among family members or neighbors.

How can we send them to school? There are male teachers in the school and our girls are grown up. How can they be taught by them? There are no separate schools for girls. (All the women started talking together about the issue.) If the girls go to a school where

\section{Case Study 1}

"I was so passionate about studying"

My name is Nausheen. I am a single child; a simple girl who was really passionate about studying.

I used to study at a primary co-education school which is located not far from our house. My school fees were never an issue. At times, my brother for money to pay my fees. Everyone would help because they knew how enthusiastic I was about studies.

But our class consisted mostly of boys. Even our teachers were mostly male. When we had any problems related to our schoolwork, the teacher would ask us to consult our male fellow classmates. This made me very uncomfortable and I felt very shy talking to them.

When I mentioned this to my parents, they pressured me to leave the school and discontinue my studies. I loved school and felt very dejected. There was another school I could have gone to, but it was too far away from my house. I had no brother and even my father was quite old, so there was no one to take me there. The only solution my parents had for me was to leave school. Their constant pressure finally forced me to discontinue my studies and I left after grade 4 .

I had had big dreams and huge plans. Like everybody else, I had always wanted to be a teacher or a doctor. I wanted to lend a hand to my parents and be their supporter. I wanted to earn for myself and my family. But now all of my dreams were scattered away.

After quitting school, I was homebound. I felt extremely sad that I could not continue my studies. I did not eat for days. The shock left me utterly broken. My mother consoled me and asked me to take over household chores and work in fields since now I had nothing else to do. Now I am just an average girl who has lost hope. mother would sell milk, take a loan, or ask her 
there are boys as well, people taunt us that your girls are getting too modern. People ask, what is the need to get the girls educated from a boys' school? FGD-Mothers-Rural-Rajanpur

Another issue highlighted was being teased by boys in the streets, which was commonly reported by mothers and girls, especially in Faisalabad and Rajanpur. Mothers from Kasur did not talk much about this issue although girls from the district did. According to girls, some boys from their community stand at every street corner on their way to school, and pass comments at passing girls. Since they have relatively easy access to mobiles, they sometimes harass girls by taking pictures of them and by listening to loud music in their presence. In this situation, parents either try to personally drop their daughters off at school, or resort to the easiest solution of not sending them to school at all. Girls also mentioned that if people in the community ever see a girl talking to a boy on the street, they come to negative conclusions that can bring embarrassment for her parents and brothers. To avoid such situations, parents decide to stop sending their daughters to school.

There are certain boys around here who bother us by teasing us in the streets. That's why our parents don't send us out-to avoid the possible dangers. FGD-Girls-Rural-Faisalabad

Often in our village there are three to four boys standing at every corner. They talk about girls among themselves, and tell our brothers, "I have seen your sister going that way today," and then our brothers ban us from going out. When it is time to go to school, the boys stand in the way, in groups. FGD-Girls-Rural-Kasur

\subsubsection{Problems at School}

After negotiating the array of issues described above, the girls who do reach school have to face another set of hurdles within its premises. The majority of girls and parents shared a number of problems, most of which were related to the quality of education. They included poor ways of teaching; non-availability of female teachers; teachers' absenteeism; teachers' discouraging and taunting behavior; physical punishment by teachers; their inappropriate and undue demands from students; teasing by peers; absence of amenities; and a non-supportive system, especially in terms of menstrual hygiene management. Most issues were associated with government schools, while only a few were mentioned in regard to private schools.

It is important to note that only some of the above issues were reported to be reasons for dropping out, while others were discussed as general difficulties; this distinction is highlighted in Figure 4.2. The problems leading to dropping out were highlighted by the majority of mothers and fathers from Rajanpur. In contrast, parents from Faisalabad mostly talked about quality-related issues, while parents in Kasur either had only minor complaints or were satisfied with the quality of education.

Fathers, especially from Faisalabad, emphasized two main issues: gaps in the knowledge of teachers and an insufficient number of teachers, especially in public schools.

In our area (Dijkot), 150 teachers are needed in the government schools but the government does not want to do anything. In private schools, 2,200 children are getting educated and there are 120 female teachers while in government schools, there are at the most 17 to 18 teachers available per 1,000 children. Now, you tell me, how can 18 teachers teach 1,000 children? FGD-Fathers-UrbanFaisalabad 
Figure 4.2: Reported problems at school that cause dropping out or create difficulties for girls
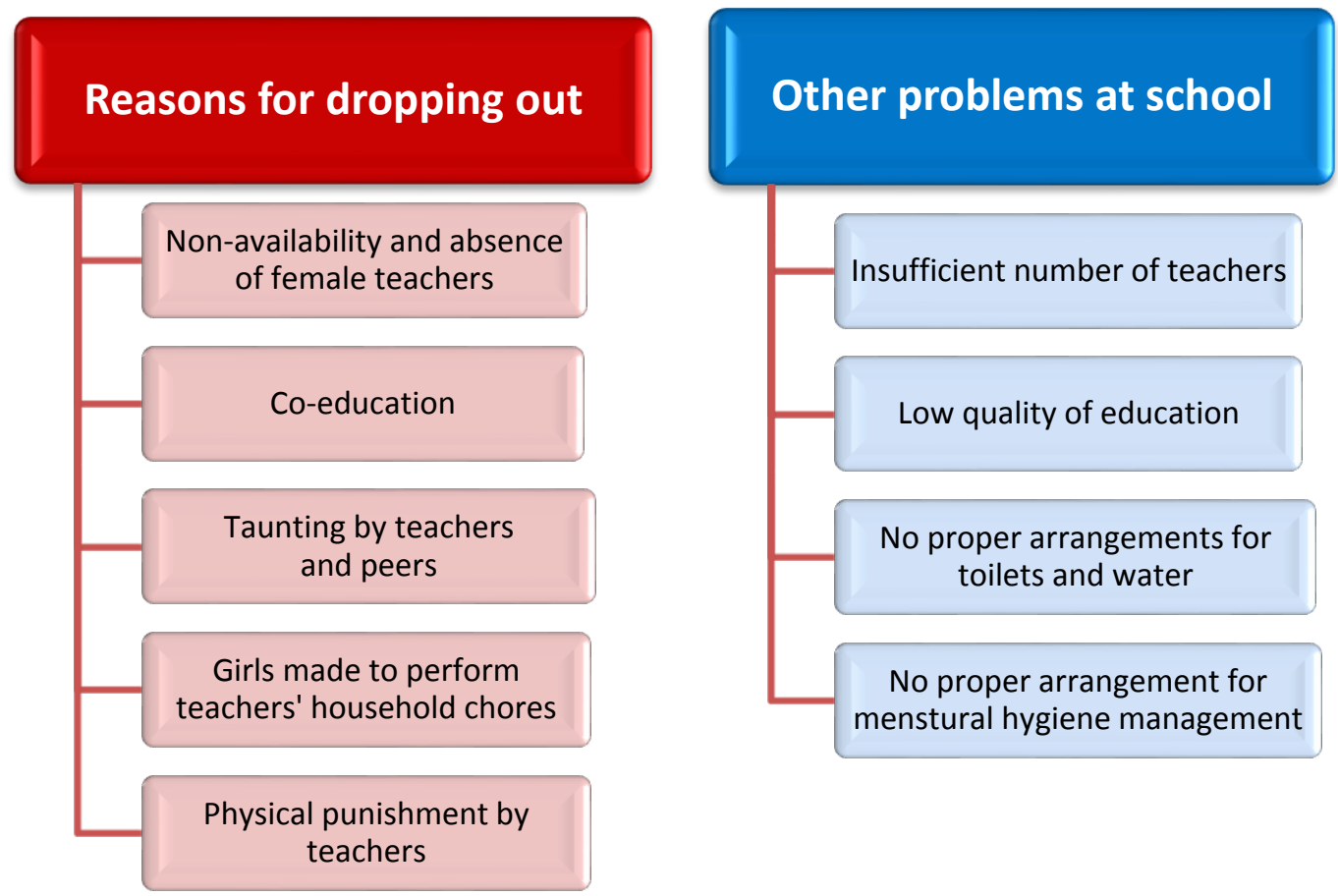

In view of this chapter's objective, we will focus here on the specific issues which are responsible for girls' dropping out, as discussed below.

\subsubsection{Non-availability of Female Teachers and Absenteeism}

The issue of non-availability of female teachers was only reported in Rajanpur, but by the majority of mothers and fathers there. Girls in the communities had no choice except to attend a co-educational school where no female teachers were available. Parents remain under constant stress if their young daughters are taught by male teachers.

A further issue is absenteeism among teachers, especially in private schools. According to parents and girls in Rajanpur, frequent switching of teachers and their irregular presence are major barriers in the provision of quality education.

Because there is no female teacher there, our girls cannot go to that school. We even requested a female teacher. We are all agreed on the point that if the environment is feasible, we all can continue our daughters' education. FGD-Fathers-Rural-Rajanpur

A lady teacher was visiting to teach us for two months but later she left because she was not paid. No one was there to pay any attention to us. We also wanted that there should be someone who pays attention to our studies; there should be a school where we could study. If a teacher was provided, we would definitely have studied. What shall we do now? Our parents are not educated and how could they afford to send us to cities for studies? We cannot even afford our meals. We only think about food. Worries about other things come later. FGD-Girls-Rural-Rajanpur 
We got them admitted in the school earlier but then the female teacher who was teaching them left. So we discontinued our girls' education. That teacher taught for some time in the earlier days of school but then she left. FGD-Mothers-Rural-Rajanpur

Other studies have also examined the challenges of non-availability of and absence among female teachers at schools in Pakistan, which are generally segregated by gender. A 2004 survey of primary schools in rural Pakistan showed that while 14 percent of male teachers were absent, 32 percent of female teachers were not in school (World Bank 2002b in Ghuman and Lloyd 2007 in Hunt 2008). The shortage of female teachers particularly affects rural schools (Ghuman and Lloyd 2007 in Hunt 2008). In their study of eight districts in Punjab, Hussain, Salfi, and Khan (2011) found 87 percent of respondents identifying the shortage of teachers as a major reason for dropping out; most primary schools in Punjab have only one teacher, who has to manage five or six groups of children. Nearly the same proportion of respondents in the study said that a key factor underlying the shortage of teachers was appointment of teachers far from their homes. This seems to be supported by Ghuman and Lloyd's (2007) finding that teachers born and living in the district where the school is located show lower absentee rates, particularly in the case of female teachers.

\subsubsection{Co-education}

It was observed in the study communities that both boys and girls, even in primary schools, are of older age than the normal range of about 6-10 years, probably due to late enrollment and, in some cases, grade repetition. This is the reason parents reported that the presence of adolescent boys makes their girls more vulnerable to teasing and harassment. In this situation, they consider it more advisable not to send their daughters to co-educational schools. Moreover, in their traditional society, such 'mixed' arrangements are not easily accepted and parents are pressurized by family and community members, who object to girls sitting in the same class as boys. This situation ultimately compels parents to stop sending their daughters to school, despite their own aspirations and those of their daughters.

They have co-education and there are big boys studying there, so we can't send our grown-up girls to the school. FGD-Mothers-Rural-Rajanpur

I left school in second grade. There were much older boys there too, and my father used to object to that and eventually stopped me from going to school. FGD-Girls-Urban-Rajanpur

\subsubsection{Forced Labor at Schools and Teachers' Homes}

Based on their own experience, girls reported that teachers frequently ask their students to perform chores, both within the school itself as well as in the teachers' households. This was most frequently reported in Faisalabad, where the majority of girls mentioned it, followed by Rajanpur and Kasur. Since this was directly experienced by girls, they were highly expressive and actively participated in discussions about this problem. Parents spoke less about the issue and at times were not even aware of it, as they were not being told about it by their daughters.

Assignment of school chores was mainly reported in primary-level public schools. Most of the girls reported that they had to clean school yards, classrooms, and even school toilets. Their turns were 
fixed in rotation, probably because of insufficient support staff at schools. Girls reported that they felt offended cleaning the toilets.

Girls usually sweep or mop the floor or do tasks like dusting in the school yard and our own classroom. The yard of the school was paved. I first went to the government school and then to a private one later on. I did cleaning chores only in the government school. FGD-Girls-Urban-Kasur

The washrooms were too filthy, and the teachers used to ask us to wash them. Then we used to wash them ourselves. I used to be so angry over all this, that why is she making us work? So I left my school due to that. FGD-Girls--Urban-Faisalabad

Teachers were also reported to exploit their students at their own homes. They reportedly sent the girls to clean their houses, and sometimes asked them to do their own domestic work inside the school, such as cooking for them, washing their dishes, combing their hair, and chopping vegetables. Some girls spent much of the day in such activities and felt their time at school was wasted. Among some girls, there was a perception that teachers reserve this kind of behavior for the poor students and do not treat well-off students the same way. In Rajanpur, it was reported that when some parents see their daughters doing the teachers' household work, they tell their daughters to leave school and stay at home.

(I was) cleaning her (the teacher's) house, washing dishes, and other such chores. I spent all my time there and didn't know anything about my lessons. I had to work hard for my exams on my own but still failed. FGD-Girls-Rural-Faisalabad

They brought vegetables with them from their homes and made us clean and cut them. We did not report this at home, otherwise they (the family) would be angry because they sent us to get educated, not to chop vegetables there. FGD-Girls-Rural-Kasur

\subsubsection{Physical Punishment by Teachers}

A number of girls also mentioned physical punishment by teachers as a reason for dropping out. This issue was reported only for government school teachers; the girls wished they could afford to attend private schools, which do not engage in such practices. The girls gave two main reasons for receiving physical punishment: not obeying teachers in performing chores, and low performance in studies.

She used to make us wash the toilets, and clean the floors and the rooms. If someone refused, they would be beaten with a stick. They used to make us clean the classrooms and clean the schoolyard. FGD-Girls-Urban--Rajanpur
My teacher used to beat me a lot. She used to make me do work other than studies at the school. She would force me to sweep the floors and clean the bathrooms, both the students' and the teachers'. We used to go to school for learning, and they used to make us work instead. We felt angry and we used to cry too, but we were helpless. If we refused, they would beat us with sticks and pull our hair. She used to slap us and mistreat us. FGD-Girls-Urban-Faisalabad 
When they have to punish a student, they make him or her stand out in the sun. That is why I left the school, because they made students stand in the sun in the scorching hot weather. FGD-Girls--Rural-Kasur

It was observed that, in most cases of corporal punishment, students put up with the punishment and do not share their experience with their parents. This is due to fears that their parents will either stop them going to school or complain to the teachers, who will punish them even more in retaliation. On the other hand, some mothers and fathers even supported punishment from teachers on the grounds that they were probably given for the child's own good.

Mostly children do not tell their parents that they were punished that day. When their parents come to know this, they do not let them to go school. They mostly say, if you are beaten there, why should we let you go? Now stay at home and do some work. FGD-Girls--Rural-Rajanpur

In their 2011 study in Punjab, Hussain, Salfi and Khan found a remarkable 93 percent of respondents agreeing that corporal punishment was one of the major reasons for students dropping out of school. Beatings at school were considered culturally acceptable to ensure obedience, even though corporal punishment at school has been banned in Pakistan since 1999. According to Hunt (2008), while the direct link between use of corporal punishment and dropping out has not been fully explored in literature, the relationships have been alluded to in terms of how beatings and intimidation lead to a gradual corrosion of the child's motivation to attend school (e.g., Boyle et al. 2002). Moreover verbal abuse from teachers is also recognized to lead to dissatisfaction and dropping out (Liu 2004 in Hunt 2008)-this is borne out by the findings presented in the following subsection.

\subsubsection{Taunting by Teachers and Peers}

Apart from the burden of chores such as cleaning, mopping, washing and cooking at schools as well as in teachers' houses, as well as physical punishment, some girls also have to face emotional abuse from teachers and peers. This really disheartens them and can force them to give up their studies. This issue was raised by girls in all three districts. According to the girls, teachers punish, scold, or taunt them if they are unable to perform well
I did not have proper, covered school shoes. The teachers would make me stand during morning assembly for not wearing proper shoes. I felt utterly humiliated. I would think: Isn't it obvious I don't have proper shoes? If I had them, I would surely wear them! I used to cry for a while and then forget. I still remember those feelings.

The teachers used to beat us too. And the girls would tease us in the class for being too poor to even afford school shoes. Obviously, I felt bad. Sometimes, I would borrow shoes from someone, just so I could wear them to school for a few days and not get beaten.

Once, my friends came to my home with me and afterwards they told everyone that my house is made of clay and mud. I felt so embarrassed. It made my heart heavy and I used to cry a lot.

Ultimately, I stopped going to school for these reasons. People kept passing insulting remarks. I had eight siblings; that's why we could not afford school expenses. FGD-Girls-Rural-Kasur 
in studies; fail a test or grade; don't pay their fees on time; do not have notebooks and books; or do not wear the proper uniform and shoes, even when they can assess that families are unable to buy these things due to financial constraints. In these situations, teachers humiliate them in front of others, sometimes in the classroom and sometimes even in the morning assembly. Other girls who can afford these things also make fun of the girls for being poor. The heightened plight of poorer girls is captured in the second case study presented in this chapter (Box 2). Some parents mentioned that they had to pull their daughters out from school because they could not afford school-related items. However, in a few cases, girls mentioned that their teachers supported them by buying the required items for them or at least urging other students to not make fun of their poorer peers.

The girls' responses suggest that emotional abuse by teachers corrodes students' self-esteem, leads to feelings of inferiority, and eventually convinces them that they cannot study. Peers can also contribute to low self-esteem through negative remarks on others' poor performance. In this nonsupportive-hostile even-environment, and with their self-belief eaten from within, it is a tremendous challenge for girls to muster the confidence to learn.

Sometimes it happens that a girl fails her exams and has to sit in the same class the next year. The teacher starts harassing her. She harasses the student and if the student is unable to learn her lesson, she taunts her about studying everything for the second time and still being unable to grasp it. Such behavior hurts the students and then they don't feel like studying. FGD-Girls-Rural-Faisalabad

\section{At that time, I was having trouble learning the lessons. I used to learn them but when I went to the teacher for the oral test, I would forget. My teacher then said that I should quit school and learn something at home. IDI-Girls--Rural-Kasur}

The above accounts of the girls underscore the urgent need to improve the quality of schools through better training and monitoring of teachers and schools. Similarly, Hunt (2008) describes how poor school quality is associated with poor academic results; higher levels of repetition and drop-out; and lower progression rates to higher levels of the education system. He also shows how teachers can contribute to this by discouraging some students and projecting hopelessness on them. Moreover, parents' perception of quality affects whether they think the school is worth the investment of their household's time, energy, and economic resources. If teachers are absent, students are not learning, and eventually do not even get promoted, then parents may see no point in sending them to school. Low learning achievement and repetition; a rigid formal system at early stages of education; and inflexibility of the examination system are perceived to be important reasons for dropping out of school in Punjab (Hussain, Salfi, and Khan 2011). In addition, Zaidi et al. (2012) found that, after controlling for economic standing, access to schools (in terms of numbers and distance) had more of an effect on enrollment among primary girls than on older girls, while secondary enrollment was much more responsive to the quality of schools.

With regard to problems at school, there is a clear distinction between issues identified by parents and those by girls. Parents mostly talk about system-related issues, such as non-availability of female teachers, absenteeism and the poor quality of education; whereas girls, based on their personal experiences, mostly share problems related to teachers' negative behaviors, which are often mirrored and compounded by their peers. 
All of these complaints point to a great need for better management and supervision of schools. Among the key institutional and management challenges affecting the quality of education in low-performing countries, Birdsall et al. (2005 in Hunt 2008) highlight high teacher absenteeism; spending and investment that is unresponsive to local needs and preferences; and a lack of accountability and incentives for performance. In Pakistan, Ghuman and Lloyd (2007) especially note the lack of accountability and monitoring mechanisms in some schools, noting how teachers, once hired, are difficult to fire, making it difficult to guarantee both attendance and performance.

In their consultation about what is causing children to drop out of school in Punjab, Hussain, Salfi, and Khan (2011) found over 73 percent of respondents citing careless supervision and weak administration, and 77 percent pointing to the indifferent attitude of administrative and supervisory personnel towards the teaching community. One third of the respondents agreed that teacher absenteeism and undue political interference were also major factors.

\subsubsection{Role of Menstrual Management Issues}

The availability of separate sanitary facilities is important for female retention at schools, particularly as girls get older and start menstruation (Colclough, Rose and Tembon 2000, Fentiman, Hall and Bundy 1999, and Lafraniere 2005 in Hunt 2008). In Pakistan, lack of proper toilets, hygiene and privacy arrangements have been identified among reasons why girls drop out (Rihani 2006, Shahidul and Karim 2015 Kazi 1999). In her study of six schools in Rawalpindi and Swabi, Aziz (2013) found water, sanitation and hygiene (WASH) facilities at schools to be in very poor state, with water shortages and highly inadequate cleaning arrangements. In particular, there was absolutely no arrangement to provide girls with sanitary products or pain medication in school, or even for them to dispose of used products. The girls had numerous misconceptions, which were adversely affecting their health and hygiene, and often experienced great anxiety in the school during their period. Despite the dire need for girls' education and decent arrangements for menstrual management, teachers, school heads, policymakers, and even the girls themselves, were very reluctant to discuss the issue of menstrual hygiene management.

All girls and mothers who participated in the current study were asked whether, according to their own experiences or those they had heard about, menstrual hygiene management was a reason for girls' dropping out of school. (The question was not part of fathers' FGDs, in view of cultural sensitivities.) This was the only topic on which a consistent response came from all districts, and from urban as well as rural areas. It was reported strongly by both OOS girls and in-school girls, as well as mothers, that menstrual management issues do not cause girls to drop out of school. The girls who had dropped out before getting their period could not draw on their own

It was reported strongly by oOs girls, in-school girls, and mothers that menstrual hygiene management is not a reason for girls' dropping out. However, it does promote absenteeism due to non-availability of supportive arrangements at school. experience in this regard, but nevertheless said that it would not lead to their leaving school. Some mothers, especially from Rajanpur, mentioned that girls in their communities drop out before primary education is complete, and therefore have not reached an age where menstruation might pose problems. 
When asked whether they had ever heard any case of a girl leaving school because of problems associated with menstruation, all 232 girls and 86 mothers responded unanimously that they had never heard of such a case. According to these groups, girls typically handled any such issues by taking the initial one to two days of menstruation off school, especially if they experienced pain.

They send us home because there is no arrangement (for menstruation support). If the girls do not have their own preparation for this, then they leave because of this too. IDI-Girls-Rural-Faisalabad

We have heard about a big school where if any girl says she has pain in her stomach, the teachers either give her the day off or give her some painkiller. Mostly, teachers send the girls home. The girls come back home if they get their period in the school. FGD-Mothers-Rural-Kasur

Girls talked in detail about menstrual management issues at school, explaining that schools generally do not have any supportive arrangements. It was reported from all districts that teachers generally send girls home if their period starts at school and they do not have sanitary products available, although it is also not easy for girls to get home, especially if their clothes are stained. They have to cover up properly in chadors to avoid any embarrassment on the way home. In some rural areas, where the school is close to the girl's home, she does return to school after a brief trip home. A few girls from an urban area in Kasur reported that their teachers ask them to pool money so that they can purchase material for management of such issues inside the school.

Teachers do not tell them (the girls) about this (menstruation and how to manage). There is no system for it in the school; they come home after taking leave. FGD-Mothers-Rural-Kasur

There was not any suitable arrangement for handling such issues. If girls were facing the problem, they were told to go home because there was no source available to handle this issue. IDI-Girls-UrbanFaisalabad

The girls, especially those who had dropped out during middle or high grades and girls who were currently in school, described at length how girls remain stressed in school. They have to spend school hours without changing their sanitary napkins due to the absence of proper washrooms in public schools; non-availability of water; broken doors; and a complete absence of dustbins. This problem intensifies in co-educational schools, according to respondents from Kasur. Absence of support for menstrual management leads to absenteeism and anxiety amongst girls in schools. Special efforts are required to destigmatize this natural part of girls' lives, fulfil their needs for health and hygiene information, meet their need for sanitary products and pain medication, and provide them with decent arrangements for maintaining hygiene and cleanliness.

There was nothing like that. If some girl spoiled her clothes because of menstruation, the teacher would laugh at her. Other girls used to give her some shawl so that she could cover herself and then she used to go home. They were just busy eating, or having tea. She often brought food from home. IDI-Girls-Urban--Rajanpur

There were toilets in our schools, but the boys used to sit so close to them that we felt shy and never went to the toilet. It was a private school. Boys and girls used to be together in the school. The boys' classroom was close to the toilet, that's why we never had enough courage to go there. FGD-GirlsUrban-Kasur 
The obstacles holding girls back from secondary education are broadly summarized in Figure 4.3, which illustrates how a number of girls drop out at each barrier, until finally, only a few are able to reach the desired level of schooling.

\section{Figure 4.3: Summary of factors that contribute in girls' dropping out}

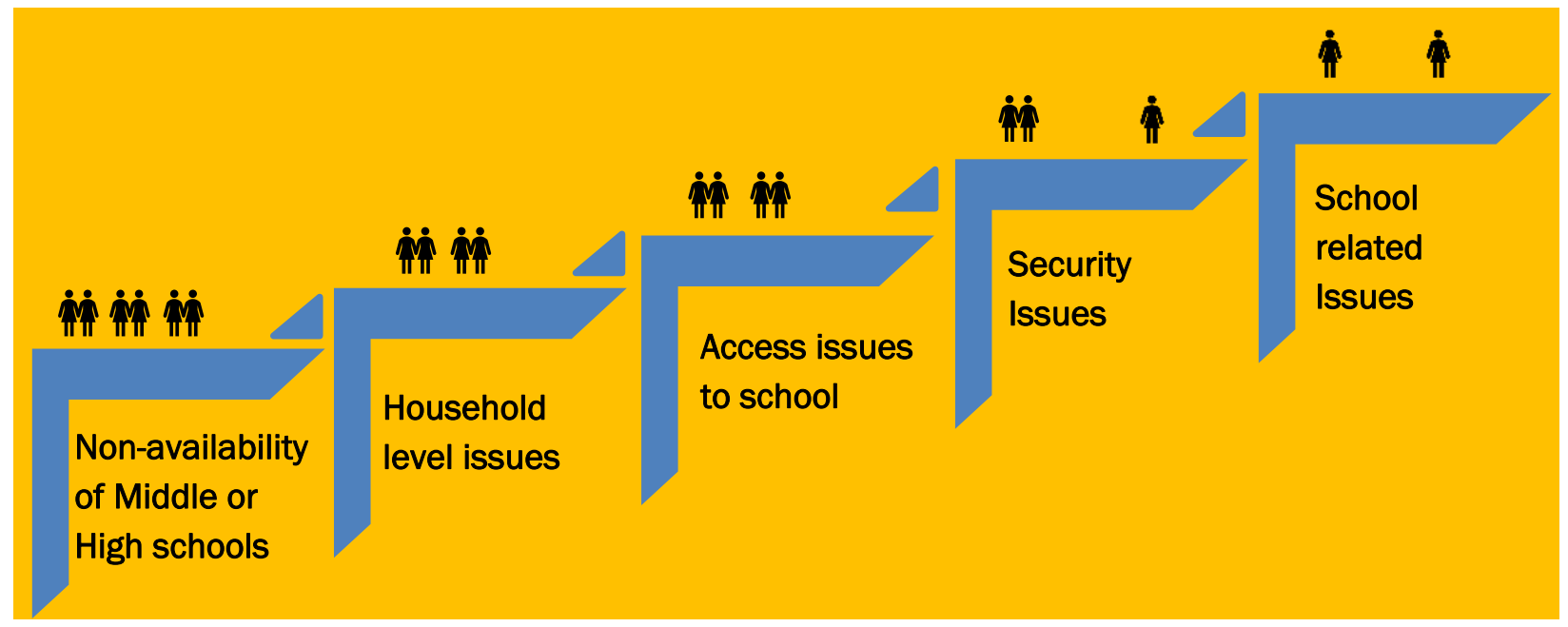

\subsection{Gender Differences - Reasons for Boys' Dropping Out of School}

After a detailed discussion of reasons for girls' being out of school, all respondents were also asked why boys dropped out of school, to examine the influence of gender differentials in such decisionmaking. The discussion was held in reference to girls' own brothers and male cousins of their own age.

Interestingly, there was a pronounced similarity in the reasons identified by all respondents, although the strength of individual reasons varied across districts. In contrast to the long and diverse list of reasons for girls being out of school, only four major reasons were mentioned by all respondents for boys leaving school. These reasons, which are described below, included (a) boys' own lack of interest in studies, (b) difficulties in affording school expenses, (c) boys' responsibility in bearing household expenses, and (d) low likelihood of getting a suitable job after finishing school.

\subsubsection{Lack of Interest}

The reason most frequently reported by all respondents and in all districts was that boys are not interested in continuing their schooling. This reason was mentioned more frequently in Faisalabad and Kasur than in Rajanpur. All mothers, fathers, and especially girls perceived that boys are supported and sometimes forced by their parents to pursue their education, but their own absence of interest in studies ultimately results in their dropping out from school.

In marked contrast, this reason was barely mentioned for girls. In discussions it was explained that boys have access to certain facilities and provisions that are not available to girls, and this disparity contributes to boys' losing interest in their studies. According to respondents, unlike girls, boys of this 
age group do not have mobility restrictions and they can go wherever they want, whenever they want. Further, in the company of their friends, they also find support in bunking school, playing games, and roaming around aimlessly. The feeling of freedom and involvement in these activities gradually reduces their interest in studies.

Moreover, boys also have easy access to mobiles and computers, and their excessive use and enjoyment of these technologies diverts their attention away from studies. In addition, a few girls and mothers from rural Faisalabad and Kasur mentioned that boys are involved in drug abuse, which keeps them away from studies.

Boys are nasty - too nasty. They are not interested in studying. They leave their homes saying they are going to school but they never go there. They just have fun, keep themselves busy on mobile phones or watch movies sitting in some hotel. My uncle has two sons. Both of them have sat their exams twice, and they failed both times. And now they are not even interested in studying. FGD-GirlsRural-Rajanpur

Mothers and fathers further reported that boys do not pay attention or follow instructions given by their parents. Parents sometimes also showed their helplessness, in that they cannot control their sons by beating or restricting them because they would just get more stubborn. Mothers mentioned that sometimes boys threaten to leave home if their parents are too strict.

Some boys are stubborn by nature. Even if you educate them, they do not pay attention, and if you beat them, they get worse. Fathers-Rural-Faisalabad

Failing a grade also makes boys less interested in studies, and they prefer to spend time with their friends instead of paying attention to their studies. This factor was mainly reported by girls and mothers.

The boys who fail in their class over and over again ultimately lose interest in studying. They sit with other boys somewhere over a cup of tea or watch movies. Although they tell us at home that they are going to school, they just go and have fun watching movies, drinking tea and eating together. IDI-Girls-Rural-Rajanpur

Liu (2004 in Hunt 2008) categorizes parents into three areas: those supportive of children dropping out, those indifferent, and those opposed to it. In most cases, the study finds that children appear to make the decision to quit schools themselves, with parents opposed to the move often scolding, trying to persuade and physically punishing the youngster in order to get them to rethink; but those supporting the decision providing little resistance. In many cases a "lack of hope" both on the part of parents and children seems to infuse decisions to drop out of school, particularly for boys. In the case of boys in Pakistan, the lack of hope Liu perceives may be driven both school-related factors, as described above in the girls, and by the irrelevance-real or perceived-of education for their immediate and even longer term financial needs, as discussed below. 


\subsubsection{Economic Role in Households}

According to respondents, due to the poor condition of households, boys have to contribute financially to meet their families' needs. This reason is directly related to poverty, and boys are part of the household coping mechanism. Although poverty was mentioned by respondents from all districts, the strength accorded to it was lower in Faisalabad and Kasur than in Rajanpur. As mentioned earlier, in Rajanpur, OOS girls are also assisting their parents in economic activities, but boys are asked to contribute more actively. Sometimes they drop out of school on their own, realizing they must work and earn, and sometimes their parents ask them to discontinue their schooling because they want their sons to be involved in economic activities.

We had financial problems from the very beginning due to which my brothers started to work; we were hardly meeting our expenses. My brothers left education and started to work from an early age. IDI-Girls-Urban-Faisalabad

Sometimes they have to earn to fulfill the expenses of their household. Therefore, they start working from a very young age. If a family has a son as the eldest child, he is compelled to work thinking that he is the elder of the family and he has to work to meet the household expenses. FGD-Girls-Rural-Kasur

These findings suggest that both boys' and girls' access to education is hampered by poverty in Rajanpur, although the precise outcomes may differ by gender. Their situation seems to resemble the pattern described in Hunt (2008) of how poverty, gender, location, household education levels, household income levels, and season can interact with child labor to influence a child's access to education. Rural children are more likely to work (Ersado 2005 in Hunt 2008). Girls often have more household duties than boys (Kane 2004 in Hunt 2008), although boys from poor urban households may have particular pressures on them to work (Brock and Cammish 1997 in Hunt 2008).

\subsubsection{Low Likelihood of Getting Suitable Jobs after Schooling}

A reason mainly mentioned by fathers from Faisalabad and Kasur was non-availability of jobs for educated youth, and a sense of hopelessness that education would translate into any economic benefit. Some of the respondents perceive that education, especially for the poor, is a waste of time because there is no guarantee of securing an appropriate job upon completion. Sometimes, people also weigh the potential earnings of OOS children against the spending on schooling and earnings afterwards, and conclude that it pays more to stay out of school.

I am a poor person. I cannot meet his expenses. Obviously, his education has stopped now. Even after completing tenth grade, he is a laborer with me. After getting them educated, in Pattoki, they do not get a job. So they must leave their studies and join us in the fields. If, even after getting an education, he cannot become a great man, what is the use? It is just a waste of time. FGD-Fathers-Rural-Kasur Here in our area people do not want to educate their children but some of them get their boys educated. If these boys do not get any job, they start to work in the fields. So parents mostly say, "If you are going to work in the fields anyway, what is the need for education?" FGD-Girls-Rural Rajanpur 
These responses indicate the importance of ensuring, both, that education is relevant to the current and future needs of students as well as their families, and that suitable jobs are available for educated youth. The perceived benefits to a household from education have been found to depend on a range of factors including prospective remittances the family can expect from their children; the likelihood of obtaining paid work; the way individual children can translate education into improved productivity; and the time preferences of the household (Al Samarrai and Peasgood 1998 in Hunt 2008). Hunt (2008) discusses at length how some researchers conclude that non-educated parents cannot provide the support or often do not appreciate the benefits of schooling-a position that could be adopted on the basis of the above findings of this study-but other studies attribute this conclusion to a lack of real understanding and misinterpretations of parental/household motivations around schooling. The PROBE (1999 in Hunt 2008) calls it the "myth of parental indifference" towards children's schooling. Boyle and colleagues found, despite claims to the contrary from teachers in Bangladesh, Nepal, Sri Lanka, Kenya, Uganda and Zambia, that "on the whole, the poorest parents and their children do indeed value education and usually have clear and rational reasons for not participating, or participating infrequently ... (Indeed) ... one of the clearest threads running through (the country reports) is the strong sense that the poorest income groups, as much as the richest, are making very reasoned judgments about schooling children based on assessments of the quality of education available, value for money, and investment potential" (Boyle et al. 2002, ix, in Hunt 2008).

In the research conducted in Punjab by Hussain, Salfi and Khan (2011), a large proportion of respondents felt that parents' low motivation, due to their own illiteracy and lack of appreciation of the value of education, was a factor in children's dropping out. At the same time, however, about half agreed that students also dropped out because there was no immediate financial return from acquiring an education, while two thirds agreed that the primary curriculum in Pakistan was neither in harmony with the needs and abilities of children, nor responsive to community needs.

\subsubsection{Difficulty in Affording School Expenses}

Inability to afford school-related costs was reported as a reason for girls' being out of school, and the same issue was also raised in the context of boys, implying that financial constraints affect both genders. Significantly, however, while the majority of mothers and fathers cited this reason for girls' dropping out, only a few respondents mentioned this reason for boys, suggesting that it is not an important reason in the case of boys, except in situations of extreme poverty.

Parents can let them be in school as long as they can bear the expenses. But then they have to take them out. My own son couldn't continue for the same reason, and the government school didn't have enough space for his admission. He desperately wanted to go to school. The private schools were very expensive and we could not afford it. FGD-Mothers-Rural-Rajanpur

Sometimes, because of financial issues, parents stop the schooling of boys. If the boy sees that his parents do not have the money, he leaves the school by himself. When they start to go to school, they demand pocket money from their parents to buy some things. If their parents do not have money, they think, if our parents do not have money, then what is the point of getting an education? So because of this, boys leave their studies. FGD-Fathers-Rural-Kasur 
Generally, in Pakistan's largely patriarchal society, parents focus more on providing opportunities and support to male children so that the latter can establish and secure their future. The discussion above clearly shows the gender differences in reasons for discontinuation of education between girls and boys. The list of reasons for girls dropping out is conspicuously longer than that for boys. A simple analysis of responses given, shown in Table 4.1 below, suggests that boys do not have issues in physically accessing schools, nor security issues; their mobility is not restricted, and they do not need to be accompanied.

Table 4.1: Reasons for being out of school: A comparison of girls and boys

\begin{tabular}{|c|c|c|c|}
\hline Issues & & Girls & Boys \\
\hline \multirow[t]{5}{*}{ Household issues } & Hard to meet basic needs & $\checkmark$ & $x$ \\
\hline & School costs & $\checkmark$ & $\checkmark$ \\
\hline & Transport costs & $\checkmark$ & $x$ \\
\hline & Household chores & $\checkmark$ & $x$ \\
\hline & Responsibility to share household economic burden & $x$ & $\checkmark$ \\
\hline \multirow[t]{3}{*}{ Access issues } & Security issues & $\checkmark$ & $x$ \\
\hline & Boys' teasing & $\checkmark$ & $x$ \\
\hline & Need for someone to accompany to school & $\checkmark$ & $x$ \\
\hline \multirow[t]{6}{*}{ Issues at School } & Non-availability of female teacher & $\checkmark$ & $x$ \\
\hline & Teachers' absenteeism & $\checkmark$ & $x$ \\
\hline & Taunts by teachers and peers & $\checkmark$ & $x$ \\
\hline & Physical punishment & $\checkmark$ & $x$ \\
\hline & Co-education & $\checkmark$ & $x$ \\
\hline & Having to perform teachers' personal chores & $\checkmark$ & $x$ \\
\hline \multirow[t]{2}{*}{ Personal concerns } & Lack of interest in education & $x$ & $\checkmark$ \\
\hline & Unlikelihood of getting a job after education & $x$ & $\checkmark$ \\
\hline
\end{tabular}

\subsection{Girls' Aspirations}

During both IDIs and FGDs, the girls were asked about their aspirations or goals in life. The responses showed their strong desire to complete their education to gain a better position in their lives. The majority of girls across the three districts mentioned that they wanted to be a teacher after getting educated; no other profession was reported as frequently as this, probably because teaching is generally considered a socially acceptable and respectable profession for girls. The girls gave mixed reasons for wanting to be teachers. Some had good teachers, whom they admired and wanted to emulate. Others had had bad experiences with their teachers and wanted to set the example of a good teacher for their students. A few girls also mentioned that they wanted to teach their siblings and their own children in the future. Two out-of-school urban girls had more specific aims: one wanted to be a science teacher and the other wanted to teach computer studies. 
I wanted to study till grade 10. I wanted to be a teacher and learn computers. I had a fondness for computers. If I had completed 10th grade, I might have studied further too. I wanted to become a computer teacher. IDI-Girls-Urban- Faisalabad

I want to be a teacher. Because the teachers "teach" the children, they pave the way for the whole world. The teachers work comfortably while sitting in a room. They don't have to do hard work. IDIGirls-Urban-Rajanpur

The second most frequent career aspiration of girls was to become a medical practitioner, such as a doctor, surgeon, or nurse, so that they could treat the poor. This aspiration was also prominent in a study of marginalized adolescent girls in Sindh (Plan Pakistan 2015). In addition, several girls wanted to join the army, navy, or police forces; the main source of such aspirations was usually a role model in the family or in their community, and they were attracted by the uniform, the lifestyle, and the prospect of serving the people and country. Interestingly, a number of both rural and urban girls wanted to be beauticians and to set up beauty salons in their houses or communities.

There are many wishes but nobody is there to fulfill them. I have not studied much. I left school when I was in grade 3. My father sells miswaak (twigs for cleaning teeth) and my mother is also a laborer. My elder brother has passed away. I have younger brothers. That's why I cannot continue my studies. It was my wish to study a lot and get a good job, like a doctor or a nurse or something significant. FGD-Girls-Rural-Kasur

I want to join Navy because I want to serve my country. I like their uniform, I like everything about them. They are serving our country. When I look at them in their uniforms, I wish I could do something for Pakistan too. FGD-Girls-Rural-Faisalabad

While discussing their career aspirations, girls clearly mentioned the additional objective of supporting their parents and changing the financially constrained condition of their families. They saw education as the first step in such a transformation and voiced feelings of inadequacy and regret at having missed this opportunity already. Being out of school pointed to a huge gap between their aspirations and actual lives. They felt deprived, and were acutely aware that leaving school had put their life on a negative trajectory, which they felt powerless to change.

I wish I had become an officer after completing my studies, but instead I pick cotton on hot summer days. I could have been a doctor or any senior officer, and I could sit under a roof. At least I would not be doing farm labor. They (Educated people) work in some kind of shade, not in the sun. I only wish that I had some education. Now I have to work in the fields. I could have had a [proper] job, like others who have an education. IDI-Girls-Rural-Rajanpur

This deeply felt desire to be educated was also noted in the above mentioned study of marginalized adolescent girls in Sindh, for whom acquiring an education was the greatest goal, and who saw education as a pathway to wisdom and a better chance of well-paid employment (Plan Pakistan 2015). 


\subsection{Respondents' Suggestions for Getting Girls Back to School}

The findings presented above clearly indicate that the attitudes of girls and their parents towards education are highly positive, and it is only due to a range of challenges that the girls are out of school. The girls feel deprived, having little hope of positive change in their lives without an education. The majority of the girls with whom we interacted (197 of 232) are still willing to resume their education, as they consider it pivotal for changing their life trajectory. Only a few girls said they did not want to resume their education, as they were 'grown up' and had lost interest. Similarly, very few mothers said they did not want their daughters to resume their education; they felt their daughters were grown up and it would be better for them to learn some skill instead.

Parents say that if not a lot at least the girls should have something. They should get educated up to fifth grade at least. What kind of parents would not want their girls to get any education? FGDMothers-Rural-Rajanpur

The positive attitude of most girls and their willingness to resume their education if provided an opportunity led naturally to the question, posed to all respondents, of what could be done to persuade or enable their parents to permit them to start or resume their education? All respondents, especially girls and mothers, participated enthusiastically in this discussion and gave several suggestions, which are outlined below.

\subsubsection{Establishment of Girls' Secondary Schools within Communities}

Non-availability of schools within the community is a major issue, and most respondents, especially mothers and fathers, suggested that higher level schools for girls should be available in the community. According to them, this option would address all access and security issues, as well as transportation cost issues.

If the school starts here, all the children will go. Everyone will let their girls to school earlier; it (the school) was too far away, that is why our males were not giving permission, saying "How could they go now? Our girls are grown up!" FGD-Mothers-Rural-Rajanpur

Fathers, particularly from Rajanpur, emphasized that the availability of female teachers for girls would persuade them to allow their daughters to attend school.

If the boys and girls have their separate schools, then it will be a lot better and if there is a separate campus then all the younger children and grown up girls could go together. FGD-Mothers-Rural-Rajanpur

If the school is somewhere nearby then we might get a chance to attend. If we are given scholarships and the distance is not too much, then a lot of girls of this community might get an education. FGDGirls-Urban-Kasur 
A few girls from Rajanpur also suggested that there should be an arrangement for separate classes for older students, so they could avoid embarrassment and not be taunted by children who were more educated than them.

I left school when I was very young. If I go back now, the girls will say, "She left school before, and now she has come back," and they will be younger than me and I will be older; it will be awkward. IDI-Girls-Urban-Rajanpur

I still have the aptitude for it but now I think that I am such a grown up girl, how will I be able to study? I will feel ashamed sitting in the junior classes and kids will make fun of me. This is what I think and I cannot even take tuitions from anyone. IDI-Girls-Rural-Rajanpur

\subsubsection{Financial Assistance to Girls and Their Households}

Affordability of school-related costs was reported to be one of the major issues by girls as well as mothers and fathers, especially from Rajanpur and Kasur. Accordingly, the majority of mothers, fathers and girls emphasized that financial support would resolve most of the issues girls faced in resuming their education. Financial support to poorer girls for school fees, uniforms, books, and stationery was suggested as a major solution. Respondents also suggested that these items be provided especially by the government for girls, for the encouragement of girls and their parents.

The girls should be supported, i.e., they should be provided with uniforms, books, etc., so that they can study. We are very poor, we need financial support (e.g., scholarships) and when, after some time, we become capable of supporting our own selves, then we will be able to do everything by the grace of Allah. FGD-Fathers-Rural-Rajanpur

Uniforms, books and stationery items should be given for free. If all these facilities are available, then I can stand up to my husband too and ask him who is he to raise any objections when she has a scholarship for her education. I can tell him that I want to get my daughters educated in every way possible. FGD-Mothers-Urban-Kasur

Poverty was mostly reported from Rajanpur, and as expected, respondents from this district emphasized the need for financial assistance more than those in other districts. Girls in particular stressed that providing such assistance would reduce the financial burden on their parents.

In addition, a few respondents also suggested that there should be some financial incentive provided for meeting basic needs in the households of the girls. A father explained that, following the devastating 2010 floods, food incentives were provided to girls to increase their enrollment, which were very effective; such incentives should be re-introduced.

Financial assistance really has an impact. We are poor. Our parents are busy in the fields and in other household affairs. They cannot pay attention to us or our studies, so financial assistance would decrease the burden of educational expenses. FGD-Girls-Rural-Rajanpur 
After the 2010 floods, the attendance at the school improved because the NGOs used to provide biscuits and ghee (clarified butter). Parents used to plead for their children's admissions. FGD-FathersRural-Rajanpur

\subsubsection{Transportation to Girls' Schools}

A few mothers and fathers, especially from Faisalabad, said that if the government could make special transport arrangements for girls to travel to school, it would persuade them to allow their daughters to attend school. However, this suggestion was not mentioned very frequently by respondents in other districts.

The main issues are transport and financial conditions. If people are helped at the local level, then the circumstances for girls' education can be improved to some extent. Those people who are not educating their daughters will start doing it. FGD-Fathers-Rural-Faisalabad

\subsubsection{Role of Brothers in Resuming Education}

After gathering the perspectives of respondents about possible steps that could persuade parents to allow their daughters to start or resume their education, it was specifically discussed how brothers might help girls in this respect. There were both positive and negative points of view about brothers' potential support. Most of the girls and about half of the mothers reported that brothers can play a positive role in the resumption of girls' education, whereas the other half of mothers, and several girls, said they cannot play any such positive role.

According to respondents, especially girls from all three study districts, brothers could support them by accompanying them to and from school, which would alleviate their parents' stress about security. Further, brothers could bring books and other required items from the market, and could even support them financially, if involved in an economic activity, in paying the fees and bearing other expenses. In addition, girls also mentioned that if a brother is educated, he can help his sisters in getting admission and in their studies. Girls from Rajanpur also mentioned that brothers could help convince their sisters if they were not willing to resume their education.

They can help us a lot. Even if they are just accompanying us to and from school, our parents will have this reassurance that their girl is not going out alone, and nobody will ever speak ill of her because her brother will be accompanying her. (All the girls agreed to this statement.) FGD-Girls-RuralKasur

Brothers can help in studying. If a girl is not that sensible, they can convince her to get an education. They can help her in her studies, and they can pay her school fees. They can help by picking and dropping her from and to school. They can also bear her expenses. FGD-Girls-Rural-Rajanpur

The opposite point of view, however, was that brothers could not help their sisters in this regard, because they themselves were not serious about their studies, or had dropped out. They also argued that boys involved in economic activities would not have the time to escort their sisters to and from school. 
Brothers have to work in some factory or mill. If they are supposed to take charge of their sisters, how are they going to work for them? And if they don't work, how will they earn the family's bread and butter? What else can a poor person earn from? FGD-Mothers-Rural-Kasur

\subsection{Conclusions}

While the study communities generally have at least primary level schools, higher level public schools are lacking, leaving girls with limited options. They might go to private schools, but these are beyond the reach of poorer families. They might attend more distantly located public schools, but this seems to open a Pandora's box of issues, including security and social risks, and transport costs among others. Notwithstanding some highly negative past experiences of schooling-such as teachers who ridicule, punish, and exploit them, and offer no support when they are vulnerable-the girls maintain highly positive attitudes towards education, which are largely shared by parents. Education is considered an important pathway to improve one's life, through learning etiquette, developing sound judgment, and gaining better quality employment to support parents and siblings. Most girls express strong feelings of sadness and deprivation at not being able to go to school.

According to the girls and parents, the main reasons why girls drop out include non-availability of girls' schools within the community and household level issues, in which financial issues are very important, as is girls' expected heavy contribution to domestic responsibilities, especially when their mothers are sick or have to work. Physically accessing schools is also a major challenge due to insecure environments that exert a strong pressure on parents to restrict their daughters' mobility. Some schoolrelated issues, such as co-education and absence of female teachers, are unacceptable to parents. Other problems include physical punishment by teachers, taunts from teachers and peers, and teachers' exploitation of girls to perform personal chores during the school day, which can force girls to quit school.

Gender differences are apparent when the reasons for girls' leaving school are compared with those for boys. Importantly, the foremost reason mentioned for boys is their own lack of interest. The other reasons are related to financial challenges: households' poor economic situation, the expected role of boys to shoulder their families' economic burden, and the expectation that education will not necessarily result in better-paying jobs in the future.

While the girls dream of being strong professionals, they are also painfully resigned to the reality that they can never attain these dreams without an education. Most of them are still willing to resume their education, as they consider it pivotal for changing their life trajectory.

The key suggestions from respondents regarding what would convince parents to send their girls to school reflect the main reasons they are currently out of school. Higher level public schools for girls must be set up in each community, or reliable and safe transportation arranged for them to attend more distant schools. Moreover, financial assistance should be provided to girls' families, to ensure that school attendance does not place any further stress on their already strained budgets, and to compensate for the loss of income from unpaid work. The brothers of such girls may be able to help, especially by escorting them to school in some families, but the mixed responses of mothers in this regard suggest that placing a universal reliance on such help is not an option at present. 


\section{Chapter 5 \\ Work Prospects for Adolescent Girls}

Financial constraints play a strong role in keeping older adolescent girls, as well as boys, out of school. However, while a large proportion of their male peers are able to go outside the home, find opportunities to work, acquire skills for livelihoods, and eventually become financiall5.y independent, the NEEM girls remain confined to their homes, many of them painfully aware that their marginalized state implies a future of perpetual dependence and lack of personal fulfillment.

As outlined in Chapter 1, for girls who cannot return to school, participation in paid work

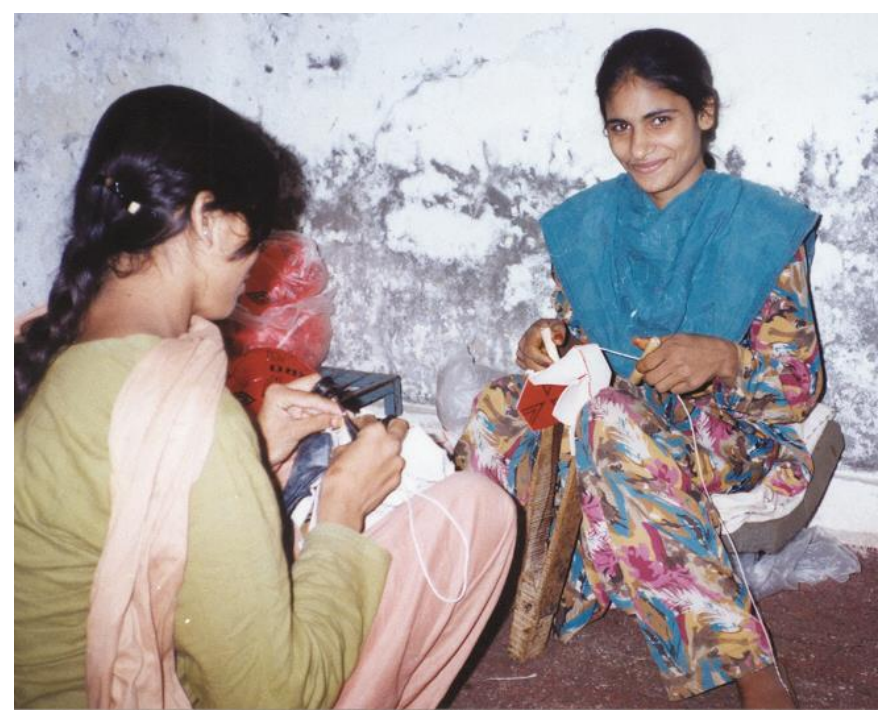
may offer an alternative route to empowerment, at least in some aspects of their lives. Certain risks must be kept in view, such as resistance from community and family members, the doubling of their work burdens, and relegation to low-skill, low-pay positions. By preemptively addressing these pitfalls, and leveraging opportunities that do exist at the community level, it may be possible to create a second chance for the NEEM girls.

This chapter presents our findings on the current context of girls' employment in the study communities; the opportunities available specifically for girls; and the barriers preventing out-of-school girls from getting involved in paid work. We explore parental perspectives on girls' involvement in economic activities, and outline the key measures that must be taken, according to respondents, to make parents amenable to their daughters' working. In addition to adolescent girls, parents, and influential community members, this chapter also draws on the perspectives of actual employers in the study districts, who were interviewed regarding the prospects of their employing local girls.

\subsection{Work Opportunities in the Community}

All respondents, including girls, mothers, and fathers, were asked about the broad economic opportunities available in their areas. Generally, girls were not aware of factories nearby, but mothers and particularly fathers did mention that local employment opportunities existed. In Faisalabad, respondents reported that while farming was their main work, there were a number of cotton factories in the vicinity. These factories included textile mills, units that recycle waste cotton pieces, garment factories, and hand looms, among others. Near one of the rural communities in Faisalabad, there was also a large-scale factory producing professed food items; however, it does not employ local people. 
In Kasur, a number of factories were mentioned by respondents, such as leather factories, shoe factories, cotton mills, and garment factories, although these were located at some distance. In addition, a large number of people also commute daily to the adjacent district of Lahore, to work in different industries there. Respondents from the urban area reported that girls also go to factories located in Lahore, which have arranged buses to pick and drop them.

There, in Lahore, there are so many factories. Mostly, about 25-30 buses take them to factories. Girls also go to work in factories. FGD-Fathers-Urban-Kasur

Respondents from Rajanpur reported that there are only small-scale opportunities available in their area, mainly for men and boys. Males provide labor in other farmers' fields, and at hotels, tea stalls, and shops, from where they earn nominal sums. In addition, they also migrate to Lahore, Faisalabad, and Sialkot to work. Generally, very few factories were present in the vicinity of communities; for example, one cotton ginning factory and a sugar mill were located about 15 kilometers and 45 kilometers away, respectively, from one of the rural communities.

There is only one sugar mill in the whole district of Rajanpur and that is quite far away. If you talk about this area, there is only one cotton factory and that too 2 kilometers away. Our children do not go to work there. Their work is tender based. They bring their own laborers and contractors with them and all the work is their responsibility. They do not give work to any local person here. Only men work there but those are all brought by the contractor. They do not hire local laborers for work. FGD-Fathers-Rural-Rajanpur

When asked about work opportunities for girls specifically, respondents generally perceived there to be limited options, particularly for OOS girls, because they felt a 'proper job' requires education. Interestingly, respondents did not even think of the possibility that girls might work in the places where males in their community were currently employed. Girls in Faisalabad and Kasur were aware of the presence of a number of factories in the vicinity, but they perceived these only as opportunities for boys and men, or for married women. In Rajanpur too, girls mentioned some factories where boys and men from their community work, but they did not think these would provide opportunities for their own employment.

\subsection{Current Work Spheres for Girls}

When the study respondents were asked what type of work girls usually do in their communities, girls shared a number of activities in both FGDs and IDIs, whereas mothers and especially fathers shared only limited information. Notably, as discussed in Chapter 2, NEEM girls are occupied with various domestic duties for an average of seven hours a day-a commitment practically equivalent to a fulltime job. In addition, girls in the southern district of Rajanpur contribute an average of three hours daily to their parents' work in the fields.

In terms of paid/economic activities, respondents mostly talked of activities available for both girls and their mothers, reflecting that it is not girls but primarily married women who are involved in economic activities. Respondents mentioned the specific types of work girls and women do in their localities, which varied to some extent across districts. 
In Faisalabad, almost all girls mentioned that their peers are mostly not involved in any paid or unpaid economic work. Those who are working are mainly involved in farm work, stitching and embroidery of garments, simple stitching (overlocking) of cloths, and packing of clothes. Some also work in the beauty trade, and a few who are educated provide tuition to younger children or teach at private schools. A few girls from very poor families also work as housemaids within the community, while some girls and women work in factories.

Some of them do stitching, embroidery, and the others earn through tuitions. Some bring orders from the cities and package dresses at home. Sometimes their brothers bring those things to them. They do beadwork on gota (a traditional lace) and on jewelry too. Then someone comes from a nearby village and collects the products from them. FGD-Girls-Rural-Faisalabad

In Kasur, girls and mothers mentioned that women usually work from home, stitching clothes, and producing bead laces and other clothing-related embellishments. A few respondents said women also work as housemaids and run their own shops, while some women and younger girls were reported to be working at factories manufacturing shoes, socks, or jackets; the factories provided transport for them. It was reported that while older adolescent girls also work for a shoe factory, specifically on the upper part of the shoes, they work from home because they are not allowed to go to the factories. In addition, a few girls who are educated to some level are teaching at private schools. The girls reported that they were less involved in economic activities, but sometimes accompanied their mothers to assist in providing domestic services. In addition, fathers mentioned that their daughters do embroidery or stitching at home, and girls also help their parents or brothers in cotton picking and harvesting. However, they emphasized that they do not send their daughters to earn alone. As mentioned earlier, fathers from urban areas reported girls being employed in factories situated in Lahore, but this was not a common practice.

The girls and women do harvesting work. Now they have to harvest pulses, sugarcane, and wheat as well. They have to pick cotton too and they reap wheat. They go with their parents and brothers and come home with them. We do not send our daughters to unknown areas to work with unknown people. FGD-Fathers-Rural-Kasur

Most of the girls are not doing anything. There are a few who work at people's houses. Some girls make shoes and do stitching at home. Some of the girls do the work of unweaving sweaters and winding the yarn, which is sent to the mills for processing into new thread. FGD-Girls-Urban-Kasur

However, in Rajanpur, all respondents emphasized the fact that opportunities for girls to work were very limited. The girls do want to work but can only do stitching or help in the fields, mainly in the harvesting of cotton, sunflowers, and wheat. It is interesting to note that mothers from rural areas mentioned that girls and women work alongside men in all agriculture-related activities-labor was shared regardless of gender. Women and girls also make baskets and mats on a small scale, in their homes. In urban areas, women reportedly do stitching work.

Here, our parents are workers or laborers throughout their lives and we have to do the same thing.

Those who have shops mostly sell some limited grocery items. FGD-Girls-Rural-Rajanpur 
Parents and children all work together where the men and women are working together. It is not as

if only males were working and women were not. If they water crops at midnight, we go with them too. My sister-in-law goes with her husband to sell wheat. FGD-Mothers-Rural-Rajanpur

The above discussion suggests that girls from Faisalabad and Kasur have at least a range of employment options available, although they are not involved to the extent that they could be. In Rajanpur, opportunities for females are limited but women and girls are contributing to their household economy though informal and unpaid farming activities, working as hard as the men in their families. The generally limited view of respondents regarding the areas in which girls could work support Kazi's (1999) observation that multiple constraints circumscribe women's work options in general, including exclusion from more remunerative non-farm employment; perceived suitability of occupations among family and employers; need for compatibility of work with domestic duties; and lack of mobility beyond short distances.

The mention from every district of girls' involvement in farm work is also noteworthy. Studies indicate that the ranks of "unpaid family helpers" are rising at an alarming pace (Labour Force Survey 2003-4 and SPDC 2010), implying an unfulfilled need to draw women from the unorganized to the organized sector (Mumtaz 2007).

\subsection{Girls' Perspectives on the Effects of Working for Pay}

Although most of the girls who participated in the FGDs were either not working or engaged in some unpaid or low-paid activity, the majority had a very positive attitude towards working: they wanted to earn money and support their families, although this desire was not as intense as the desperation with which they wanted to complete their education (as discussed in the previous chapter).

According to data collected from the 42 interviewed girls about

Most of the girls want to work, earn money, and support their families, but they are less desperate to do so than to resume their education. what they would prefer to do given the opportunity, about half want to pursue their education, a quarter want to attain any technical skills that might help them earn, and the rest want to be involved directly in some economic activity, deeming further education to be a waste of time. Encouragingly, the girls are willing to dedicate an average 3-4 hours per day to these activities, by managing their household responsibilities more efficiently and reducing their leisure activities.

The girls perceived that participation in a paid economic activity would bring positive changes in their lives. They were able to list a number of specific positive impacts when asked how paid economic work might affect their lives. These are shown in Figure 5.1. At the same time, however, there was a common perception that work opportunities were limited for OOS girls, since they do not have adequate education. 


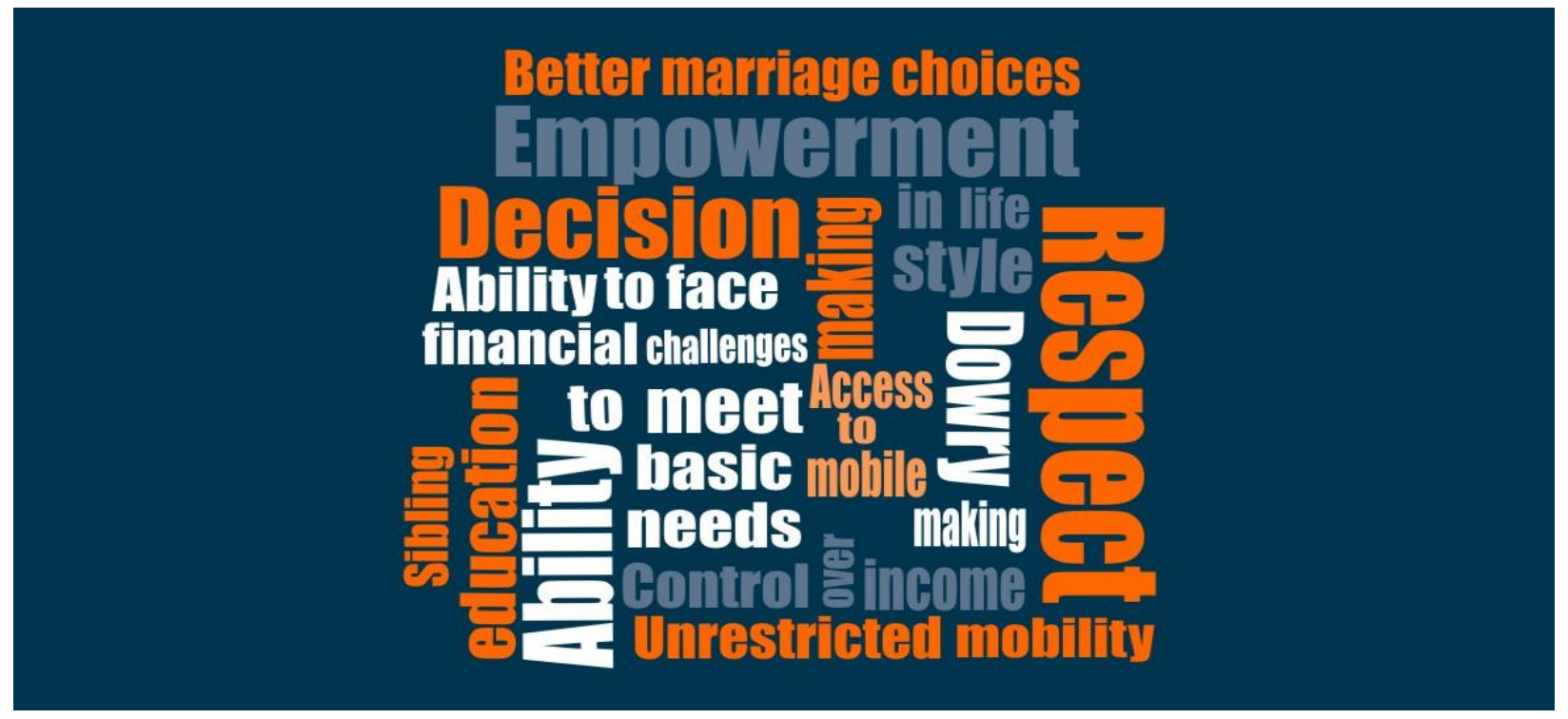

During the IDIs and FGDs, the majority of girls reported that a girl's employment and monetary contribution to the household change her status, not only at the household but also at the family and community levels. Work was reported to be a source of girls' empowerment. Respondents elaborated that when girls have control over their earnings, their opinion starts to count and family members involve them in decision-making. They can spend their money as they wish, and their mobility does not remain so restricted. Girls from Kasur also mentioned that they would buy mobile phones with their earnings-ownership of this asset was considered a sign of empowerment.

It gives satisfaction to the girl when she sees how much she has earned, and the parents are happy too when their needs are being fulfilled. If a girl is making her contribution to the household expenses, her parents will also ask for her opinion while making decisions. FGD-Girls-Rural-Rajanpur

Girls also emphasized that working would not only transform a girl's own self and status, but also the circumstances of her family, particularly if it is poor and deprived of basic needs. Apart from raising the standard of living, the girls expected to reduce the stress and anxiety associated with financial difficulties. Although these benefits can apply to work by anyone and are not gender-specific, the girls identified them from the perspective of their own employment.

She can fulfil all of her needs. She can do that only when she has money, because if she hasn't, then she cannot buy anything for herself. She can bring change to her life too. And she can take care of her siblings' education and needs as well. A girl can educate her children as well. She will have enough to eat. Everything in her life can change. FGD-Girls-Rural-Faisalabad

In the girls' discussion of perceived effects of girls' working and earning money, respect was the most commonly mentioned benefit. The girls explained that they would feel satisfaction in being contributors in their household, and their parents would be proud of them for helping to meet household needs, including medical care for parents and education of siblings, which are hard to manage otherwise. 
Being able to provide financial support to their families would confer upon them a degree of respect that they could probably not inspire in any other way. During FGDs, girls noted that those of their peers who earn are treated differently by family members and are involved in family decisions.

She can fulfill her needs. There is no constraint if she wants to buy anything. It also affects her domestic life. Her family gives her respect. Money is necessary for fulfilling any need, like education or health care. IDI-Girl-Rural-Faisalabad

Interestingly, the girls also expected that contributing to the household income would lead to similar privileges as male bread-earners: roles would be reversed, with family members serving them meals and laundering their clothes, rather than the other way round.

We know because when the girls who earn come home, they are served with food. Everyone does things for her at home. The family washes and irons her clothes. They do everything for her as she is earning for the family. She becomes the breadwinner of the household. FGD-Girls-Rural-Faisalabad

The girls also mentioned the effect employment might have on their marriage and marital life. They felt that a girl who earns can receive good proposals and also help her parents pay for her dowry and shoulder other major expenses of marriage. Moreover, her ability to earn enables her to support her husband and in-laws, and to educate her children. Girls and fathers also pointed out that a girl who earns is better able to face any challenges that arise in her marital life.

Yes, it has a strong effect. She thinks about her future life. It brings comfort for her family too. When the family wants to marry her off, the parents are less burdened because of her job. She can fulfil every wish of her children. When any of her in-laws need money, they can ask her. IDI-Girl-Rural-Rajanpur

To sum up, the girls view involvement in paid work as a means for acquiring some autonomy and achieving a positive shift in gender roles and division of power in their natal as well as marital homes. They also expect their earning to improve standards of living in their household, leading to less domestic stress and strife. It is interesting that the girls do not expect any negative effects of paid work on their lives. As outlined in Chapter 1, the actual impact of work on women's lives can be mixed; while autonomy in some spheres certainly increases, there are also some risks, such as doubling of work burden and a higher risk of gender-based (including spousal) violence.

\subsection{Why OOS Girls are Not Engaged in Paid Work}

As indicated in the time use profile of NEEM girls in Chapter 3, the majority of the girls, especially in Faisalabad and Kasur, spend about a third of their time on household activities, but then have some time left over for leisure and personal activities. They view their possible involvement in economic work positively, with the understanding that this would have far-reaching progressive effects on their own lives. The question arises why, despite having time and being receptive to work, these NEEM girls are generally not involved in any paid economic activity. In the case of girls from Rajanpur, the majority of whom are already engaged in agricultural activities as unpaid family helpers, and who are also in favor of working to earn, the question is: Why do they not get involved in independent paid economic activities, even those that are agriculture-related? 
Discussions conducted with girls, mothers, and fathers suggest that while the list of challenges holding girls back from paid work is not as long as the reasons for their being out of school (Chapter 4), this issue is more complex. The study team sensed that there is a huge difference in the values attached to educational attainment and to employment among girls. It is

Communities see girls who go out for education very differently from girls who go out for work. considered respectable for girls to attain an education, but their employment, at workplaces outside their homes and where men are present, is generally not endorsed by the community, especially in rural areas. According to prevailing cultural norms, girls are considered a source of izzat (honor) for the family, and families prefer them to stay within the home. Their going out for education is seen differently from their going out for work. In the latter case, they are seen to be earning for male family members, which is viewed negatively.

Also interesting was the contrast in levels of participation by respondents when discussing reasons for girls being out of school in contrast to reasons for their not being engaged in paid work. In the former discussion, all categories of respondents, especially girls and their mothers, spoke at length and in detail. However, respondents had relatively little to say about girls' participation in paid work. One reason could be that more respondents had direct experience of the challenges keeping girls out of school, while the idea of girls working for pay was relatively new and evoked a more mixed response, with respondents drawing more on observations about others than on their own experience.

As we have seen in the previous chapter, the barriers keeping girls out of school operate sequentially, somewhat like a ladder, with girls facing new problems at each rung. With respect to participation in paid work, however, the girls seem to confront a daunting interplay of multiple challenges operating simultaneously, most of which are rooted in discouraging cultural norms. The main challenges are indicated in the word cloud in Figure 5.2 (with the font size reflecting the frequency with which each issue was cited) and then described in detail.

Figure 5.2: Reasons given by girls for not being able to engage in paid work

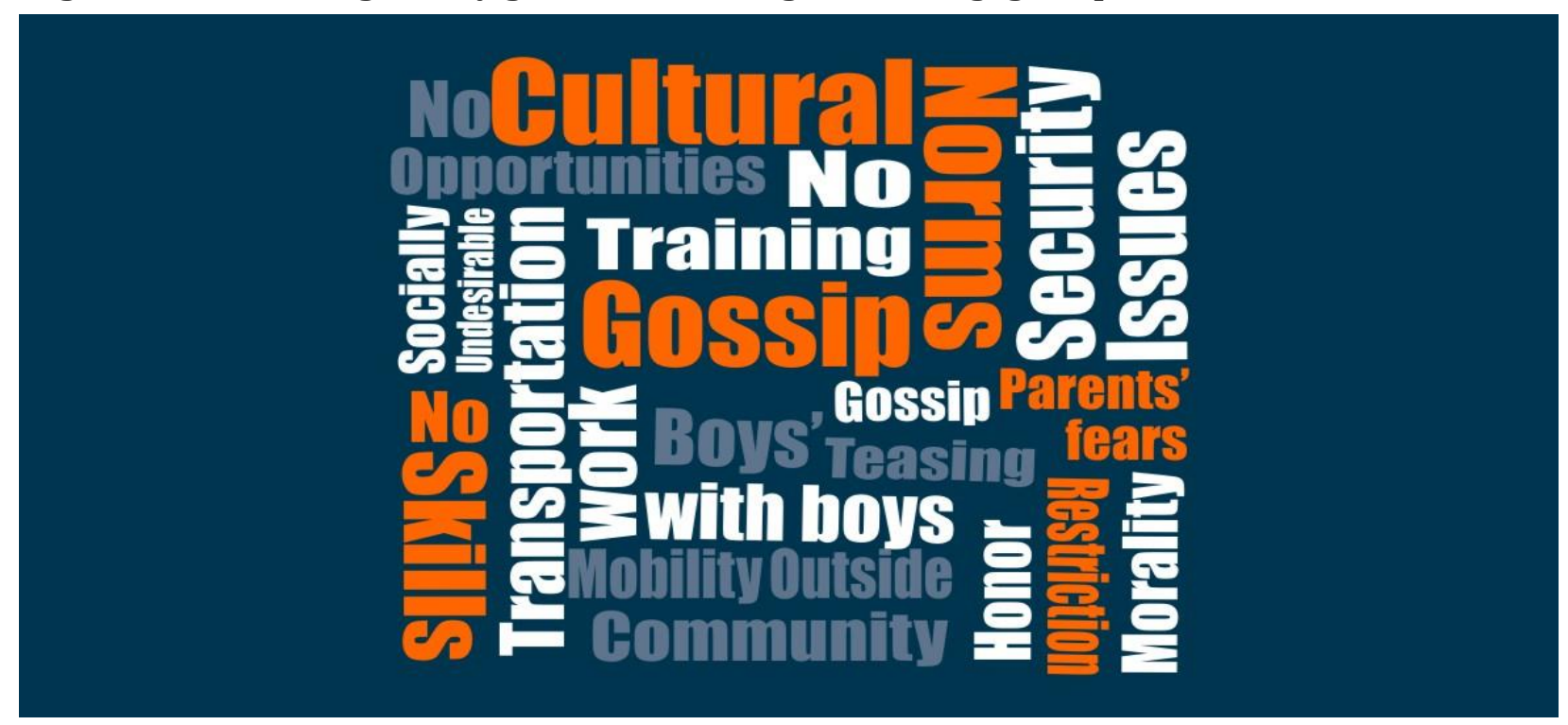




\subsubsection{Discouraging Norms and Community Pressure}

In the patriarchal cultural context of the study communities, male members of the family are seen to be responsible for working and fulfilling households' financial needs, whereas females are seen to embody the honor of the family, which must be guarded closely. In traditional and rural settings, a girl stepping out of the house alone, especially for work, is not viewed as socially acceptable. Rural girls and fathers from all three districts emphasized this issue. In spite of the fact that girls themselvesand sometimes even their parents-wish they could be involved in economic activities, they fear that it would evoke considerable resistance from family and community members, demonstrated in negative behavior such as taunts and gossip.

Even if the girls were ready to confront such social risks, they do not have the power to act independently. Various studies show that females in Pakistan, particularly those who are young and live rurally, have limited autonomy to make decisions about whether to work, as well as about the nature of that work. Using data from the Pakistan Integrated Household Survey (1998-99), Naqvi and Shahnaz (2002) found that in contrast to older, educated and urban women, younger, poorly educated women from larger families do not enter the labor market out of their own choice. Decisions about whether they go out and get a job are made by other household members, at times even without any consultation. Likewise, Sathar and Kazi (2000) found that only 31-41 percent of women in Punjab have the autonomy to decide to work outside the home. The findings of the current study suggest that girls aged 15-19 are not among these women. All respondents indicated that girls have to do what their parents-and particularly their fathers-decide for them. It is usually fathers and brothers who decide not to send girls out for income-earning activities, in order to avoid taunts and other discouraging responses by family and community members. 
The reason is that nobody values these jobs here. Instead, people make up stories, and I do not want to hear their talk. Also, there is no special advantage in doing these types of work here, so I just do not feel like doing them. Yes, it is my wish to earn and work on my own but the environment here does not allow it. IDI-Girl-Rural-Kasur

We cannot send a lone woman out to work. This is against our Baloch traditions. That's absolutely true. FGD-Fathers-Rural-Rajanpur

Girls do not work because they are scared that people will speak ill of them. They think it is better to stay at home than to go out and listen to people gossip about them. The girls are not allowed to work by their fathers either. FGD-Mothers-Rural-Faisalabad

Cultural norms that severely restrict female mobility; segregate activities of men and women; and make paid work outside the home socially undesirable could be a key reason why large proportions of economically active rural women work on their own farms as unrecognized members of the productive labor force (Khan 2007, citing Kazi 1999).

\subsubsection{Parents' Fears about Girls Working with Men}

In addition to the unsupportive community environment, parents are held back from letting their daughters work elsewhere by the common stereotypical mindset that a girl who works alongside men outside the home cannot be of good character. This issue was particularly reported by mothers from the central districts, from rural and even urban areas. Mothers felt that when girls and boys work at the same place, it inevitably leads to undesirable relationships and activities between them. The environment provides an opportunity to interact with the opposite sex and to be "corrupted," through working and eating together. During an FGD with girls in Kasur, it was mentioned that two girls who had been working at a nearby factory had run away with the boys they worked with. This incident made fathers more careful and strict about girls working outside the home. Owing to fear of what might happen, factories are generally not regarded as suitable workplaces for girls by their fathers and brothers. They dread that the girls might "get involved in something" or that "people will gossip about them," leaving their honor open to question.

Whilst this impression was not voiced as strongly from Rajanpur, this is probably because the prohibition on girls' working at factories is even more entrenched there. The girls have almost no exposure to work at factories; instead, they work with their family members in the fields.

Girls like us cannot go to work there because young girls and boys are not allowed to work together. Our families are not in favor of girls and boys working in the same place. They think it is not a good thing and it affects the environment. Parents get scared when they look at what's happening in the world. They fear that their children might indulge in some wrongdoing, be it at the factory or any other place. FGD-Girls-Rural-Kasur

They work in the factory for 12,000 rupees, and then they have tea there with boys and get spoilt. Mostly girls get corrupted because of it. People do not send their girls out because of this fear too. 
(Although) If a girl is 16 years old, she gets only 4,000 rupees from working at someone's home when she could earn 12,000 in a factory. FGD-Fathers-Urban-Faisalabad

\subsubsection{Lack of Work Opportunities for Girls}

A fundamental reason cited for girls' not working was that opportunities are simply not available within the community. This reason was reported by most respondents across the districts, especially in rural areas. Girls' mobility is restricted by cultural norms, and they are not allowed to move outside their communityespecially for work. This was one reason given for why girls do not work at factories, which are located near the study communities but at some distance, particularly in Rajanpur.

Furthermore, it was generally perceived across districts that OOS girls can only do limited types of work, such as stitching, embroidery, or farm work, and do not have the larger range of options that educated girls have. Within this narrow range of options, girls from Rajanpur reported that they considered stitching and embroidery to be a better choice than going out to assist their parents in the fields.

Collectively, the responses seem to indicate that the lack of opportunities is largely perceived to flow from cultural norms and practices imposing strong restrictions on what girls can and cannot do. Therefore, respondents can only conceptualize work options that are in their immediate vicinity and, moreover, restricted to activities considered part of the female domain.

Studies indicate that caste and kinship structures can further limit work opportunities for the poorest women workers (Collective for Social Science Research 2004). In a study of marginalized girls in three poor communities in Sindh, many of the girls interviewed cited their caste as a major barrier to realizing their life aspirations (Plan Pakistan 2015). This notion is also corroborated by the current study. A few fathers from Rajanpur said during FGDs that they belonged to the "Baloch" caste, and therefore do not like to send their daughters out for earning, especially in an environment where boys work alongside girls.
Case Study 3

"I could at least lighten my family's burden"

My name is Amina. I have studied till fifth grade. I was very keen to earn money and support my family. I wanted to start stitching and embroidery work from my home in order to earn money, so that at least my siblings could study in school. Being a girl, I was not allowed to work outside the home, so this seemed very suitable work that I could do sitting at home.

However, there is no one in my village who can train me on how to do stitching or embroidery work. I cannot even leave the house to learn and even if I was allowed, I don't have enough money to attend such training.

So I go with my parents to harvest wheat from the fields and that is how I earn money. I think sometimes, that if I could do some other work, I could at least lighten the burden of my family and support them so that we too could live in peace.

(Raianpur)

There are a lot of problems in employment. For example, this sort of earning is not considered appropriate where our daughter has to sit among unknown men. I can never think about such an employment. This type of earning is not good. This is against our Baloch traditions. FGD-Fathers-RuralRajanpur 


\subsubsection{Lack of Training Opportunities}

Mothers from all three districts and fathers from Rajanpur also pointed to the non-availability of training centers where girls could learn vocational skills, mainly referring to stitching and embroidery skills. They also mentioned that the cost of sewing machines was beyond their reach. Without training and resources, the girls cannot learn new skills or apply these to earn an income. This challenge was particularly stressed by fathers, who were more strongly against sending girls out of the home to earn.

There is a VTI (vocational training institution) operating some distance from here. They teach stitching and computer work to girls. But the problem is, every girl cannot go to the VTI. We want that a facility be present in our vicinity to give training, like that VTI is providing to girls. They must teach stitching, embroidery, computers, and other skills like these. FGD-Fathers-Urban-Rajanpur

\subsubsection{Security Issues}

In one or two FGDs with girls and mothers, mainly in Faisalabad and Kasur, the problem of security was also raised. Respondents mentioned that girls can be harassed by boys on the way to work and therefore a member of the family needs to accompany them. Mothers in an urban community in Kasur pointed out that it was difficult for male family members to spare time to accompany the girls. Overall, however, this issue was mentioned far less frequently and with less intensity than it had been cited as a reason for girls being out of school. This could be because the majority of girls were not involved in paid work, and so respondents had negligible experience of these issues. Another possible reason is that parental and community resistance to girls' working in the first place is a more fundamental barrier.

\subsection{Boys' Participation in Economic Activities in the Study Communities}

According to the Pakistan Labour Force Survey 2014-15, about 48 percent of 15-19-year-old boys participate in the labor force, compared to only 18 percent of girls. Thus, boys' involvement in economic activities greatly exceeds that of girls. This situation is clearly captured in Figure 2.1 (in Chapter 2), which shows stark differences in the life trajectories of older adolescent girls and boys, particularly in terms of participation in economic activity. While boys also drop out of school as their age increases, contrary to girls in the same age group, their involvement in economic activities also increases with age. Looking at district patterns, the largest proportion of OOS boys involved in paid economic activity is in Rajanpur, followed by Kasur and Faisalabad. The percentages of boys who are OOS, not working and not married are far lower than those of girls, particularly in Rajanpur, possibly because they are compelled by poverty to provide financial support to their families.

The above inference from secondary data was generally endorsed by respondents during FGDs. It was reported that most boys who are not going to school start earning, at least through some nominal job, or get involved in farming to assist their fathers, especially in Rajanpur. In fact, in one rural community in the district, respondents said there was not a single OOS boy who was not engaged in some economic activity. However, a few girls and mothers from Faisalabad and Kasur districts mentioned 
that some boys are neither interested in studies nor in work, indulge in drug abuse, and are idle; very few such cases were mentioned in Rajanpur.

Direct interviews with boys were not included in the scope of this study, but girls, mothers, and fathers were asked about the jobs boys do in their communities. The purpose was to identify the employment options available for them, and also to obtain girls' perspectives about whether they might contemplate doing similar jobs. Responses indicate that boys in the study communities are involved in a range of work activities, with some variation across the three districts. Boys in Faisalabad were reported to be working as laborers at textile mills and garment factories, electricians, and assistants in shops and general stores, in addition to assisting in tailoring, farming, and masonry work. In Kasur, boys were reported to be working in textile mills and other factories where they packed food items, as well as in shops. Boys were also engaged in the repair of mobile phones and motorbikes, farming and livestock rearing, and working as drivers and hawkers. Boys from Rajanpur were reported to be working as hawkers; shopkeepers; carpenters; mechanics for repair of mobile phones, motorbikes, and tractors; computer operators; shoemakers; masons; electricians; and also as farmers.

The boys do farming, go to factories, or they learn computer work from a company. Some study.

Some do work on daily wages. Some grow vegetables. IDI-Girl-Rural-Kasur

Most of the occupations reported for boys were similar across the three districts. The main difference between the central and southern regions was the presence of a number of industries especially in Faisalabad, giving boys here a wider range of options than their peers in Rajanpur.

When girls were asked whether they would like to do the same work as boys in their areas, most responded in all three districts that they could not do the same jobs as boys, except for a few options that did not require physically demanding work. These options included mobile phone repair, computer-based tasks and factory work, as well as shop-keeping. Even when girls identified these activities as not demanding rigorous labor, they pointed to other constraints, such as the need for training to acquire skills for mobile repair and computer use; the need to base shops within their own homes; and the need for a separate section where girls could work in factories. However, mothers mentioned that computer- and mobile-related work could only be done by educated girls, therefore OOS girls had limited options, and they could only do farming-related activities.

Girls cannot do the tasks meant for boys. They can work on computers though. She can do if she is educated. If she is not educated, she can only sew clothes. FGD-Mothers-Urban-Rajanpur

Girls cannot do the same work as boys. Girls can do electrical work like repairing fans at home. But only if there is someone to teach her at home. She cannot go out to learn it from any stranger of course. It would be better if there was some woman to teach them all this. FGD-Mothers-Rural-Kasur 


\subsection{Preferred Work Spheres for Girls}

The OOS girls, mothers, and fathers were asked what type of economic activity NEEM girls could engage in. A major point on which all respondents agreed was that, while it was acceptable for OOS girls to work for income, the work should be a home-based activity or at least be available within the community. This condition was aimed at minimizing the perceived risks of undesirable social activities and social censure discussed earlier.

In terms of specific economic activities, respondents could only name a few traditional activities. The option cited most frequently, in both urban and rural areas, was stitching and embroidery, followed by beauty care services, which were mainly mentioned by girls themselves. In addition, mothers especially mentioned that girls could provide home-based packaging services for garments and food items. A girl interviewed in Rajanpur said OOS girls could also be Lady Health Workers (LHWs), as their work was restricted to the community. Running tuition centers was mentioned as a preferred option for girls, although it is not feasible for girls who have not completed their education.

\subsubsection{Stitching}

The majority of study respondents expressed a strong preference for stitching work, as girls would not have to leave their homes to do it, and moreover, they would only be dealing with female customers. The girls had a strong desire to start this activity for income generation. The main obstacles they mentioned were their own lack of skills and the absence of any help or training source within the community. In a very few cases, they also mentioned that they could not afford to purchase a sewing machine or pay for training. It is important to note that girls from both urban and rural areas have an interest in this option, while most mothers and fathers find this to be the only occupation appropriate for OOS girls.

I would be able to stitch my own clothes and my parents' too. I would also stitch clothes for women in my neighborhood and collect some money that would be helpful for making my own dowry. Yes, I will do a home-based job like stitching if someone trains me for it. I want you to teach me stitching. IDI-Girl-Urban-Faisalabad

\subsubsection{Beauty Care Services}

The majority of girls in both rural and urban areas, especially from Faisalabad and Kasur, mentioned that they would like to work as beauticians and set up their own beauty salons. They highlighted the feasibility of such work, pointing out that it could be done inside the home and would enable them to earn more to support their families. The girls were also aware that training to provide such services is expensive, and said their inability to afford it was a key challenge. Interestingly, while beauty care is the main preference of the girls themselves, mothers did not mention it as a preferred option.

If I learnt parlor work there would be some addition in the earning of the household. This could solve the problems of our home. I have an older sister at home; we have to marry her. Obviously if there was money at home, only then her marriage could take place. One of my father's eyes is also damaged-I would get that treated. FGD-Girls-Urban-Kasur 
Overall, all respondents, including both parents and girls, have very limited vision about possible employment options for girls, especially for those who are out of school. Girls from Rajanpur particularly expressed their helplessness due to poverty and lack of education, saying they have no option but to work in the fields.

No work can be done here. There is a lot of poverty. Girls can only earn money through cotton picking.

After cotton, there is the wheat season. That we cut with tractors. IDI-Girl-Rural-Rajanpur

The above responses indicate that culturally defined gender differences in the household, alongside perceptions of a strong gender division of labor, have a strong influence on respondents' preferences regarding employment options for girls. For boys, parents do not worry so much about mobility, distance to the workplace, security, or even that boys are working in an environment where girls are present. In marked contrast, all of these issues are priority concerns in considering work options for girls.

\subsection{Scope for Expanding Work Choices for Girls}

When girls, mothers, and fathers mentioned only a small number of work options for OOS girls despite exhaustive probing, they were prompted by interviewers with a list of additional options, to gauge their response to each. The purpose was to make them think about the possibility and feasibility of other, relatively out-of-the-box, options.

Give us some options and we will tell you which ones the girls can do. Otherwise we will only want them to do stitching work. FGD-Mothers-Rural-Faisalabad

The respondents' reactions to various suggested activities are described below.

\subsubsection{Online Work}

Girls from both rural and urban areas in all three districts showed their interest and willingness for online work, although they generally perceived that computer literacy requires education, which they lack. A few girls and mothers rejected the option outright, saying it could not be done without a certain level of education and was therefore not feasible for OOS girls. However, most girls and mothers were interested, and felt girls could do such work after the necessary training. There was one urban community in Kasur where seven girls mentioned during the FGD that many girls were already working online on computers. They were aware that short courses could be taken to develop the necessary skills, and expressed their need and desire to attend such training, preferably within their community. Interestingly, while mothers did not have a clear idea of how online work could be done, they were enthusiastic and keen about their daughters getting training and a chance to participate in such work.

If you teach us how to work with computers, then it is possible. There are many people who are not very educated but they know how to work on computers and are earning quite a bit through this. FGD-Girls-Rural-Kasur 
Yes, I am very interested. I keep on learning about it from the children in the family and they often ask me why I don't know it already even though I am older than them. Then I tell them that nobody allowed me to go to school so I could not learn it. IDI-Girls-Urban-Rajanpur

\subsubsection{Mobile Repair Work}

The idea of mobile repair work was received more positively by the girls than by mothers. A general view was that mobile repair work could not be done without education and training. Nevertheless, about half the girls who participated in the IDIs and FGDs, mainly those from Faisalabad, said they could learn and do this work. One of the girls from Rajanpur commented that her brother does mobile repair work and, by observing him, she has learnt enough to do such work already.

They (girls) will. There is no job that girls can't do if they are passionate about it. My brother repairs mobile phones at home and I have learnt to do that too, by observing him. If any mobile phone stops working, I repair it on my own. IDI-Girl-Rural-Rajanpur

However, some girls felt that mobile repair work was not a feasible option due to their lack of education; because their community environment was not conducive; and because their parents would not give them permission to learn this work. They preferred to earn money from a more traditional option like stitching or beauty care.

These jobs require you to have the proper diploma first, and that will require me to go out of my home. My family will not give me permission for that. IDI-Girl-Rural-Kasur

Most mothers opposed the idea of girls repairing mobile phones to earn money. In all three districts, they said that the girls would not get permission from their fathers and brothers to engage in this work. They did not find the occupation suitable because girls are not usually allowed free access to mobiles. Nor can they set up shops, or provide repair services from home, because it would not be appropriate for boys and men in the community to visit them. Mothers were further concerned that if the girls pursued this line of work, people would talk, accusing the girls of not just repairing mobiles but also talking to paramours on their phones. They even feared that this situation might actually materialize, as having access to phones would increase the chances of girls "getting corrupted."

The girls will not do mobile repairing work. Here in our village, people even accuse mothers (of misuse of mobile phones), and you are talking about girls repairing mobiles for different people and boys? They cannot. FGD-Mothers-Rural-Faisalabad

People will say, "God knows who she is talking to on the phone." People blame others easily. A woman cannot open her own mobile repair shop. FGD-Mothers-Urban-Kasur

\subsubsection{Processing of Dairy Products}

The option of processing dairy milk products was appreciated by the majority of rural girls and mothers. Respondents, especially from Kasur and Rajanpur, said this work was feasible because a number of girls from both of the districts were already assisting household members in selling milk and 
processing dairy products, such as butter. Although some girls were not very keen to do this work due to the stringent schedule it demands, they said they could take it up as a proper and independent economic activity. Girls and mothers from Faisalabad were particularly interested in selling packaged milk and dairy products from home, provided they had livestock. One of the major attractions of this economic activity was that it is home-based.

We have cattle. We like the work of taking care of these animals and the girls can sell butter. We sell milk from home. Customers come to our homes to buy milk. So why would our girls go out to sell it? FGD-Mothers-Rural-Rajanpur

On the other hand, girls and mothers from urban areas did not find this a suitable occupation for girls as it would not be feasible to maintain livestock in their urban communities.

\subsubsection{Work at Factories}

Very few girls in Faisalabad and Kasur were interested in working in factories. The majority of girls did not want to join factories due to their apprehensions regarding issues of mobility, access, and transport (since factories are usually situated far from communities), and also because of the potential problems associated with working with male co-workers. Mothers and fathers were also reluctant to send girls outside their home to distantly located factories where they felt the environment was inappropriate for girls. In Rajanpur, where there are fewer factories that are situated much further away from the communities, girls did not like this option.

Nobody will allow us to work in the factories. They will simply say, "What do young girls have to do in factories? Sit at home and try to live within what we are bringing home." If the work is given to be done at home, then it is all right. FGD-Girls-Rural-Kasur

The girls living in the village cannot work in a factory. They will not be allowed to go that far. FGDGirls-Rural-Rajanpur

That's not appropriate work for girls. He (My father) says that boys and girls work together there and talk to each other, which is not a good thing. They cannot let me go alone. IDI-Girl-Urban-Kasur

\subsubsection{Community Health Work}

When asked whether they would be interested in community health work, girls from Faisalabad and Kasur said they would need to be educated. However, girls from both urban and rural areas of Rajanpur, apparently not considering the need for education, said their parents would permit them to work as community health workers. They admired the Lady Health Workers (LHWs) in their communities and had some understanding of their role. They knew the job required mobility, with visits outside the community as well, but felt this issue could be addressed with the provision of a vehicle.

We will get permission to work as polio vaccinators if we are accompanied by our brothers. We will have someone to accompany us. Girls have already done this job in our community. FGD-Girls-RuralRajanpur 
The LHW goes for polio vaccination on foot but if she has to go to some other locality then she has to have her own transport. That is why it is necessary to have a vehicle and a driver so that there is no commuting issue. FGD-Girls-Rural-Rajanpur

The above findings suggest that girls are relatively receptive to the idea of adopting new professions, such as online computer work, mobile repair services, and beauty care, indicating some margin to expand income generation opportunities for them. However, the discussions also strongly suggest that girls and their parents prefer jobs that the girls can perform from home or at least within their community, and that do not require interaction with males.

Girls are generally attracted to a wider range of options than their parents. They want something new and exciting, especially beauty care work, which might be more aligned to their more youthful interests. They are relatively skeptical about options built around what they already do, perhaps because they do not see them as having transformative potential. In contrast, parents are conservative in their thinking and are attracted to options that do not rock the boat. Actual interventions may need to balance these seemingly contradictory motivations.

\subsection{Respondents' Suggestions for Persuading Parents to Permit their Daughters to Work}
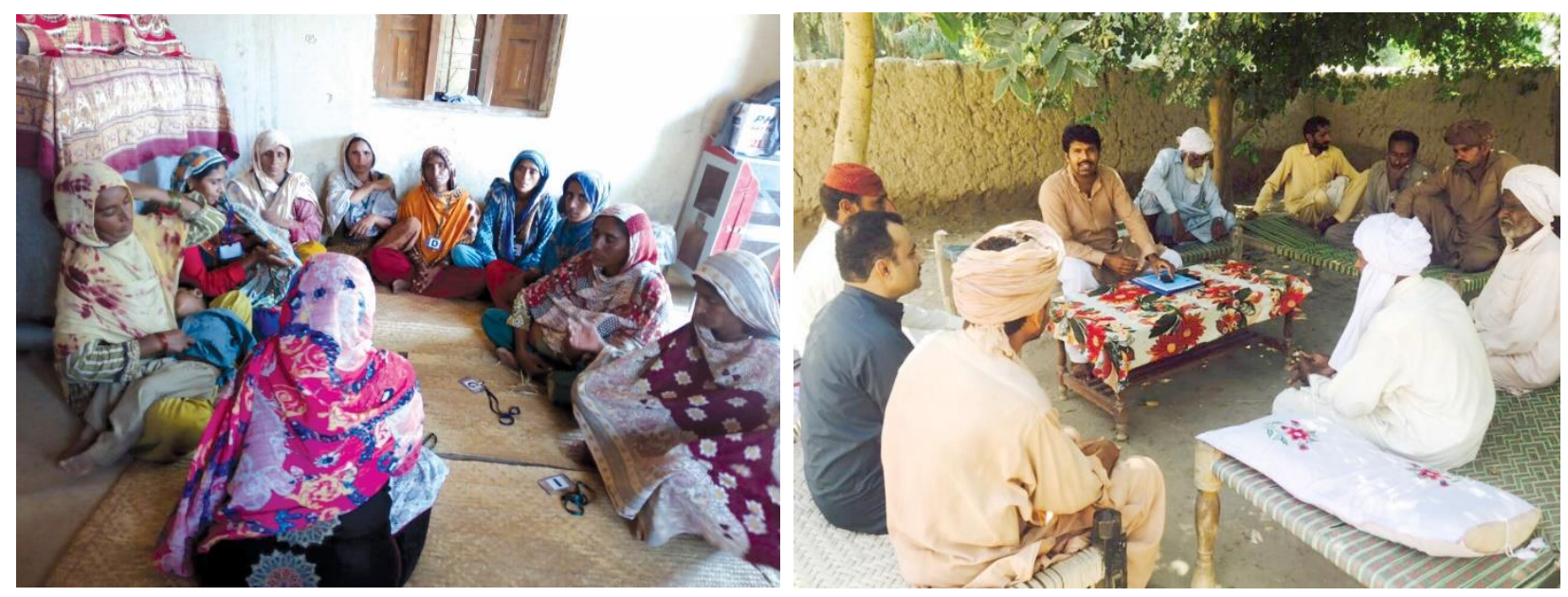

In contrast to the rich discussion on ways in which girls might be assisted in resuming their education, the conversation about their potential employment was somewhat restricted. Mothers and fathers were able to suggest only a few measures to persuade parents to allow their daughters to work. This difference in responses seems to be due to the fact that girls' education is seen as a positive outcome, while girls' employment is not yet seen as socially approved or free of social risks. Girls from all three districts emphasized the need to convince their parents to allow them to work. Parents' resistance to girls' working is either due to poor security or social pressure, in varying degrees. The girls suggested that if some elders in their family could be involved, they might succeed in convincing their parents to let them work. 


\subsubsection{Training and Work Opportunities within the Community}

A point that came up time and again in the discussions was that opportunities for training and employment of girls are not available within communities. Girls need to go out to find work, which entails a number of other problems, such as transport, security, and also social issues. Both girls and parents perceive that if work opportunities were available within their communities, girls would more frequently be allowed to work.

Due to this concern, mothers and fathers emphasized that girls should be involved either in stitching and embroidery or in beauty care work, so they can stay at home or within the community. The necessary training facilities should also be available within the community. Girls from all three districts strongly asserted that if there were such facilities inside their community, they would all get permission to work.

If someone could visit our relatives' homes and train us there, then I could get permission. My cousins are taught by a lady like that. I could open a beauty parlor for myself then and I could independently earn for myself. IDI-Girl-Urban-Rajanpur

We can send them out to work within our own village. We cannot send our daughters outside the village. They must learn how to work and it is enough for them to learn stitching. They have interest in that. Those who have learnt the skill will definitely work, but inside the home or community. FGDFathers-Rural-Faisalabad

\subsubsection{Safe Transport Arrangements for Work outside the Community}

Regarding the possibility of work outside the community, parents and girls were of the view that arranging transport for girls would address some concerns of parents. Evidence of this was observed by the study team, especially in Faisalabad: women from a number of communities were working in factories, and in all of these cases, transport was being provided by the employers.

Fathers do want that their daughters work. Girls are making so many things at their homes and they sell these things. We say that, here, small (training) centers must be established. If someone can provide pick and drop services to access these centers, then parents will give permission. FGD-FathersRural-Rajanpur

\subsubsection{Gender Segregation at Workplaces}

Parents and girls also strongly suggested that if there were arrangements for girls to work in separate female-only sections at factories, they would be allowed to work there. This point of view was reported from all three districts, and is obviously related to widely prevalent apprehensions among parents about the possible social risks of girls interacting with boys.

Girls like us cannot go to work there because young girls and boys are not allowed to work together. Our families are not in favor of girls and boys working in the same place. They think it is not a good thing and it affects the environment. Parents get scared when they look at what's happening in the 
world. They fear that their children might indulge in some wrongdoing, whether at the factory or any other place. FGD-Girls-Rural-Kasur

\subsection{Perspectives of Employers on Girls' Employability}

A total of nine employers at factories, three in each district, were interviewed during the study to learn about their perspectives and attitudes towards girls' employment; their reasons for employing (or not employing) female workers; and options for enhancing female employability. Speaking to employers was useful in understanding the supply side of the picture, in terms of the actual context in factories, and the extent to which their views corroborated or negated the concerns of parents.

Of the nine factories where employers were interviewed, only four employed females. These included two cotton sorting concerns and two garment factories, one of each type in Faisalabad and Kasur. Those that did not employ females, included a paperboard factory in Faisalabad, a garment factory in Kasur, and all three factories visited in Rajanpur, which included cotton ginning concerns and a garment factory.

In Faisalabad, employers said they did not have any particular criteria for employment in terms of educational qualifications or skills; staff were hired and then trained. However, in Kasur, employers mentioned that they only employ skilled workers and young employees, so that work could proceed efficiently.

We prefer skilled people and the age factor also has to be noted because young people are much more active and can work under pressure. Then we pay some allowances or overtime to them. Employer-Faisalabad

When asked for their view of girls' employment, all interviewed employers gave a positive response. In principle, they supported girls' employment in factories and emphasized that such work would not only be beneficial for girls, but would also prove advantageous to factories themselves, as female employees usually work more diligently. They were of the view that if the nature of the job and place were suitable, then females should certainly get a chance. Those who want to work should have the opportunity.

The employers said such opportunities were particularly important where girls could not rely on any other bread-earner or where they had basic education or skills that could be honed at work. Such work could also improve their household circumstances, even after marriage, when they could help their husbands support the household and provide a better standard of living for their children.

It is the need of the times, and also a need from a financial point of view. Only if she works will it (a decent standard of living) be manageable. We will not get anything from keeping our women tied up. If we are getting her educated, then there should be some application of that education too. Even

village women are working and they work equally with men. So the solution is to provide them opportunities for their betterment. Employer -Rajanpur 
Female employees are better than boys because they concentrate more on work and are consistent. For example, if they work in a cotton recycling factory where they are sorting pieces, where boys sort 100 pieces, a girl will sort 150 pieces in the same time. Employer-Faisalabad

\subsubsection{Reasons for Not Employing Females}

The five employers whose factories had no female employees were asked why they did not employ women. The employer at the Faisalabad paperboard factory responded that the work at his factory involved hard labor, which was not feasible for girls. At the garment factory in Kasur, the employer said that it was a small-scale setup, where it was not possible to provide a separate work space for women. Echoing the apprehensions voiced by parents in communities, the employer said women preferred not to work in such an environment.

Employers from Rajanpur listed multiple reasons for female workers not being employed, most of which related to concerns voiced by communities. For their own part, they said, employers were not reluctant or opposed to employing women or girls. They explained that in the local social environment, women did not work at factories, and people feared they would confront social pressure if they sent their female relatives out to work. Girls working, in particular, is not considered good in the family or community and looked down upon. An employer running a cotton ginning factory said that the work involved heavy labor, which is why female employees could not be hired. Another reason mentioned was that since men or boys are present in large numbers at factories, women do not feel comfortable working there, and do not apply for jobs. Generally, all employers also said there was a lack of opportunities for girls, and that they face greater commuting and security issues.

Employers also commented that even where parents might be willing to let their girls work at factories, they did not have information about which factories did employ girls, and which did not. They did not try to seek information from the factories, and employers simply hired workers who contacted them for jobs, who were mainly boys. Another challenge for girls' unemployment was that some types of factories, such as textile mills, require skills and experience, which the girls could not offer, especially as they had no opportunities to train.

People don't have the mindset and parents are not aware about resources like this that could help them even after marriage. There's no awareness and then there are certain circumstances under which girls can't work. Then there are social issues, like issues at home and in the family. EmployerKasur

\subsubsection{Suggestions for Increasing the Employability of OOS Girls}

Employers suggested a number of ways to increase the employability of girls in factories. First of all, they emphasized across the districts that attainment of some technical skill is very important for girls to get a job. Employers from Rajanpur suggested that the government establish vocational training centers for girls so that they can acquire skills to be able to get more jobs, whereas employers from Faisalabad suggested that existing vocational centers for girls be better utilized. 
They also mentioned that changing negative attitudes associated with girls' working and provision of separate work sections for girls and boys working in factories would increase employability for girls, as would provision of a transport facility by the employer to address girls' commuting and security issues.

If girls grasp a single skill and become experts in that skill, then that is of great importance and value too. Employer-Kasur

People do not look at working girls respectfully. If these attitudes were eliminated from society, girls would never be sitting idle at home. They would earn for their families. In my opinion, the first and foremost thing is security. Employer-Faisalabad.

There must be a privacy. Secondly, there should be a friendly environment so that their parents can visit if they want to. Employer-Kasur

\subsection{Conclusions}

The findings presented in this chapter lead us to the conclusion that there is a huge difference in the value attached to educational attainment and to employment among girls. It is considered respectable for girls to attain an education, but their employment is generally not appreciated by the community. This is largely due to gender norms that associate honor with women's conduct, and strongly discourage the free interaction of males and females, especially for unmarried females. The challenges associated with involving OOS girls in economic activity are clearly more complex than the schooling issue.

Girls' desperation to resume education is far stronger than their desire to be involved in employment. Most respondents, especially the girls themselves, generally perceive that work opportunities are limited by lack of education. Even then, there is also a realization that engaging in paid economic work would improve their lives by providing them a better standard of living; earning them respect in the household; increasing their say in decision-making; and strengthening their capacity to cope with challenges, including problems after marriage. These girls would also feel great personal satisfaction as contributors to their families' financial uplift.

Discussions with study respondents suggest that girls from the central districts, especially Faisalabad, at least have a range of employment options available, because there are factories in the vicinity. However, girls are usually not working here to the extent that they could. On the contrary, in Rajanpur, such opportunities for females are limited because factories and industries are few and far between. Nevertheless, women and girls in the district are contributing to their household economy though informal and unpaid farming-related activities.

Employers at factories in the vicinity of study communities are at pains to emphasize that their doors are open to female workers, and that they would even prefer girls and women, as they are perceived to work more responsibly. However, parents are not receptive to girls working at factories, primarily because they would be working alongside males. Provision of gender-segregated work spaces and transport arrangements from the employer are suggested by both parties as measures that might 
make it possible for girls to work in factories. In addition, employers suggest that girls acquire specialized technical skills to enhance their employability.

Parents, however, have a strong preference for girls to be involved in home- or community-based work, in spheres that would not involve interaction with males, with training support also provided within the community. The main spheres of work of interest to respondents include stitching and embroidery, home-based packaging work for factories, dairy product processing, and online work. In addition, girls themselves are keen to take up beauty care. They are also interested in mobile repair work, but their parents do not like this idea, as it would give them access to mobile phones and also involve interaction with male customers.

Overall, the findings presented in this chapter suggest that girls in general, and their parents in particular, are not as enthusiastic about girls' participation in economic activities as their education. The girls do see paid work as an alternative pathway to empowerment, but are not sure they would get far without an education, and especially, without the approval of their parents and communities. However, respondents are certainly receptive to the idea of paid work and are willing to consider viable options. Parents may not be willing to compromise on gender segregation and security, but are open to training and work opportunities that can enhance their girls' productivity without exposing them to social risks. 



\section{Chapter 6}

\section{Discussion and Recommendations}

\subsection{Discussion}

This qualitative study of the lives and perspectives of NEEM girls in nine urban and rural communities in three districts of Punjab suggests that the girls interviewed currently have few opportunities to develop their productive potential. Furthermore, the girls are acutely aware that in the absence of such investment, they will continue to have little say or control in their lives. If they are to be equipped for a more empowered life as adults, urgent attention must be given to creating opportunities for them to complete their education to the extent possible; to grow in life and livelihood skills; and to acquire the confidence and agency they will need to carve out spaces for their voices and actions in environments that traditionally marginalize them.

The study's findings on how adolescent girls use their time suggest that they are working hard, both as unpaid workers and especially through their heavy contribution to domestic duties. There are some variations in the pattern across districts, the most conspicuous being the heavier involvement of girls from Rajanpur in unpaid agricultural labor. The girls are clearly dissatisfied with this state of affairs and would like to see change. They are poignantly aware that their capacity to make sense of their world and to deal confidently in society is compromised by their lack of education. They express an inhibiting sense of inferiority to the peers they see going to school. They also see quite clearly that their brothers, by virtue of contributing to the household income, enjoy respect in the family and a say in household decisions that is denied to them. This is because their own efforts, however important to the household, do not generate money. Girls yearn to resume their education, and in spite of their hopelessness, they aspire to be breadwinners, heroically coming to their parents' financial help, and inspiring the respect and solicitous attention they see lavished on male family members.

The study has probed deeply into the reasons behind the derailing of girls in the studied communities from a more productive path, beginning with why they are not in school. The reasons given by girls, as well as their parents, largely confirm the findings of other studies. Schools are either not available within the communities, or if available, are not gender-segregated. Since private schools are unaffordable for poorer households, only public sector options are viable, and even then, the indirect costs associated with sending the girls to school, such as buying school uniforms, can be prohibitive. Sending girls out of the community raises a plethora of issues, such as the risk of sexual harassment or abduction; the unavailability and unaffordability of transport; and the need for a family member to escort them. And then there are problems at school itself. In addition to the lack of girls' schools, female teachers, absenteeism, and the persistence of corporal punishment-which other studies have also documented-this study reveals a disturbing pattern of forced child labor in some schools, with teachers exploiting students to clean and cook, both at the school premises and in their own homes. Many girls still bear scars from the emotional wounds inflicted by their teachers and peers on account of their difficulties in learning and their poverty. 
But there is a silver lining. Everybody, including the girls, their mothers, their fathers, and their communities, would like to see girls complete their education. The girls' being out of school is not seen as a desirable situation. On the contrary, it is considered highly respectable for girls to attend school, provided this does not involve interaction with male peers or teachers. In other words, the reasons for girls being out of school have to do with the accessibility and quality of schools and with the financial and family circumstances of households, rather than norms or social disapproval that discourage girls' education per se, which were identified in earlier literature (e.g., Sathar et al. 2003a, Purewal \& Hashmi 2014).

That said, the poorest parents do want evidence that educating their children will translate into economic benefits. Their distressed circumstances do not allow them the luxury of foregoing their children's direct or indirect support to household income for anything less. They are also skeptical after seeing young people complete their education, only to return to work in the fields or be consigned to low-paid jobs. This concern is particularly relevant to boys.

While this study did not include conversations with boys, it did explore their reasons for dropping out in conversations with girls and parents. Gender differences were apparent: the foremost reason given was that the boys themselves are not interested in continuing school. Other reasons included the need for boys to work and contribute to the household income, a perceived lack of economic benefit from education, and inability of households to afford the expenses of school.

The outcomes of leaving school are clearly quite different for the two sexes. As indicated in this study's analysis of young people's transitions, most of the boys who are out of school in the study districts join the work force and start earning. This situation is not ideal and entails certain risks, but it does provide boys access to a wider social network, opportunities to learn life and livelihood skills, an income, a chance to build their confidence, and a higher standing in their homes and communities. On the other hand, most of the girls who leave school can look forward to little besides domestic chores and helping their parents in their economic activities. Their life is in the doldrums, and the girls are surprisingly perceptive and articulate about this: they know that education is a pathway to a better life, and they are very fearful that they have missed the boat while their more fortunate peers are forging ahead. The parents of adolescent girls, especially mothers, are worried too, and state categorically that they would not deprive their daughters of an education, and everything it implies in terms of improving their life and future, if the matter was in their hands. The problem could be resolved, according to respondents, by providing financial assistance to girls' households and setting up girls' secondary schools within their communities, or providing them safe transport to access such schools.

In marked contrast to the enthusiastic support for facilitating girls in education, the study finds a more tempered response to the idea that they participate in paid work. The girls have dreamt of being teachers, doctors, and even military personnel; want very much to play a role in lifting their families out of financial difficulties; and are well-aware that such a role would not only empower them in their current households, but also afford them more choices when they are married. Yet they approach the idea of commencing work in their current stage with some trepidation. This is partly because they feel ill-equipped without a complete education, and partly because they expect resistance from their parents and wider community. 
The girls' latter concern is quite valid. Discussions with mothers, fathers, and influential community members indicate that the matter of unmarried females' going out to work is far more complex than their attending school. While going to school is viewed positively in the community, girls' participation in paid work arouses suspicion and condescension. Parents do appreciate the current and future advantages their daughters might reap from paid work, but they are concerned about the social risks, including gossip about the girls and their families and what might happen if girls work alongside males. They also point to practical barriers such as lack of training opportunities; lack of suitable work opportunities for girls within the community, especially as they are not educated; and the risks to girls' personal security, should they venture outside their community. The strength of responses implies that the availability of job and training opportunities is a secondary concern to the fears of gossip and scandal.

Gender norms appear to be at the heart of this issue. Earning an income is seen to be a masculine responsibility, and the participation in this role of young women-who are seen to espouse family honor-can reflect badly on the adequacy of male members of the household. Moreover, if a girl's job involves interaction with men, it is also considered dishonorable, since even talking to males is frowned upon. Parents fear that their young daughters might become entangled in romantic relationships with male co-workers, an eventuality that has occurred in some cases, and has led to elopements.

In light of these concerns, parents prefer that girls work with them or from home. If they must work alone outside, conditions apply: the workplace must be gender-segregated, and it must either be located within the community--which is preferable--or the employer should ensure safe arrangements for the commute. Respondents' ideas about feasible work spheres for adolescent girls reflect these restrictions. They strongly prefer home- or community-based economic activities, suggesting limited traditional options such as stitching and embroidery, and home-based packaging services for garment and food processing industries. In addition, the girls are keen to take up beauty care, which they feel they could do from home.

Respondents had limited notions of what work girls might do beyond these spheres, and asked the study team to prompt them with options. The discussions that ensued indicate that girls are receptive to adopting new professions, such as online computer work and mobile repair services. In contrast, parents are generally conservative in their thinking, and reject any work that might involve interaction with men, or even provide access to mobile phones; they are attracted to simpler home-based options, like making dairy products, which would not evoke a negative reaction in their communities.

While an assessment of the labor market for girls was beyond the scope of this study, employers were interviewed at three factories in each study district to gauge their position on employment of adolescent girls and young women. The responses of these nine employers are encouraging and indicate that, except in the case of heavy work that would be physically taxing for females, their doors are open for young female workers, who they consider to be more diligent than boys. They are moreover cognizant of the concerns and preferences of people in their surrounding communities, and identify a gender-segregated work environment; provision of transport by the employer; and girls' attainment of technical skills as key actions for enabling more girls to work at factories. 
Overall, the study indicates that the girls are highly motivated, even desperate, to force a positive shift in their life trajectories, especially by resuming their education. Interventions to educate them would be enthusiastically welcomed in their communities, while measures to improve their participation in paid work would be considered and accepted if practical and responsive to cultural sensitivities. In terms of what NEEM girls want, the data collected in this study indicates that about half want to pursue their education, a quarter want to attain any technical skills that might help them earn, and the rest want to be involved directly in some economic activity, deeming further education a waste of time. Encouragingly, the girls are willing to dedicate an average 3-4 hours per day to these activities, by managing their household responsibilities more efficiently and reducing their leisure activities. Given the variation across districts in their current workloads, it is likely that the actual time availability would need to be assessed for each intervention community.

Of the approximately 6 million girls of 15-19 years in Punjab, about 37 percent are neither at school, nor employed for pay or profit, and have not yet made the transition to marriage. The current qualitative study provides important clues about the nature of the barriers that must be addressed-and also how they might be addressed-to provide these girls better opportunities for improving their productive potential. However, given the small scale of the study, and the variations in findings across districts and urban and rural locations even within this limited scale, it must be stressed that the findings of the study cannot be generalized to the population of the province. Further research must be conducted to examine both the lives of NEEM girls in the province and especially the interventions that could improve the opportunities available to them.

\subsection{Lessons Learned}

Based on our field observations and experiences, as well as our findings, the study team has learned the following lessons:

1 One major challenge in conducting this study was the identification of at least 25 girls within each of the nine selected communities who met the specific study criteria for IDIs and FGDs. To complete the set of IDIs and FGDs planned for most of the sites, the team had to visit and work in 2-3 communities adjacent to the selected community. To identify and contact girls of ages 15-19, we had to work with multiple sources, such as the local school administration, teachers, respectable figures from the community-both male and female-and also, in a few cases, educated girls and mothers. Cultural norms severely restricted the mobility of girls in some communities, to the extent that obtaining their parents' consent for their participation was a challenge. This was particularly the case for FGDs, where girls had to step outside their homes and gather at a common place, despite the fact that every attempt was made to find a safe and neutral venue. A female key informant or facilitator from the community remained essential to support the field team.

2 Carrying out field activities in urban areas was in some ways more difficult, due to challenges in contacting cooperative influential community members, the identification of girls who met the study's specific criteria, and getting consent for IDIs and especially FGDs. It took much longer than anticipated to arrange these discussions. These considerations must be 
addressed in the timelines and plans for similar studies in the future, and donors and other stakeholders sensitized to accept this as an integral part of planning.

3 The study focused on examining the lives, aspirations, and perspectives of older adolescent NEEM girls; identifying the reasons for their exclusion from opportunities; and probing the gender norms and behaviors underlying their marginalization. While the study did include fathers, male community members, and employers in the interview schedule, adolescent boys, including brothers of the interviewed girls and others, were not directly interviewed. To ensure a more thorough gender comparison, we recommend that future studies include interviews with adolescent boys. The number of boy and girl respondents does not need to be equal as this risks detracting from the focus on adolescent girls, but ensuring that boys comprise about 30 percent of sample would help achieve a better understanding of masculinities, the boys' roles in relation to opportunities for their sisters and other girls in the community, and their perspectives on how any adverse influences could be reversed.

4 The dominant global gender discourse urges swift action to address girls' and women's strategic needs and to bring about a shift in unequal gender relations. We need to bear in mind, however, the strength of gendered social norms in many communities in Pakistan. In research studies in such settings, the community must be closely involved. We discovered through this study that parents, particularly fathers, and many community members were much more keen to address girls' practical needs than to consider a shift in gender relations. Parents, for instance, expressed their reluctance to let their girls go out and work alongside males; they feared this would inevitably lead to undesirable relationships and activities that could dishonor the family. And even where parents were personally willing, they feared gossip and pressure from the community and thus preferred their girls to work from home, or at least within the community. The findings of this study suggest that working incrementally to address girls' practical gender needs is a good entry point to larger change in communities. We endorse this approach, whilst advocating that even practical steps should be carefully formulated keeping in sight the strategic 'bigger picture' of unequal gender relations. Working to address girls' practical needs has to be seen as a stepping stone to work on interventions to enhance their self-reliance and agency, and to change gender-negative social norms, e.g., by increasing community members' approval for girls' increased mobility outside the home.

5 The study quotes a study of working women in Karachi (Kazi 1999) which found child deaths to be significantly higher for informal sector workers employed outside the home, even after controlling for income and education. Siddiqui et al. (2006) and the PDHS (2012-13) further found that women working outside the home were at a greater disadvantage in terms of child survival than home-based workers, also from poor households. Evidence was also found that women engaged in paid work were more likely to suffer spousal violence and to fear their husbands for this reason (Sathar and Kazi 2000). Most working women are employed in the informal sector, which they typically join to meet their financial needs after having several children. Women working in the formal sector, especially those in jobs valued by society and with the hope of upward mobility, have lower fertility (Sathar and Kazi 1990). Khattak (2001) 
concludes that work can be simultaneously empowering and disempowering, often due to its informal nature, and the overriding influence of poverty. Research is needed to learn to what extent Khattak's finding is relevant seventeen years on. And until we have this research, we must plan our programming ambitiously, but also in a manner which minimizes risk to adolescent girls.

6 The study's findings cannot be generalized to the provincial or national population, although they do provide very useful insights for framing further investigations about NEEM girls. The inter-district and urban-rural variations captured within this study also confirm the need for more rigorous research in settings beyond the communities and districts covered.

\subsection{Recommendations}

The findings of this study suggest that effecting transformative change in the lives of the NEEM girls will require a combination of measures to increase their access to education and work opportunities. Both supply- and demand-side interventions are needed, and these must be carefully calibrated to respond to the different ages, levels of educational attainment, and aspirations of the NEEM girls, as well as the often considerable differences in opportunities and challenges prevailing across specific settings. Below, we outline some of the key steps and approaches that are indicated by the findings of this study, and from experience of programming for girls and young women in Pakistan and similar settings.

\subsubsection{Increasing Girls' Access to Education and Skills}

1. Set up more secondary schools for girls, especially in the public sector. Non-availability of separate girls' schools, especially at the middle and high school levels, has been reported as a fundamental issue for girls' being out of school. There is a need to build more public schools, as well as affordable private schools, and train more teachers, male and female, especially in rural areas of Punjab that currently do not have schools in the vicinity. Secondary schools should be a focus, as these are less available, more relevant to the NEEM girls, and their availability would also contribute to primary enrollment and retention (Birdsall et al. 2005 in Hunt 2008). Investments should also be made in introducing reliable school bus services for communities beyond walking distances of schools.

2. Make co-educational schools more girl-friendly through some structural changes. In some communities, girls' primary schools are not available but co-educational schools are. However, many girls do not attend these schools, reportedly because their parents are uncomfortable with sending them to the same schools as boys, and because the teachers are mainly male. Such schools could be made more acceptable for girls by recruiting female teachers, appointing female heads of school as far as possible, and introducing gender-segregated classes to address parents' concerns. The specific changes should be made in consultation with communities, and preferably with the involvement of local religious leaders. Carefully supervised co-educational schools could serve as important environments for boys and girls to acquire the social skills to coexist respectfully in a non-segregated world, and also to make communities more receptive to the idea of coeducation at higher levels. 
3. Introduce special accelerated education programs for OOS girls. Girls who have dropped out from school can resume their education. However, as many said in this study, they would need separate arrangements to go back to school, since they feel embarrassed about sitting with younger girls. There is a need to introduce separate, accelerated classes for older students within the regular systems of public schools. Private schools could also follow this strategy with corporate social responsibility (CSR) support. Supportive behavior from school management and especially teachers could encourage and motivate other OOS girls to come and resume their education. Such programs could also be offered through accredited distance learning options, as discussed below.

4. Provide incentives to girls' parents for their schooling. Simply increasing the number of schooling channels may not be enough; complementary demand-side policies, such as incentive and income support through conditional cash transfer, food incentives, and reducing school related costs, will be needed at the household and community level, especially in rural areas, to reduce the opportunity cost of sending girls to school. In this regard, conditional cash transfers have shown impact in Punjab. An early evaluation of the Punjab Female School Stipend Program (FSSP) showed that the enrollment of eligible girls in middle-school increased in the short term by nearly 9 percentage points (Alam, Baez and Carpio 2011). Food incentives have also been found to work in various developing countries (UNESCO 2013, Meng \& Ryan, 2003), and respondents from Rajanpur specifically mentioned that during post-2010 flood recovery activities in their area, girls were provided food items which increased their enrollment and attendance at school; they were keen for such an intervention to be reintroduced.

While tuition is free at public schools, costs of school items were identified as an important reason for girls leaving their studies. This suggests a need for greater responsiveness to the financial constraints of the poorest students. Administration of existing concessions, such as provision of free textbooks, should also be improved to ensure that the intended benefits reach the girls.

5. Improve the quality of education. While many aspects of school quality need to be addressed, the main measures required to facilitate NEEM girls' reentry into school include the following:

a. Ensure that schools offer a socially safe environment. The study's findings suggest an urgent need for firm enforcement of the ban on corporal punishment, and orientation of teachers in child psychology and their training so they can support students with varying needs (Hussain, Salfi and Khan 2011), rather than humiliating them and discouraging them from continuing their education. The practice of forced child labor at schools must also be addressed by the Education Department through improved monitoring and accountability measures. It is also important that the schools have properly built bathrooms with functioning water and sanitation arrangements.

b. Remedial support for struggling students. This research corroborates other studies' findings that repetition of grades contributes to dropping out. Instruction should be improved and struggling students provided remedial support (Hussain, Salfi and Khan 2011), rather than being discouraged or forced to repeat grades. Teachers' encouragement and support will also reduce negative peer behavior where a girl fails her exams.

6. Flexible school timings and region-specific school calendars for seasonally absent children. In order to reach children who work to supplement their family income or livelihood, especially girls who are 
engaged in household or farm work during typical school hours (as in Rajanpur district), it is necessary to introduce flexible school timetables, and school calendars that are responsive to regional/local seasonal needs. Second shifts can be introduced at schools (Hussain, Salfi and Khan 2011).

7. Reinvigorate distance learning for secondary and higher secondary education. Distance learning could be a feasible solution to bring back OOS girls into education and can be used to offer both formal courses, pertaining to the completion of secondary and higher secondary education, as well as non-formal courses. Our conversations with girls during this study revealed that they were largely unaware of the existence of distance learning options, and in need of information and guidance for enrollment. All courses must be accredited by the government so that they are recognized and valued. The potential of harnessing mobile technology to share information could be explored. To circumvent mobility issues, classroom/workshop attendance requirements should be minimized, and it should be ensured that the girls do not have to travel outside their district to sit examinations or complete any other necessary formalities.

8. Offer non-formal education (NFE) in communities. For girls who cannot or do not intend to return to school, NFE programs can be offered. This approach can benefit girls who have never been to school as well as those who have dropped out by providing, at the very least, basic numeracy and literacy skills, as well as life and vocational skills. The best platforms for conducting NFE programs would be schools in the community, which could be utilized during or after school hours, depending on space availability and suitable timings for participants. Where schools are not available for such activities, other safe, girls-only spaces can be identified in consultation with the community. The Population Council and its partners have applied a targeted, evidence-based approach to adolescent girl programming in over 20 countries, prioritizing neglected (Bruce \& Hallman 2008) and exceptionally at-risk adolescent girls. This approach uses community-based spaces ("platforms") where marginalized girls can build protective health, social, economic and cognitive "assets" as the foundation for agency, self-esteem and the ability to claim their human rights and decent livelihoods. This model can be adopted here in Pakistan to provide both numeracy and literacy skills to OOS girls and also livelihood skills and opportunities.

\subsubsection{Increasing Girls' Access to Work Opportunities}

1. Base livelihood interventions on a thorough assessment of local opportunities. Livelihood interventions for girls should be preceded by thorough assessments of livelihood improvement possibilities in the communities, which should be conducted by specialists, looking both at the market and stakeholders, as well as communities' receptivity and preferences regarding various options. Moreover, business plans should be developed for specific activities to be introduced. The experiences of rural support programs and NGOs working for livelihood improvement, particularly those that have been formally evaluated to have impact, would also be an important point of reference in this work. During these assessments, we recommend that special attention be paid to understanding girls' and women's current participation in agricultural work, largely as unpaid workers, to identify means for leveraging this participation so that greater profits and control accrue to the female workers. 
The Population Council's experience of promoting young women's economic participation in rural areas of Egypt shows that technical and vocational training programs should be demand-driven by employment opportunities and aligned with local business needs. Involving market leaders in the design of livelihood programs; investing resources, time, and expertise in identifying new markets; and making sure products and services produced are of high quality is important to ensure business success and job placement for women. Businesses can provide internship and on-the-job training opportunities, which eventually will help girls secure employment (Population Council 2014).

2. Build girls' vocational skills. The specific vocational skills imparted to girls should ideally be identified in region-specific assessments of livelihood opportunities. The current study indicates potential for both home-based and factory work, although the former is preferred. Existing preferences could be the starting point of interventions, with more unconventional options introduced as the confidence of communities grows.

Regarding skills for home-based work, promising spheres include stitching, handmade leather goods, processing of dairy products, beauty care services, and computer-based work, such as transcribing and tasks related to search engine advertising. Among less conventional options, inspiration could be drawn from work such as that of the United Nations Industrial Development Organization (UNIDO) in Pakistan, Mexico, the Gambia, and Tunisia, which is aimed at inducting women into better quality jobs, often in spheres dominated by men. The organization's work in the Gambia shows, for instance, that girls with little or no education can be trained to install and maintain solar power systems in their villages, and can earn an income from providing these services to neighboring communities as well. In Mexico, less educated girls have been trained to conduct plant grafting, a technical skill that has transformed their employability.

Training must be imparted by female trainers and mentors. Training programs should be developed with input from specialized vocational training institutions as well as employers/industry leaders. Skills for external employment should reflect available opportunities, such as the types of factories in the vicinity. In this context, it would also be helpful to study the reasons for underutilization of existing vocational training institutes by girls, and to explore the potential of including vocational elements within the mainstream secondary education curriculum to increase the practical value of schooling from the perspective of the poorest households.

3. Provide transport facilities for girls. Haque (2006) finds that provision of transport facilities plays an important role in females' decision to work in Pakistan. The current study also found that girls in Kasur were working at factories in Lahore because the employer provided a bus service for their commute. The fact that the girls were able to work well beyond their communities in a neighboring district, despite unsupportive norms, indicates that basic supportive structural measures can lead to transformative change, overcoming or altering social norms to engender acceptance of girls' work outside the home. Arrangements for chaperoning girls to their workplaces could also be facilitated at the community level to address mobility issues.

4. Create safe and girl-friendly workplaces. Moreover, it is recommended that civil society work with employers to create girl-friendly workspaces and flexible work arrangements for women, as well as safe and nondiscriminatory environments (Population Council 2014). This study's findings indicate 
that ensuring that workplaces are gender-segregated, allowing girls to work with older women, such as their mothers, and making work environments accessible for parents to visit from time to time would help allay parents' fears. In lieu of gender segregation, carefully supervised work environments with firmly enforced rules against sexual harassment could also be introduced to give girls and young women more confidence to work alongside male colleagues.

5. Support home-based opportunities for young women. The current study's respondents expressed a clear preference for home-based opportunities. Other studies also recognize that options that allow women to participate in economic activities from their homes (e.g., greater access to micro credit or home-based employment) would be important to bring in the bulk of women who are unable to seek paid employment outside their homes (Naqvi and Shahnaz 2002), and therefore cottage industries should be nurtured and given tax breaks and necessary amenities (SPDC 2010).

In order to engage in economic work from home, girls will not only require vocational training but also the development of entrepreneurship skills and links with the market and with credit opportunities. In this regard, the experience of the Population Council's Neqdar Nesharik project in Egypt is relevant: while finding suitable markets for the products and services of women who have started businesses may be difficult, their access to markets can be enhanced by contracting businesses to help sell products and encouraging women to start group businesses with partners who focus on marketing. It is also critical to have continued support and mentoring for the girls and women, particularly during the early stages of starting a business and finding employment.

\subsubsection{Leveraging Interventions for Transformative Social Change}

We propose that the measures suggested above be implemented with a long-term vision for achieving a shift in the norms that perpetuate gender inequality and lead to the marginalization of adolescent girls from opportunities to develop their knowledge, skills, social networks, and agency. In this regard, we recommend the following approaches.

1. Strike a balance in meeting practical and strategic gender needs through interventions for girls. Interventions should be framed around girls' practical needs that are also priority concerns of the target communities. However, to the extent possible, these measures should be leveraged to achieve change at a more strategic level, by influencing the norms that restrict the capacity of girls and women to "increase their own self-reliance and internal strength," including "the right to determine choices in life and to influence the direction of change, through the ability to gain control over crucial material and nonmaterial resources." (Moser 1989).

In some cases, it will be advisable to proceed with extra sensitivity. Given the reluctance of parents to allow their girls to venture into workplaces on their own, and the negativity around this issue at the community level, it is recommended that earlier interventions to engage girls in paid work be mainly aligned with the concerns of parents, rather than directly challenging existing norms. This will be necessary to begin the process of girls' participation in economic activities, and to sustain it until economic benefits begin to filter through to households, and change starts to diffuse on a wider scale. 
2. Ensure community leadership of interventions. Community ownership and leadership must be cultivated in all interventions as a fundamental prerequisite for sustainability, and particularly to ensure support for interventions that attempt to change social norms. This study found a generally positive attitude towards education among girls as well as their parents, with most respondents regretting that the girls had had to discontinue their education. This suggests that, for the most part, communities do not require convincing regarding the advantages of education. However, they still need to be persuaded to accord a higher priority to their daughters' education, and to tackle barriers with greater commitment. On the other hand, there is a strong need for advocacy around girls' work participation at the community level. This could begin during the assessment of livelihood opportunities in each target community. Allowing communities to lead the process of identifying work options for girls would preempt much of the possible resistance. Potential employers could also be included in the discussions to build trust and coordination.

a. Mobilize parents and especially women. Community-level communication could aim to mobilize parents, especially mothers, at the grassroots level. For example, parents could be encouraged to organize neighborhood arrangements to escort girls to and from school, training institutions, or workplaces. Greater engagement with schools could also address the concerns of parents whose daughters dropped out due to problems at school, such as co-education, teacher absenteeism, failing a grade, or mistreatment by teachers. Certain forms of community involvement with schools have been found to improve educational access, reduce drop outs, and improve teacher attendance (Birdsall et al. 2005). Community groups could also liaise with large employers, such as factory managers, and conduct occasional visits to ensure that the work environment is suitable for girls.

We recommend that women be supported to play a primary role in such community-based platforms. Grassroots mobilization of women is acknowledged to be one of the most potent routes for women's empowerment in developing countries (Moser 1989). While the organizations would be set up to help meet practical needs related to girls' access to schools and work, the capacity building of members could include components to build, for example, their cognitive and negotiation skills, organization and financial management skills, and awareness of rights and laws. The presence of such women's bodies would not only contribute to a more conducive environment for interventions for adolescent girls, but also create space for a more active and visible role for women in community affairs.

b. Involve religious leaders and the mass media. The Council's field experience, especially the Neqdar Nesharik project, shows that mass media and religious institutions can play a role in promoting progressive discourse regarding women's roles and rights, which helps create an enabling environment for women's empowerment (Population Council 2014). Within Pakistan, the Council has worked successfully with religious scholars, representing all regions and schools of thought, to formally endorse girls' right to education and women's right to birth spacing (Population Council 2015). Building on this potentially paradigm-shifting development, Islamic scholars and mosque imams could be involved, along with other influential community members, to encourage communities to send their girls to school, and also to educate them 
about women's right to earn and to inheritance, which would help counter the harmful gender norms that perpetuate economic inequality.

In addition, mass media can be used to project a more positive picture of women's work force participation, especially through entertainment programming, which is popular in communities. At present, soap operas often indirectly convey negative messages about working women, e.g., by focusing on office problems and neglected children; this could be replaced with more positive messages. Awareness and advocacy campaigns need to be continued to raise policymakers' and government officials' awareness of the institutional challenges facing women in starting businesses and finding employment (Population Council 2014).

c. Address the problem of gender-based violence. Among the communities visited in the course of this study, our study team noted a nearly pervasive fear of sexual harassment and even violence, especially in rural areas. This was a central barrier in girls' access to education and employment. Notably, in recent months, a number of reports of extreme sexual violence against minors have erupted on the national news media, with Kasur emerging as a prominent hot spot, and Faisalabad also mentioned in some reports. These reports confirm that the perceived threat of gender-based violence is very real, and must be addressed on a war footing. While the strategy for addressing security risks would involve multiple stakeholders and efforts, interventions for adolescent girls can contribute by building awareness, raising the issue in community advocacy and mobilization efforts, and facilitating community-level responses to minimize risks. Importantly, the discussion of sexual violence could carefully be extended to include the forms of violence perpetrated against women and girls inside their homes and communities, often as a tool for enforcing negative gender norms.

d. Raise awareness of girls' rights. There is a general need to raise awareness of girls' rights as enshrined in laws such as the Child Protection Act, Child Marriage Restraint Act, Harassment at Workplace, and Domestic Violence Act. Discussions on these laws, and how they can be invoked, should be a part of activities for engaging communities and religious leaders. The mass media can be engaged to build awareness on a larger scale, with the help of legal experts, law enforcement agencies, and other stakeholders.

3. Conduct rigorous research to identify the most effective interventions in specific contexts. Finally, as the third major element of our recommended approach, we advocate that specific interventions be framed within an implementation science framework, for example as randomized control trials, to build evidence of what does-and doesn't-work. In 2009, the Population Council reviewed more than 300 programs being implemented around the world to promote girls' education, including their underlying strategy and the available evidence for those strategies. Of the 11 most common intervention approaches identified in the review, only two had been proven effective in previous research, while less than a tenth of the programs had an external evaluation planned (Lloyd and Young 2009). Commitment to an implementation science framework will build concrete evidence for empowering adolescent girls in Pakistan and ensure that the most effective measures are advocated and upscaled. 
As the above recommendations imply, coordinated action will be required on several fronts to improve the life trajectories of NEEM girls by enabling them to return to school and to engage in livelihood activities that enhance their productivity and status. In Table 6.1 below, we outline the specific measures that may be taken and the stakeholders who should be involved in translating these recommendations into action. 


\section{Table 6.1: Suggestions for Action}

\begin{tabular}{|c|c|c|c|c|c|c|c|}
\hline Objective & \multicolumn{2}{|c|}{ Recommendations } & \multicolumn{2}{|r|}{ Actions recommended } & \multirow{2}{*}{$\begin{array}{l}\text { Who should } \\
\text { take action } \\
\text { Provincial } \\
\text { Departments of } \\
\text { Education }\end{array}$} & Key stakeholders & $\begin{array}{l}\text { Action } \\
\text { priority }\end{array}$ \\
\hline \multirow[t]{3}{*}{$\begin{array}{l}1 \text { INCREASE GIRLS' } \\
\text { ACCESS TO } \\
\text { EDUCATION AND } \\
\text { SKILLS }\end{array}$} & 1.1 & $\begin{array}{l}\text { Set up more } \\
\text { secondary schools } \\
\text { for girls, } \\
\text { especially in the } \\
\text { public sector, and } \\
\text { introduce } \\
\text { necessary } \\
\text { structural } \\
\text { changes in } \\
\text { existing schools }\end{array}$ & $\begin{array}{l}1.1 .1 \\
1.1 .2 \\
1.1 .3 \\
1.1 .4\end{array}$ & $\begin{array}{l}\text { Set up new secondary schools } \\
\text { for girls } \\
\text { Introduce second shifts for } \\
\text { girls at existing boys' schools } \\
\text { Train more female teachers } \\
\text { Introduce school bus services } \\
\text { for communities beyond } \\
\text { walking distance of schools }\end{array}$ & & $\begin{array}{l}\text { Provincial Departments of } \\
\text { Education } \\
\text { District Education } \\
\text { administration } \\
\text { Donor agencies (UN, World } \\
\text { Bank etc.) } \\
\text { NGOs/INGOs working in } \\
\text { education and teacher training }\end{array}$ & High \\
\hline & 1.2 & $\begin{array}{l}\text { Make co- } \\
\text { educational } \\
\text { schools more girl- } \\
\text { friendly through } \\
\text { structural } \\
\text { changes }\end{array}$ & $\begin{array}{l}1.2 .1 \\
1.2 .2 \\
1.2 .3 \\
1.2 .4\end{array}$ & $\begin{array}{l}\text { Recruit more female teachers } \\
\text { and school heads } \\
\text { Introduce gender-segregated } \\
\text { classes at secondary level } \\
\text { Discuss with communities } \\
\text { what changes at co- } \\
\text { educational schools would } \\
\text { persuade them to send girls } \\
\text { Involve religious leaders in } \\
\text { supporting co-education where } \\
\text { other options are not available }\end{array}$ & $\begin{array}{l}\text { Provincial } \\
\text { Departments of } \\
\text { Education }\end{array}$ & $\begin{array}{l}\text { Provincial Departments of } \\
\text { Education } \\
\text { Donor agencies } \\
\text { NGOs/INGOs working in } \\
\text { education and teacher training } \\
\text { Community members and } \\
\text { religious leaders }\end{array}$ & High \\
\hline & 1.3 & $\begin{array}{l}\text { Introduce special } \\
\text { accelerated } \\
\text { education } \\
\text { programs for OOS } \\
\text { girls }\end{array}$ & $\begin{array}{l}1.3 .1 \\
1.3 .2\end{array}$ & $\begin{array}{l}\text { Raise awareness of distance } \\
\text { learning options and provide } \\
\text { guidance on enrollment } \\
\text { Introduce accredited distance } \\
\text { learning programs } \\
\text { Introduce separate classes for } \\
\text { older students within the }\end{array}$ & $\begin{array}{l}\text { Higher Education } \\
\text { Commission } \\
\text { Allama Iqbal Open } \\
\text { University (AIOU) } \\
\text { Provincial } \\
\text { Departments of } \\
\text { Education }\end{array}$ & $\begin{array}{l}\text { Universities offering distance } \\
\text { learning, e.g., Allama Iqbal } \\
\text { Open University (AIOU) and } \\
\text { Virtual University (VU) } \\
\text { Provincial Departments of } \\
\text { Education } \\
\text { Donor agencies }\end{array}$ & High \\
\hline
\end{tabular}




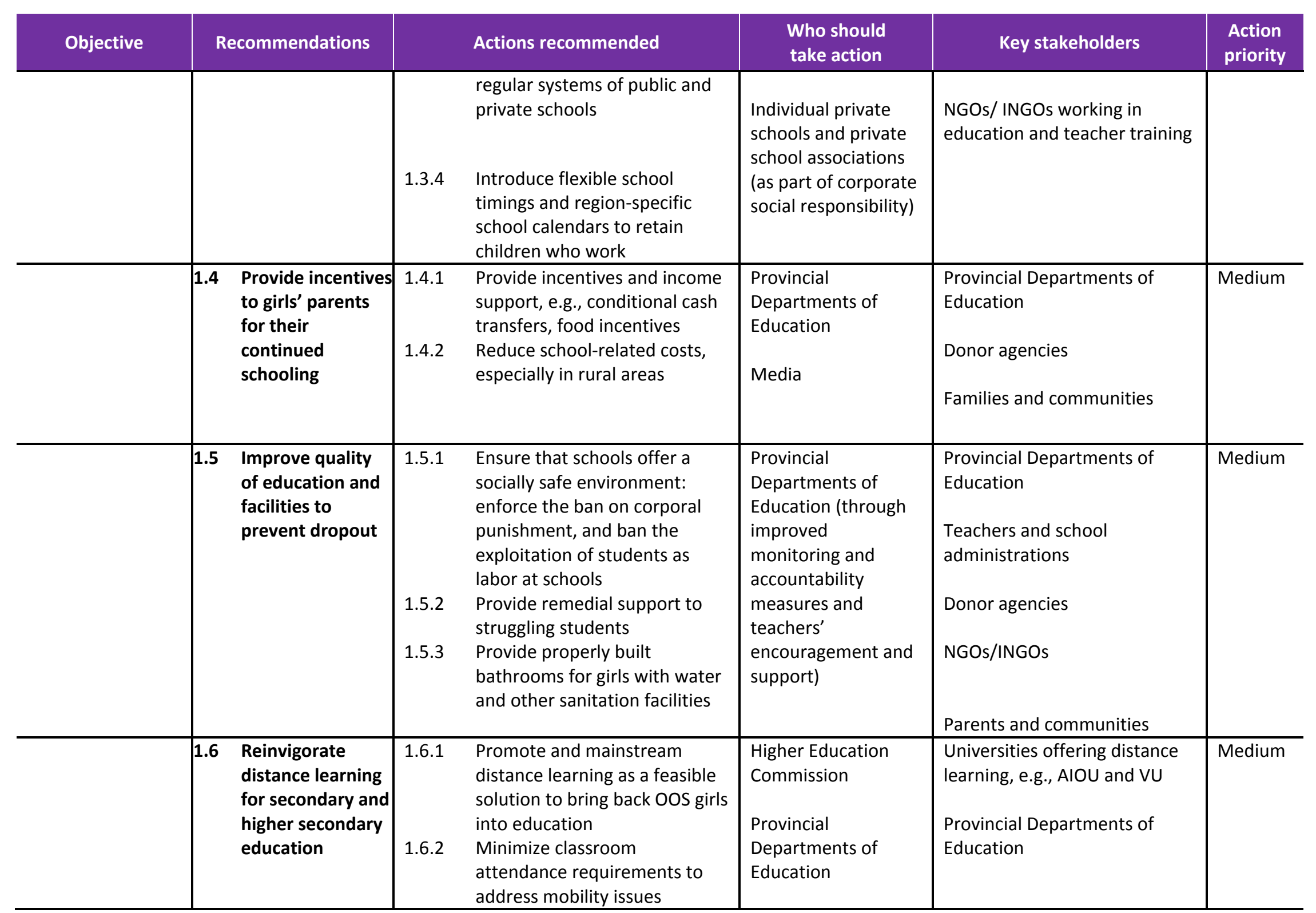




\begin{tabular}{|c|c|c|c|c|c|c|c|c|}
\hline & \multirow[t]{3}{*}{ Objective } & \multicolumn{2}{|r|}{ Recommendations } & \multicolumn{2}{|r|}{ Actions recommended } & \multirow[t]{2}{*}{$\begin{array}{l}\text { Who should } \\
\text { take action }\end{array}$} & \multirow[t]{2}{*}{ Key stakeholders } & \multirow[t]{2}{*}{$\begin{array}{l}\text { Action } \\
\text { priority }\end{array}$} \\
\hline & & & & 1.6 .3 & $\begin{array}{l}\text { Ensure that girls do not have to } \\
\text { travel outside their districts to } \\
\text { sit examinations or complete } \\
\text { any other necessary formalities }\end{array}$ & & & \\
\hline & & & $\begin{array}{l}\text { Offer non-formal } \\
\text { education (NFE) in } \\
\text { communities }\end{array}$ & $\begin{array}{l}1.7 .1 \\
1.7 .2\end{array}$ & $\begin{array}{l}\text { Offer training in basic } \\
\text { numeracy and literacy skills, as } \\
\text { well as life and vocational skills } \\
\text { for OOS girls } \\
\text { Conduct NFE programs at } \\
\text { schools in the community after } \\
\text { formal school hours }\end{array}$ & $\begin{array}{l}\text { Provincial } \\
\text { Departments of } \\
\text { Education } \\
\text { NGOs/INGOs }\end{array}$ & $\begin{array}{l}\text { Provincial Departments of } \\
\text { Education } \\
\text { Donor agencies } \\
\text { NGOs/INGOs } \\
\text { Parents and communities }\end{array}$ & High \\
\hline \multirow[t]{2}{*}{2} & $\begin{array}{l}\text { INCREASE } \\
\text { GIRLS' ACCESS } \\
\text { TO WORK } \\
\text { OPPORTUNITIE } \\
\text { S }\end{array}$ & \multicolumn{2}{|c|}{\begin{tabular}{|l|} 
2.1 Base livelihood \\
interventions on a \\
thorough \\
assessment of local \\
opportunities
\end{tabular}} & \multicolumn{2}{|c|}{$\begin{array}{l}\text { 2.1.1 Identify new markets and jobs for } \\
\text { girls and women } \\
\text { 2.1.2 Provide internship and on-the-job } \\
\text { training opportunities, } \\
\text { particularly for girls }\end{array}$} & $\begin{array}{l}\text { Ministry of Federal } \\
\text { Education and } \\
\text { Professional Training } \\
\text { Provincial Labour \& } \\
\text { Human Resource } \\
\text { Departments } \\
\text { Local employers }\end{array}$ & $\begin{array}{l}\text { Provincial Labour \& Human } \\
\text { Resource Department } \\
\text { Local Chambers of Commerce } \\
\text { and Industries } \\
\text { Local employers/Market } \\
\text { leaders } \\
\text { Rural support programs } \\
\text { NGOs/INGOs working for } \\
\text { livelihood improvement }\end{array}$ & Medium \\
\hline & & 2.2 & $\begin{array}{l}\text { Build girls' } \\
\text { vocational skills }\end{array}$ & 2.2 .1 & $\begin{array}{l}\text { Develop training programs } \\
\text { with input from existing } \\
\text { specialized vocational training } \\
\text { institutions, as well as from } \\
\text { employers/industry leaders in } \\
\text { areas of interest to girls and } \\
\text { parents e.g., handmade } \\
\text { leather goods, processing of } \\
\text { dairy products, beauty care } \\
\text { services, and computer-based }\end{array}$ & $\begin{array}{l}\text { Ministry of Federal } \\
\text { Education and } \\
\text { Professional Training } \\
\text { Provincial Labour \& } \\
\text { Human Resource } \\
\text { Department }\end{array}$ & $\begin{array}{l}\text { National Vocational \& } \\
\text { Technical } \\
\text { Training Commission } \\
\text { (NAVTTC), Pakistan } \\
\text { Technical Education and } \\
\text { Vocational Training Authority } \\
\text { (TEVTA) } \\
\text { Local Chamber of Commerce } \\
\text { and Industries }\end{array}$ & High \\
\hline
\end{tabular}




\begin{tabular}{|c|c|c|c|c|c|c|}
\hline \multirow[t]{4}{*}{ Objective } & Recommendations & & Actions recommended & $\begin{array}{l}\text { Who should } \\
\text { take action }\end{array}$ & Key stakeholders & $\begin{array}{l}\text { Action } \\
\text { priority }\end{array}$ \\
\hline & & 2.2 .2 & $\begin{array}{l}\text { work, including transcribing } \\
\text { and search engine advertising } \\
\text { Recruit and train female } \\
\text { trainers and mentors and } \\
\text { establish or upgrade vocational } \\
\text { centers for girls and women }\end{array}$ & & $\begin{array}{l}\text { Local employers/Market } \\
\text { leaders } \\
\text { Rural support programs } \\
\text { NGOs/INGOs working for } \\
\text { livelihood improvement } \\
\text { Donor agencies }\end{array}$ & \\
\hline & 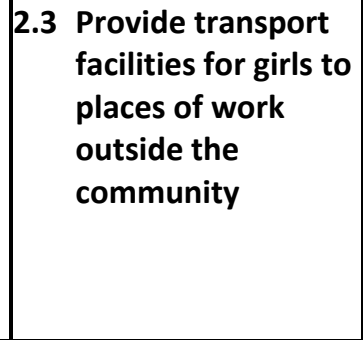 & $\begin{array}{l}2.3 .1 \\
2.3 .2\end{array}$ & $\begin{array}{l}\text { Provide transport facilities to } \\
\text { workplaces for girls and } \\
\text { women; this can overcome } \\
\text { social norms discouraging girls' } \\
\text { work outside the home } \\
\text { Facilitate chaperoning } \\
\text { arrangements to escort girls to } \\
\text { workplaces }\end{array}$ & $\begin{array}{l}\text { Provincial Labour \& } \\
\text { Human Resource } \\
\text { Departments } \\
\text { Local employers }\end{array}$ & $\begin{array}{l}\text { Local employers } \\
\text { Parents and communities }\end{array}$ & High \\
\hline & $\begin{array}{l}2.4 \begin{array}{l}\text { Create safe and } \\
\text { girl-friendly } \\
\text { workplaces }\end{array} \\
\text { work }\end{array}$ & $\begin{array}{l}2.4 .1 \\
2.4 .2 \\
2.4 .3 \\
2.4 .4\end{array}$ & $\begin{array}{l}\text { Create girl-friendly workspaces } \\
\text { and flexible work } \\
\text { arrangements for girls and } \\
\text { women } \\
\text { Develop gender-segregated } \\
\text { workplaces } \\
\text { Provide supervised work } \\
\text { environments so that older } \\
\text { adolescent girls can be } \\
\text { permitted to work alongside } \\
\text { male colleagues } \\
\text { Provide work opportunities to } \\
\text { both mothers and their } \\
\text { daughters to make the } \\
\text { environment more safe and } \\
\text { protected }\end{array}$ & Local employers & $\begin{array}{l}\text { Civil society } \\
\text { Local Chambers of Commerce } \\
\text { and Industries } \\
\text { Local employers } \\
\text { NGOs/INGOs working for } \\
\text { livelihood improvement } \\
\text { Donor agencies (UN, especially } \\
\text { UNIDO, World Bank, etc.) } \\
\text { Parents and communities }\end{array}$ & Medium \\
\hline
\end{tabular}




\begin{tabular}{|c|c|c|c|c|c|}
\hline Objective & Recommendations & Actions recommended & $\begin{array}{l}\text { Who should } \\
\text { take action }\end{array}$ & Key stakeholders & $\begin{array}{l}\text { Action } \\
\text { priority }\end{array}$ \\
\hline & $\begin{array}{l}2.5 \begin{array}{l}\text { Support home- } \\
\text { based } \\
\text { opportunities for } \\
\text { young women }\end{array} \\
\end{array}$ & $\begin{array}{l}\text { Provide access to micro credit } \\
\text { or home-based employment } \\
\text { (with tax breaks and necessary } \\
\text { amenities) so that older } \\
\text { adolescent girls and women } \\
\text { can work from home }\end{array}$ & $\begin{array}{l}\text { Provincial Labour \& } \\
\text { Human Resource } \\
\text { Department } \\
\text { Microfinance banks } \\
\text { Local employers }\end{array}$ & $\begin{array}{l}\text { Donor agencies (UN, especially } \\
\text { UNIDO, World Bank, etc.) } \\
\text { Rural support programs } \\
\text { NGOs/INGOs working for } \\
\text { livelihood improvement }\end{array}$ & High \\
\hline \multirow[t]{3}{*}{$\begin{array}{l}\text { LEVERAGE } \\
\text { INTERVENTIONS } \\
\text { FOR } \\
\text { TRANSFORMATIVE } \\
\text { SOCIAL CHANGE }\end{array}$} & \begin{tabular}{|} 
3.1 Ensure community \\
leadership of \\
interventions
\end{tabular} & $\begin{array}{l}\text { 3.1.1 Conduct advocacy campaigns on } \\
\text { the benefits of girls' } \\
\text { participation in work at the } \\
\text { community level } \\
\text { 3.1.2 Enable communities to lead the } \\
\text { process of identifying work } \\
\text { options for girls to preempt } \\
\text { possible resistance } \\
\text { 3.1.3 Include potential employers in } \\
\text { discussions to build trust and } \\
\text { coordination }\end{array}$ & $\begin{array}{l}\text { Provincial Labour \& } \\
\text { Human Resource } \\
\text { Department } \\
\text { Civil society } \\
\text { NGOs \INGOs } \\
\text { Local employers }\end{array}$ & $\begin{array}{l}\text { Provincial Labour \& Human } \\
\text { Resource Department } \\
\text { (through public service } \\
\text { messages) } \\
\text { Civil society } \\
\text { NGOs\INGOs } \\
\text { Local employers } \\
\text { Communities }\end{array}$ & High \\
\hline & $\begin{array}{l}\text { 3.2 Mobilize parents, } \\
\text { especially women }\end{array}$ & $\begin{array}{l}\text { 3.2.1 Launch community-level } \\
\text { communications through group } \\
\text { meetings and messages to } \\
\text { sensitize and mobilize parents, } \\
\text { especially mothers, to support } \\
\text { their older adolescent daughters } \\
\text { to work outside the home }\end{array}$ & $\begin{array}{l}\text { Civil society } \\
\text { NGOs\INGOs }\end{array}$ & $\begin{array}{l}\text { Civil society } \\
\text { NGOs\INGOs } \\
\text { Parents and communities }\end{array}$ & High \\
\hline & $\begin{array}{l}\text { 3.3 Involve religious } \\
\text { leaders and the } \\
\text { mass media in } \\
\text { supporting }\end{array}$ & $\begin{array}{l}\text { 3.3.1 Involve Islamic scholars and } \\
\text { Imams - alongside with other } \\
\text { influential community members- } \\
\text { to encourage communities to } \\
\text { send their girls to school, and }\end{array}$ & $\begin{array}{l}\text { Provincial Labour \& } \\
\text { Human Resource } \\
\text { Department } \\
\text { Civil society }\end{array}$ & $\begin{array}{l}\text { Provincial Labour \& Human } \\
\text { Resource Department } \\
\text { (through public service } \\
\text { messages) }\end{array}$ & Medium \\
\hline
\end{tabular}




\begin{tabular}{|c|c|c|c|c|c|}
\hline \multirow[t]{2}{*}{ Objective } & Recommendations & Actions recommended & $\begin{array}{l}\text { Who should } \\
\text { take action }\end{array}$ & Key stakeholders & $\begin{array}{l}\text { Action } \\
\text { priority }\end{array}$ \\
\hline & $\begin{array}{l}\text { women's right to } \\
\text { work and earn }\end{array}$ & $\begin{array}{l}\text { also to educate them about } \\
\text { women's right to earn and to } \\
\text { inherit } \\
\text { 3.3.2 Work with mass media to project } \\
\text { a more positive picture of } \\
\text { women's work force } \\
\text { participation, especially through } \\
\text { entertainment programming, } \\
\text { which is popular in communities } \\
\text { 3.3.3 Strengthen awareness and } \\
\text { advocacy campaigns to raise } \\
\text { policymakers' and government } \\
\text { officials' awareness of the } \\
\text { institutional challenges facing } \\
\text { women in starting businesses } \\
\text { and finding employment }\end{array}$ & $\begin{array}{l}\text { NGOs \INGOs } \\
\text { Potential employers } \\
\text { Religious leaders/ } \\
\text { clerics }\end{array}$ & $\begin{array}{l}\text { Civil society } \\
\text { NGOs\INGOs } \\
\text { Islamic scholars and imams } \\
\text { Electronic and print media }\end{array}$ & \\
\hline & $\begin{array}{c}\text { 3.4 Raise awareness } \\
\text { about girls' rights }\end{array}$ & $\begin{array}{l}\text { 3.4.1 Work with mass media for } \\
\text { advocacy campaigns to raise } \\
\text { awareness about relevant child } \\
\text { protection laws as well as laws } \\
\text { against child marriage, } \\
\text { harassment at workplaces, and } \\
\text { domestic violence }\end{array}$ & $\begin{array}{l}\text { Media agencies } \\
\text { Law enforcement } \\
\text { agencies } \\
\text { Civil society } \\
\text { NGOs INGOs }\end{array}$ & $\begin{array}{l}\text { Electronic and print media } \\
\text { Civil society } \\
\text { NGOs\INGOs } \\
\text { Electronic and print media } \\
\text { Communities }\end{array}$ & High \\
\hline & $\begin{array}{l}\text { 3.5 Conduct rigorous } \\
\text { research to } \\
\text { identify the most } \\
\text { effective } \\
\text { interventions in } \\
\text { specific contexts }\end{array}$ & $\begin{array}{l}\text { 3.5.1 Frame specific interventions } \\
\text { within an operations research } \\
\text { framework, e.g., randomized } \\
\text { control trials, to build evidence } \\
\text { of what works (and what } \\
\text { doesn't) }\end{array}$ & $\begin{array}{l}\text { Research } \\
\text { organizations }\end{array}$ & $\begin{array}{l}\text { Donor agencies } \\
\text { Research organizations } \\
\text { (NGOs\INGOs) }\end{array}$ & High \\
\hline
\end{tabular}




\section{Appendixes}

\section{Appendix A: List of Reference Group Members}

\begin{tabular}{l|l|l}
\hline & Name & Title / Organization \\
\hline 1 & Seamus Mac Roibin & Sr. Social Development Adviser, DFID Pakistan \\
\hline 2 & Zafar Hayat Malik & Program Officer (Ed), UNESCO \\
\hline 3 & Sadia Atta Mehmood & Project Officer, Youth, UNFPA \\
\hline 5 & Jamaluddin Khan & Program Officer, UN Women \\
\hline 6 & Sadaf Zulfiqar & Research and Evaluation Specialist, UNICEF \\
\hline 7 & Kiran Qazi & Education Specialist, UNICEF \\
\hline 8 & Rosemary Arnott & WASH Officer, UNICEF \\
\hline 9 & Ayesha Khan & Gender \& Development Specialist, UNICEF \\
\hline 10 & Dr. Zeba A. Sathar & Program Officer (Gender \& SP), UNICEF \\
\hline 11 & Iram Kamran & Country Director, Population Council \\
\hline 12 & Tahira Parveen & Program Manager, Population Council \\
\hline
\end{tabular}




\title{
Appendix B: Approval of the Institutional Review Board (IRB)
}

\author{
2 POPULATION
COUNCIL \\ Ideas. Evidence. Impact.
}

Institutional Review Board

Population Council

1230 York Avenue

New York, NY 10065

\section{APPROVAL OF PROTOCOL}

DATE: July 3,2017

TO: $\quad$ Z. Sathar, Principal Investigator

FROM: Nick Gontarz, IRB Administrator, on behalf of John Bongaarts, Chairman Institutional Review Board (IRB)

RE: $\quad$ Approval of Protocol 778 - Adolescent Girls' Voices on Enhancing Their Own Productivity in Pakistan

The Institutional Review Board (IRB) on human research of the Population Council has approved the above request to involve humans as research subjects.

DATE OF IRB MEETING PROTOCOL REVIEWED AND APPROVED PENDING ITEMS:

NOVEMBER 9, 2016

REVIEW OF PROTOCOL REVISIONS AND FINAL APPROVAL ISSUED:

JUNE 27, 2017

ADVERSE REACTIONS/COMPLICATIONS: All serious and/or unexpected side effects must be reported immediately by email to the Population Council's SAE Desk (Safety@popcouncil.org) which will notify the IRB of the Population Council.

MODIFICATIONS: All Protocol changes involving subjects must have prior IRB approval.

If this project is to continue, it must be renewed as specified by the IRB. THE EXPIRATION DATE FOR THIS PROJECT IS NOVEMBER 9, 2017. This renewal application consists of a brief status report summarizing the results obtained during the past period and a short statement of the research plan for the coming year.

If you have any questions, please contact Nick Gontarz at telephone number [212] 327-7112, email ngontarz@popcouncil.org.

cc: IRB Records and Reports File for Protocol 778 


\section{Appendix C: Socio-demographic Characteristics of the Study Respondents}

Table C1: Socio-demographic characteristics of interviewed girls, by district

\begin{tabular}{|c|c|c|c|c|c|}
\hline & & Faisalabad & Kasur & Rajanpur & Total \\
\hline & & $n$ & $\mathbf{N}$ & $n$ & $\mathrm{n}$ \\
\hline Rocidenco & Urban & 4 & 5 & 4 & 13 \\
\hline Residence & Rural & 10 & 9 & 10 & 29 \\
\hline & $15-16$ years & 8 & 4 & 7 & 19 \\
\hline Current age & $17-18$ years & 3 & 5 & 7 & 15 \\
\hline & 19 years & 3 & 5 & 0 & 8 \\
\hline & No schooling & 2 & 2 & 4 & 8 \\
\hline Educational & $\begin{array}{l}\text { Dropped out from } \\
\text { grades 1-4 }\end{array}$ & 3 & 7 & 6 & 16 \\
\hline & $\begin{array}{l}\text { Dropped out from } \\
\text { grades } 5-8\end{array}$ & 9 & 5 & 4 & 18 \\
\hline & 1 & 1 & 3 & 2 & 6 \\
\hline Birth order & 2 to 4 & 4 & 3 & 4 & 11 \\
\hline Birtn order & 5 to 7 & 7 & 5 & 5 & 17 \\
\hline & 8 to 10 & 2 & 3 & 3 & 8 \\
\hline & No schooling & 11 & 10 & 6 & 27 \\
\hline Educational & Primary & 2 & 1 & 3 & 6 \\
\hline $\begin{array}{l}\text { attainment of } \\
\text { father }\end{array}$ & Middle & 0 & 0 & 4 & 4 \\
\hline & Secondary & 1 & 3 & 1 & 5 \\
\hline Educational & No schooling & 11 & 13 & 14 & 38 \\
\hline attainment of & Primary & 2 & 1 & 0 & 3 \\
\hline mother & Middle & 1 & 0 & 0 & 1 \\
\hline Total (N) & & 14 & 14 & 14 & 42 \\
\hline
\end{tabular}

Table C2: Socio-demographic characteristics of girls who participated in FGDs, by district

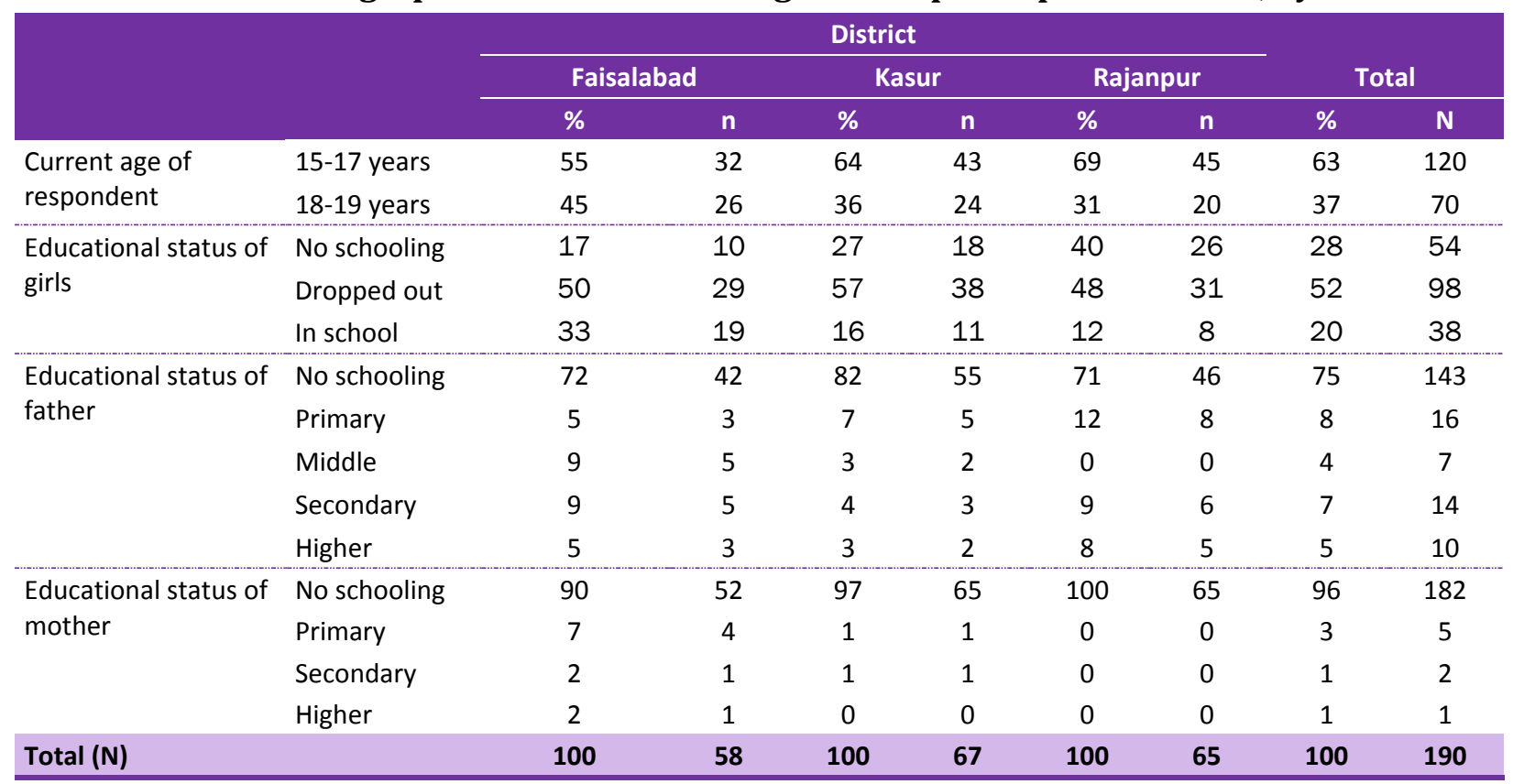


Table C3: Social-demo graphic characteristics of mothers of girls (15-19 years) who participated in FGDs, by district

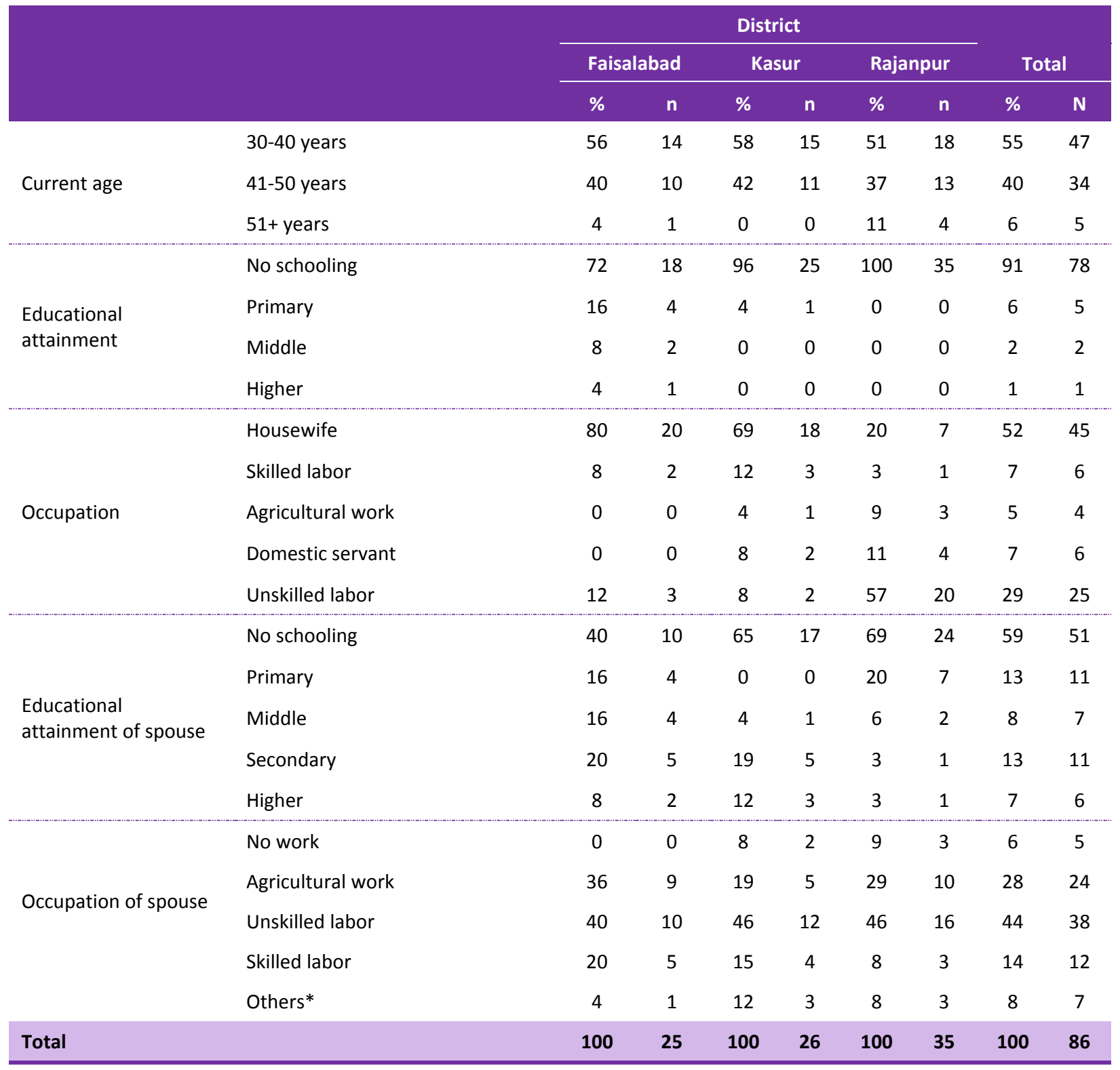

* Others include salesman, self-employed and govt. job. 
Table C4: Socio-demographic characteristics of fathers and community representatives who participated in FGDs, by district

\begin{tabular}{|c|c|c|c|c|c|c|c|c|c|}
\hline & & \multicolumn{6}{|c|}{ District } & & \\
\hline & & \multicolumn{2}{|c|}{ Faisalabad } & \multicolumn{2}{|c|}{ Kasur } & \multicolumn{2}{|c|}{ Rajanpur } & \multicolumn{2}{|c|}{ Total } \\
\hline & & $\%$ & $\mathbf{n}$ & $\%$ & $\mathbf{n}$ & $\%$ & $\mathbf{n}$ & $\%$ & $\mathbf{n}$ \\
\hline \multirow{3}{*}{ Current age } & $30-40$ years & 19 & 5 & 41 & 11 & 35 & 13 & 32 & 29 \\
\hline & $41-50$ years & 27 & 7 & 41 & 11 & 41 & 15 & 37 & 33 \\
\hline & $51+$ years & 54 & 14 & 19 & 5 & 24 & 9 & 31 & 28 \\
\hline \multirow{5}{*}{$\begin{array}{l}\text { Educational } \\
\text { attainment }\end{array}$} & No schooling & 15 & 4 & 59 & 16 & 62 & 23 & 48 & 43 \\
\hline & Primary & 31 & 8 & 15 & 4 & 11 & 4 & 18 & 16 \\
\hline & Middle & 19 & 5 & 4 & 1 & 5 & 2 & 9 & 8 \\
\hline & Secondary & 23 & 6 & 15 & 4 & 8 & 3 & 14 & 13 \\
\hline & Higher & 12 & 3 & 7 & 2 & 14 & 5 & 11 & 10 \\
\hline \multirow{4}{*}{ Occupation } & No job & 0 & 0 & 4 & 1 & 0 & 0 & 1 & 1 \\
\hline & Agricultural work & 54 & 14 & 15 & 4 & 51 & 19 & 41 & 37 \\
\hline & Unskilled labor & 31 & 8 & 63 & 17 & 35 & 13 & 42 & 38 \\
\hline & Private/Govt. job & 15 & 4 & 19 & 5 & 14 & 5 & 16 & 14 \\
\hline \multirow{5}{*}{$\begin{array}{l}\text { Educational } \\
\text { attainment of } \\
\text { spouse }\end{array}$} & No schooling & 50 & 13 & 74 & 20 & 73 & 27 & 67 & 60 \\
\hline & Primary & 19 & 5 & 7 & 2 & 16 & 6 & 14 & 13 \\
\hline & Middle & 19 & 5 & 4 & 1 & 3 & 1 & 8 & 7 \\
\hline & Secondary & 8 & 2 & 11 & 3 & 5 & 2 & 8 & 7 \\
\hline & Higher & 4 & 1 & 4 & 1 & 3 & 1 & 3 & 3 \\
\hline Total (N) & & 100 & 26 & 100 & 27 & 100 & 37 & 100 & 90 \\
\hline
\end{tabular}




\section{Appendix D: Access to and Use of Mobile Technology among Girl Respondents}

Figure D.1 shows the number of girls in each district who could access, knew how to use, and actually used mobile phones for a range of purposes. A broad observation that emerges from the figure is that girls who have access to mobiles have knowledge about their functions. They also use mobiles to perform those functions, which implies that access is an important step and, further, that mobile phones could be an important avenue that 00 girls can navigate to learn.

In terms of different functions, the girls' access, knowledge and use of mobiles revolves mostly around making phone calls, listening to music, and taking pictures in all three districts. However, hardly any of the girls can use mobiles to transfer a payment or use social media. Internet browsing is also very rare, in most cases because they do not have access to this service. Overall, girls from Faisalabad district seem to have more access to a better utility of all the above mentioned functions, reflecting more urbanized and developed district patterns. Girls from Kasur are less skilled in this respect, but better off than girls from Rajanpur district, who have far more limited access to mobiles.

Figure D.1: Number of girl respondents having access to and using mobile phones, by district ( $n=42$ o0S girls)

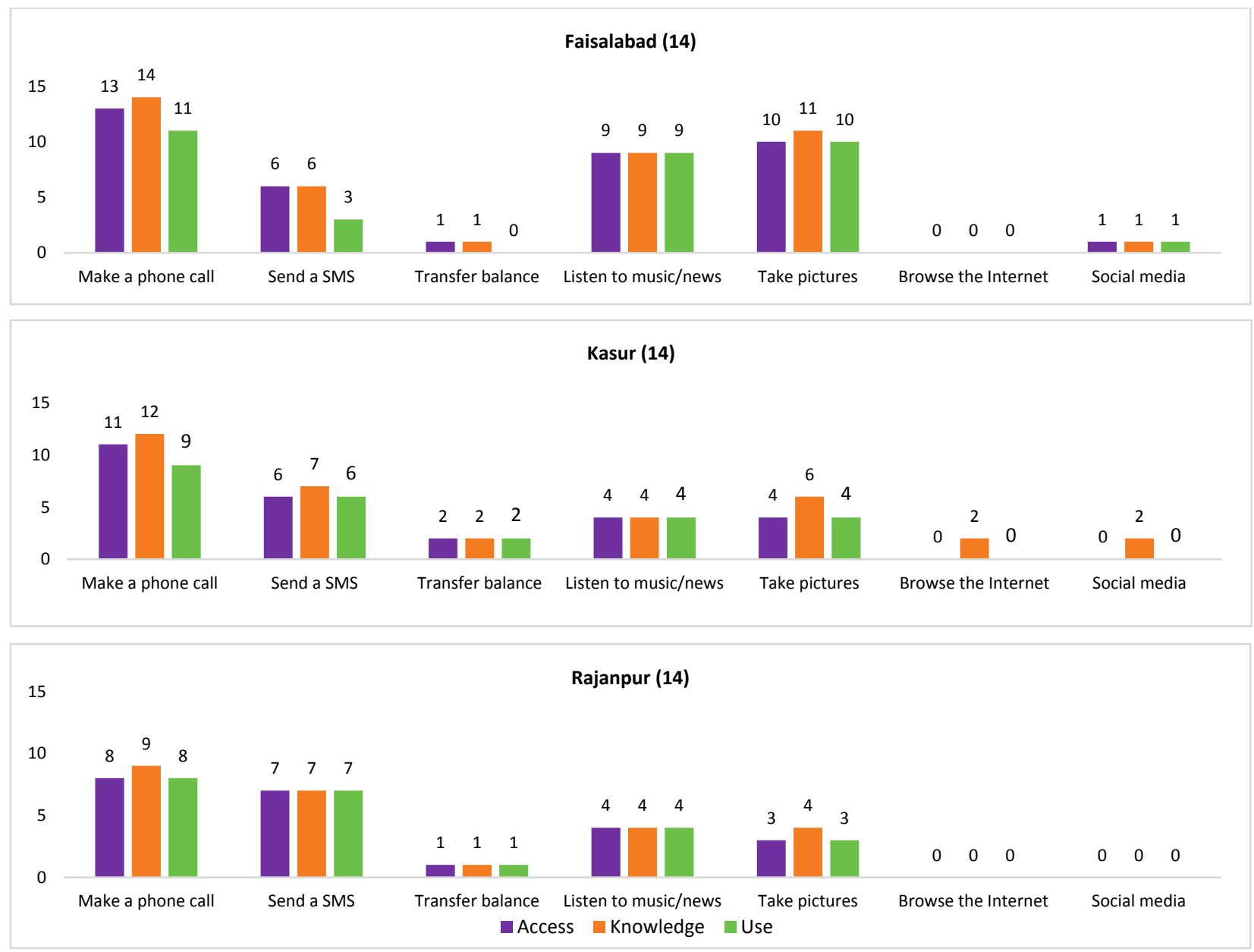




\section{References}

Al-Samarrai, S., \& Peasgood, T. (1998). Educational attainments and household characteristics in Tanzania. Economics of Education Review, 17(4), 395-417.

Alam, A., Baez, J., \& Ximena, V. X. Del Carpio. 2011. Does Cash for School Influence Young Women's Behavior in the Longer Term? Evidence from Pakistan. Policy Research Working Paper, 5669.

Alderman, H., Behrman, J. R., Lavy, V., \& Menon, R. (2001). Child Health and School Enrollment: A Longitudinal Analysis. Journal of Human Resources, 36(1), 185-205.

Arends-Kuenning, M., \& Amin, S. (2004). School incentive programs and children's activities: The case of Bangladesh. Comparative Education Review, 48(3), 295-317.

Biddlecom, A., Gregory, R., Lloyd,3 C. B., \& Mensch, B. S. (2006). "Premarital sex and schooling transitions in four sub-Saharan African countries," Paper for IUSSP Seminar on Sexual and Reproductive Transitions of Adolescents in Developing Countries, 6-9 November, Cholula, Mexico.

Birdsall, N., Levine, R., \& Ibrahim, A. (2005). Towards universal primary education: investments, incentives, and institutions. European Journal of Education, 40(3), 337-349.

Boyle, S., Brock, A., Mace, J., \& Sibbons, M. (2002). Reaching the Poor: The'costs' of sending children to school: a six country comparative study, synthesis report (No. 12830). Department for International Development (DFID), UK.

Brock, C., \& Cammish, N. K. (1997). Factors Affecting Female Participation in Education in Seven Developing Countries. Education Research Paper No 9. London: DFID.

Brown, P. H., \& Park, A. (2002). Education and Poverty in Rural China. Economics of Education Review, 21(6), 523-541.

Bruce, J. (2015). Commentary: investing in the poorest girls in the poorest communities early enough to make a difference. Global public health, 10(2), 225-227.

Colclough, C., Rose, P. and Tembon, M. (2000). Gender Inequalities in Primary Schooling: The Roles of Poverty and Adverse Cultural Practice. International Journal of Educational Development, 20(1), 5-27.

Collective for Social Science Research. (2004). A Rapid Assessment of Bonded Labor in Domestic Work and Begging in Pakistan. Infocus Programme on Promoting the Declaration, Working Paper 22. Geneva: International Labor Organization.

Croft, A. (2002). Pedagogy in School Context: An Intercultural Study of the Quality of Learning, Teaching and Teacher Education in Lower Primary Classes in Southern Malawi. Unpublished DPhil thesis. Brighton: University of Sussex.

Ersado, L. (2005). Child Labor and Schooling Decisions in Urban and Rural Areas: Comparative Evidence from Nepal, Peru, and Zimbabwe. World Development, 33(3), 455-480.

Faizunnisa, A., and Ikram, A. (2004). Determinants of Youth Development in Pakistan. Lahore Journal of Economics, 9(2), 119-133.

Fentiman, A., Hall, A., \& Bundy, D. (1999). School enrolment patterns in rural Ghana: a comparative study of the impact of location, gender, age and health on children's access to basic schooling. Comparative education, 35(3), 331-349. 
Fuller, B. and Liang, X. (1999). Which Girls Stay in School? The Influence of Family Economy, Social Demands, and Ethnicity in South Africa. Washington, DC: National Academy Press.

Ghuman, S. and Lloyd, C. B. (2007). Teacher Absence as a Factor in Gender Inequalities in Access to Primary Schooling in Rural Pakistan. Poverty, Gender, and Youth Working Paper no. 1. New York: Population Council.

Glick, P. and Sahn, D. E. (2000). Schooling of Girls and Boys in a West African Country: The Effects of Parental Education, Income, and Household Structure. Economics of Education Review, 19(1), 63-87.

Gönsch, I. (2010). Determinants of Primary School Enrollment in Haiti and the Dominican Republic. Discussion Paper 54, Justus Liebig University Giessen, Center for international Development and Environmental Research (ZEU).

Government of Pakistan, UNFPA and Population Council. (2015). Unveiling the Consensus: Putting People First in Pakistan's Development Agenda. Islamabad: GOP, UNFPA and Population Council.

Pakistan Bureau of Statistics (PBS). (2017). 6th Population and Housing Census, 2017. Islamabad: Government of Pakistan, Statistics Division, Pakistan Bureau of Statistics.

Hallman, K.K. (2007). Nonconsensual Sex, School Enrollment, and Educational Outcomes in South Africa. Africa Insight, 37(3), 454-472.

Haque, N. (2006). Foreword to Gender and Empowerment: Evidence from Pakistan by R. Siddiqui, S. Hamid, R. Siddiqui, N. Akhtar, and G.Y. Soomro. Islamabad: Pakistan Institute of Development Economics.

Hewett, P.C. and Lloyd C.B. (2005). "Progress towards 'Education for All': Trends and Current Challenges for sub-Saharan Africa," in C.B. Lloyd, J. Behrman, N.P. Stromquist, and B. Cohen (eds.). 2005. The Changing Transitions to Adulthood in Developing Countries: Selected Studies, 84-117. Washington, DC: National Academies Press.

Huisman, J., and Smits, J. (2009). Effects of Household- and District-Level Factors on Primary School Enrollment in 30 Developing Countries. World Development, 37(1), 179-193.

Hunt, F. (2008). Dropping Out from School: A Cross-Country Review of Literature. CREATE Pathways to Access Research Monograph No 16. Brighton: Consortium for Research on Educational Access, Transitions and Equity (CREATE), University of Sussex.

Hussain, A., Salfi, N., and Khan, T. M. (2011). Causes of Students' Dropout at Primary Level in Pakistan: An Empirical Study. International Journal of Humanities and Social Science 1(12): 143-151.

Kadzamira, E. and Rose, P. (2003). Can Free Primary Education Meet the Needs of the Poor? Evidence from Malawi. International Journal of Educational Development, 23(5), 501-516.

Kane, E. (2004). Girls' Education in Africa: What Do We Know About Strategies That Work? Washington, DC: World Bank.

Kazi, S. (1999). "Gender Inequalities and Development in Pakistan." In Khan, S.R. Fifty Years of Pakistan's Economy. Karachi: Oxford University Press.

Khan, A. (2007). Women and Paid Work in Pakistan. Karachi: Collective for Social Science Research.

Khattak, S. (2001). “Women, Work and Empowerment," in A. Sayeed and S.G. Khattak (eds.) Women's Work and Empowerment Issues in an Era of Economic Liberalization: A Case Study of Pakistan's Urban Manufacturing Sector, 65-87. Islamabad: Pakistan Institute of Labor Education \& Research (PILER) and Sustainable Development Policy Institute (SDPI). 
Lafraniere, S. (2005). "For girls in Africa, education is an uphill fight." New York Times. Published: Friday, December 23.

Liu, F. (2004). "Basic Education in China's Rural Areas: A Legal Obligation or an Individual Choice?" International Journal of Educational Development, 24(1), 5-21.

Lloyd, C.B. (2011). Girls' Schooling in Developing Countries: Highlights from Population Council Research. Promoting Healthy, Safe and Productive Transitions to Adulthood, Brief No. 24. New York: Population Council.

(2005a). “Schooling," in C.B. Lloyd (ed.) Growing Up Global: The Changing Transitions to Adulthood in Developing Countries, 67-167. Washington, DC: The National Academies Press.

(2005b). Schooling and Adolescent Reproductive Behavior in Developing Countries. Background paper for the UN Millennium Project report, Public Choices, Private Decisions: Sexual and Reproductive Health and the Millennium Development Goals.

Lloyd, C.B. and Grant, M.J. (2004). Growing Up in Pakistan: The Separate Experiences of Males and Females. Working Paper No.188. New York: Population Council.

Lloyd, C.B., and Hewett, P.C. (2003). Primary Schooling in Sub-Saharan Africa: Recent Trends and Current Challenges. Policy Research Division Working Paper No. 176. New York: Population Council.

Lloyd, C.B., Mete, C., and Grant, M. (2006). The Implications of Changing Educational and Family Circumstances for Children's Grade Progression in Rural Pakistan: 1997-2004. Policy Research Division Working Paper 209. New York: Population Council.

Lloyd, C.B., Mete, C., and Grant, M.J. (2007). Rural Girls in Pakistan: Constraints of Policy and Culture. In M. Lewis and M. Lockheed (eds.), Exclusion, Gender and Schooling: Case Studies from the Developing World, 99-118. Washington, DC: Center for Global Development.

Lloyd, C.B., and Young, J. (2009). New Lessons: The Power of Educating Adolescent Girls. New York: Population Council.

Lloyd, C.B., and Gage-Brandon, A. J. (1994). High Fertility and Children's Schooling in Ghana: Sex Differences in Parental Contributions and Educational Outcomes. Population Studies, 48(2), 293-306.

Lutz, W., Cuaresma, J. C., \& Sanderson, W. (2008). The Demography of Educational Attainment and Economic Growth. Population, 25(29), 15-19.

Mahbub ul Haq Human Development Center. (2000). Human Development in South Asia: The Gender Question 2000. Karachi: Oxford University Press.

Mahmood, N., and Ringheim, K. (1993). Desired Fertility in Pakistan: What is the Influence of Husbands? Paper presented at the Population Association of America Conference, Cincinnati, Ohio.

Majid, H. (2012). School Choice in Rural Pakistan. LUMS Economics Working Paper No. 12-03. Lahore: Lahore University of Management Sciences.

McCarthy, K., Brady, M. and Hallman, K. (2016). Investing When It Counts: Reviewing the Evidence and Charting a Course of Research and Action for Very Young Adolescents. New York: Population Council.

Meng, X. and Ryan, J. (2003). Evaluating the Food for Education Program in Bangladesh. Canberra: Australian National University. 
Mensch, B.S., Singh, S. and Casterline, J.B. (2005). "Trends in the Timing of First Marriage among Men and Women in the Developing World," in C.B. Lloyd, J.R. Behrman, N.P. Stromquist, and B. Cohen (eds.), The Changing Transitions to Adulthood in Developing Countries: Selected Studies, 118171. Washington, DC: National Academies Press.

Ministry of Women Development. (2005). Pakistan National Report: Beijing +10. Islamabad: Government of Pakistan.

Molteno, M., Ogadhoh, E.C., Cain, E., and Crumpton, B. (2000). Towards Responsive Schools Supporting Better Schooling for Disadvantaged Children. London: DFID.

Mumtaz, K. (2007). Gender and poverty in Pakistan. Development, 50(2), 149-153.

Mumtaz, S. (2000). Targeting Women in Micro-finance Schemes: Objectives and Outcomes. Pakistan Development Review, 39 (4), 877-890.

Moser C. O. N. (1989). Gender Planning in the Third World: Meeting Practical and Strategic Gender Needs. World Development, 17(11), 1799-1825.

Naqvi, Z.F. and Shahnaz, L. (2002). How Do Women Decide to Work in Pakistan. Pakistan Development Review, 41(4), 495-513.

National Institute of Population Studies (NIPS), Pakistan and ICF International. (2013). Pakistan Demographic and Health Survey 2012-13. Islamabad. Islamabad and Calverton, Maryland, USA: National Institute of Population Studies.

Pakistan Bureau of Statistics (PBS). (2015). Labour Force Survey 2014-2015. Islamabad: Statistics Division, PBS, Government of Pakistan.

Pakistan Bureau of Statistics (PBS). (2014). Pakistan Social and Living Standards Measurement Survey (PSLMS), 2013-14. Islamabad: Statistics Division, PBS, Government of Pakistan.

Pakistan Bureau of Statistics (PBS). (2012). Pakistan Social and Living Standards Measurement Survey (PSLMS), 2011-12. Islamabad: Statistics Division, PBS, Government of Pakistan.

Pakistan Bureau of Statistics (PBS). (2004). Labour Force Survey 2003-04. Islamabad: Statistics Division, PBS, Government of Pakistan.

Punjab Bureau of Statistics and UNICEF. (2014). Multiple Indicator Cluster Survey (MICS). Punjab 2014. Lahore.

Ravallion, M. and Wodon, Q. (1999). Does Child Labour Displace Schooling? Washington DC: World Bank.

Saigol, R. (2011). Women's Empowerment in Pakistan: A Scoping Study. Islamabad: Aurat Publication and Information Services Foundation.

Sathar, Z. A. (1987). Seeking Explanations for High Levels of Infant Mortality in Pakistan. The Pakistan Development Review, 26(1), 55-70.

Sathar, Z. A., Crook, N., Callum, C., \& Kazi, S. (1988). Women's Status and Fertility Change in Pakistan. Population and Development Review, 14(3), 415-432.

Sathar, Z. A., Lloyd, C. B., ul Haque, M., Diers, J. A., Faizunnissa, A., Grant, M., \& Sultana, M. (2003a). Adolescents and Youth in Pakistan 2001-2002: A Nationally Representative Survey. Islamabad: Population Council.

Sathar, Z. A., Kamran, I., Sadiq, M., \& Hussain, S. (2016). Youth in Pakistan: Priorities, Realities and Policy Responses. Population Council. Islamabad: Pakistan.

Sathar, Z.A. and Kazi, S. (2000). Women's Autonomy in the Context of Rural Pakistan. Pakistan Development Review, 39(2), 89-110. 
Sathar, Z. A. and Kazi, S. (1990). Women, Work and Reproduction in Karachi. International Family Planning Perspectives, 16(2), 66-69.

Sathar, Z. and Kazi, S. (1988). Productive and Reproductive Choices of Metropolitan Women: Report of a Survey in Karachi, Pakistan. Islamabad: Pakistan Institute of Development Economics.

Sathar, Z. A. and Lloyd C.B. (1994). Who Gets Primary Schooling in Pakistan: Inequalities Among and Within Families. Pakistan Development Review, 32(2), 103-134.

Sathar, Z. A., Lloyd, C. B., Mete, C., \& ul Haque, M. (2003b). Schooling Opportunities for Girls as a Stimulus for Fertility Change in Rural Pakistan. Economic Development and Cultural Change, 51(3), 677-698.

Sathar, Z. A., Wazir, A. and Sadiq M. (2013). Struggling against the Odds of Poverty, Access, and Gender: Secondary Schooling for Girls in Pakistan. Lahore Journal of Economics, 18 (Special Edition): 67-92.

Sawada, Y. and Lokshin M. (1999). Household Schooling Decisions in Rural Pakistan. World Bank Policy Research Working Paper No. 2541. Washington DC: World Bank.

Sengupta, P. and Guha J. (2002). Enrolment, Dropout and Grade Completion of Girl Children in West Bengal. Economic and Political Weekly, 37(17), 1621-1637.

Shaheed, F. and Mumtaz K. (1981). Invisible Workers - Piecework Labour amongst Women in Lahore. Islamabad: Women's Division of the Government of Pakistan.

Shahidul, S. M., and Karim Z. (2015). Factors Contributing to School Dropout among the Girls: A Review of Literature. European Journal of Research and Reflection in Educational Sciences 3(2).

Sheehan, P., Sweeny, K., Rasmussen, B., Wils, A., Friedman, H. S., Mahon, J., ... \& Stenberg, K. (2017). Building the foundations for sustainable development: a case for global investment in the capabilities of adolescents. The Lancet, 390(10104), 1792-1806.

Social Policy and Development Centre (SPDC). 2010. Trade Liberalisation and Gender Dynamics of Employment in Pakistan. Gender Research Programme Research Report No. 2. Karachi: SPDC.

The PROBE Team. (1999). Public Report on Basic Education in India; The PROBE Team. New Delhi: Oxford University Press.

United Nations Educational, Scientific and Cultural Organization (UNESCO). (2013). Education for All Global Monitoring Report Fact Sheet. UNESCO.

United Nations Children's Fund (UNICEF), (2018). Gender Action Plan 2018-2021. UNICEF.

United Nations Development Programme (UNDP). (2016). Fast Facts: Youth as Partners for the Implementation of the SDGs. Bureau for Policy and Program Support, UNDP.

Wagelndicator. (2017). “Child Labour and Pakistan." Paycheck.pk. https://paycheck.pk/main/labourlaws/fair-treatment/minors-and-youth/child-labour/child-labour-and-pakistan.

Weiss, A.M. (1992). Walls within Walls: Life Histories of Working Women in the Old City of Lahore. Boulder: Westview Press/Lahore: Pak Book Corporation.

Zaidi, B., Sathar, Z.A., ul Haque, M., and Zafar, F. (2012). The Power of Girls' Schooling for Young Women's Empowerment and Reproductive Health. Islamabad: Population Council. 